Portland State University

PDXScholar

1995

\title{
A Case Study of the Development of Oregon's 1985 Public Policy in Youth Substance Abuse
}

Sonja Carol Grove

Portland State University

Follow this and additional works at: https://pdxscholar.library.pdx.edu/open_access_etds

Part of the Health Policy Commons, and the Social Welfare Commons

Let us know how access to this document benefits you.

\section{Recommended Citation}

Grove, Sonja Carol, "A Case Study of the Development of Oregon's 1985 Public Policy in Youth Substance Abuse" (1995). Dissertations and Theses. Paper 1255.

https://doi.org/10.15760/etd.1254

This Dissertation is brought to you for free and open access. It has been accepted for inclusion in Dissertations and Theses by an authorized administrator of PDXScholar. Please contact us if we can make this document more accessible: pdxscholar@pdx.edu. 
A CASE STUDY OF THE DEVELOPMENT OF OREGON'S 1985

PUBLIC POLICY IN YOUTH SUBSTANCE ABUSE

by

SONJA CAROL GROVE

A dissertation submitted in partial fulfillment of the requirements for the degree of

\author{
DOCTOR OF EDUCATION \\ in \\ EDUCATIONAL LEADERSHIP: \\ ADMINISTRATION AND SUPERVISION
}

Portland State University

1995 
UMI Number: 9608481

UMI Microform 9608481

Copyright 1995, by UMI Company. All rights reserved.

This microform edition is protected against unauthorized copying under Title 17, United States Code.

\section{UMI}

300 North Zeeb Road

Ann Arbor, MI 48103 


\section{DISSERTATION APPROVAL}

The abstract and dissertation of Sonja Carol Grove for the Doctor of Education in Educational Leadership:

Administration and Supervision were presented December 8 , 1994, and accepted by the dissertation committee and the doctoral program. COMMITTEE APPROVALS:
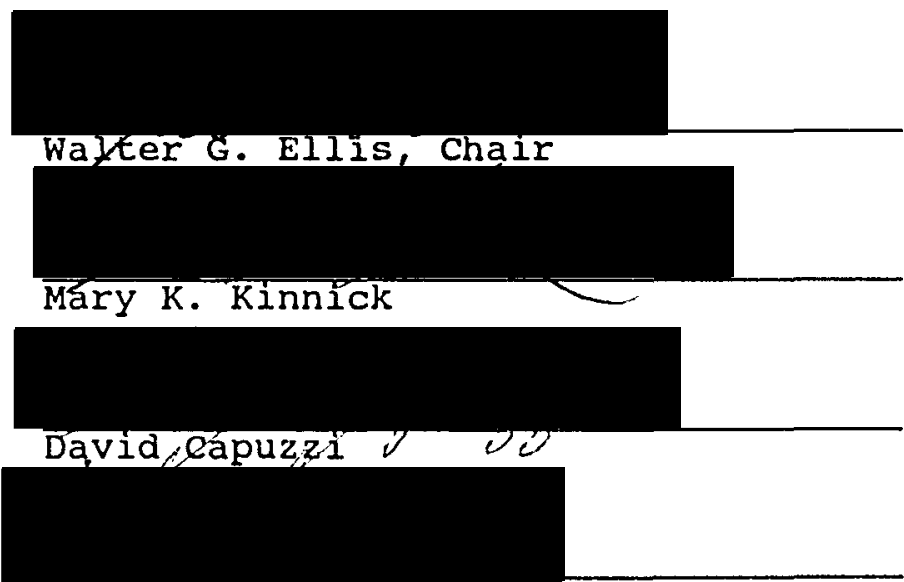

Kenneth Kempner

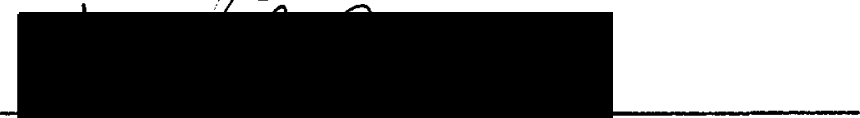

Sandra C. Anderson

Representative of the office of Graduate Studies

DOCTORAL PROGRAM APPROVAL:

Robert B. Everhart, Dean

School of Education

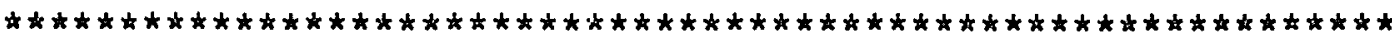

ACCEPTED FOR PORTLAND STATE UNIVERSITY BY THE LIBRARY

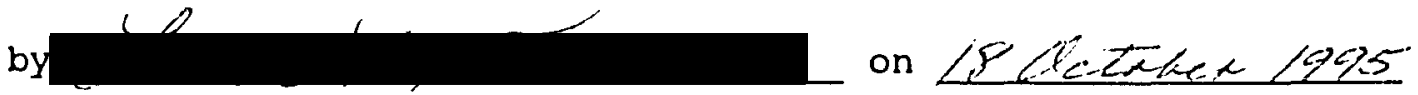




\section{ABSTRACT}

An abstract of the dissertation of Sonja Carol Grove for the Doctor of Education in Educational Leadership: Administration and Supervision presented December 8, 1994.

Title: A Case Study of the Development of oregon's 1985 Public Policy in Youth Substance Abuse

Youth substance abuse in Oregon reached epidemic proportions in the early 1980s. A response to this social issue from the Governor's office, the state legislature, and the Office of Alcohol and Drug Programs during 1983-1985 is the foundation of this case study.

Oregon, a small state of three million, was faced with a growing problem of youth and adult substance abuse. Legislative leaders, agency staff, and Governor Atiyeh recognized an opportunity to create public policy to solve problems of substance abuse including crime. The focus on substance abuse included streamlining several budgets with substance abuse monies in various state agencies.

The intent of this study was to recreate the development of public policy specifically in the area of youth substance abuse during the years 1983-1985. The final policy, Oregon House Bill 2124 (1985), represented the work 
budgets with alcohol and drug monies in various state agencies.

The intent of this study is to recreate the development of public policy specifically in the area of youth substance abuse during the years 1983-1985. The final policy, Oregon House Bill 2124 (1985), represented the work of several political entities, and presented recommendations for substance abuse treatment, budget alignments among several agencies with alcohol and drug monies, and finally, prevention of youth substance abuse.

This dissertation established that leadership and politics affected policy development more than the variables of economics, special interest groups, or research which were chosen from the literature in policy development. Research was the variable studied in depth to determine if policy developers utilized what was known about youth substance abuse to develop policy goals. Several barriers to the use of research and rational methods for policy development were uncovered. The study found that the use of research was regarded as important among policy developers, but their practice was not at all congruent with that belief.

There were many studies on youth prevention and social competency training available to policy planners which may have supported more specific policy recommendations. No collaborations between researchers and policy developers 
occurred in this case study. The barriers to collaborative efforts with researchers and the use of policy analysis methods were uncovered in this study.

The final policy document presented to the legislature lacked specific recommendations for well researched programs which appeared to be the result of political considerations rather than rational policy development. Finally, this case of policy development revealed a process that was inconsistent, politically driven, disregarded available research, and resulted in broad policy goals which have not been exceptionally successful in limiting or even addressing youth substance abuse over the nine years of implementation by the same administrator who significantly helped to develop them. 


\section{DEDICATION}

This dissertation is dedicated to my son, Jon Grove

who influenced this study in many ways, and gave me the motivation to proceed.

I also want to thank the members of my Dissertation Committee, notably Dr. Mary Kinnick who always said just the right /words to keep me on my wobbly path, and to Dr. Walt Ellis, who never gave up on me.

I acknowledge my dear friends, especially Dr. Dawn winters who always said the perfect words to keep my spirit in line, gave support in all ways, and provided the gentle guidance that made this gigantic endeavor possible.

Finally, without the thoughtful and tedious work of Pati sluys, assistant extraordinaire, the end may never have come. 
TABLE OF CONTENTS

PAGE

CHAPTER

I INTRODUCTION TO CASE STUDY OF POLICY

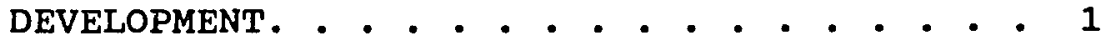

Focus of the study . . . . . . . . . . 5

Statement of the Problem . . . . . . 6

Substance Abuse Policy and Budgets

Prior to 1985. . . . . . . . . . . 8

Research Efforts Prior to 1985 . . . . 10

Appointment of the Governor's Task Force on Alcohol and Drug Abuse. . . . . . . 12

Administration and Jurisdiction of Substance Abuse Policy . . . . . . . . 14

Prevention of Youth Substance Abuse. . . 16

Oregon's Political climate . . . . . . 18

Special Interest Groups. . . . . . . 19

Leadership . . . . . . . . . . . 19

Economics or Resources .. . . . . . 20

Use of Research in Policy Development. . . 21

Substance Abuse Policy Passed in 1985. • 22

Importance and Need for the study. . . . 23

Limitations of the study . . . . . . . . 24

II IITERATURE REVIEW. . . • . . . . • . . . . 27

Social Policy Development and Methods Available. . . . . . . . . . 28 
Policy Analysis Methods. . . . . . . 32

The Variables of Policy Development. . . 34

Political Milieu . . . . . . . . . 35

Special Interest Groups. . . . . . . . 37

Economics or Resources for Policy. . . . 39

Leadership . . . . . . . . . . . 40

Research as a Policy Input . . . . . . . 41

Methods for Values Clarification . . . . 44

Data Analysis Methods. . . . . . . . 46 46

Theoretical Constructs in Decision

Making . . . . . . . . . . . . 47

History of Substance Abuse in Oregon . . . 51

Research on Risk Factors for Youth . . . 56

III METHODOLOGY FOR CASE STUDY . . . . . . . . . 62

Research Methods . . . . . . . . 65

Interviews . . . . . . . . . . 66

Survey Data. . . . . . . . . . 69

Archival Records . . . . . . . . 70

Secondary sources. . . . . . . . 70

Analysis of Data . . . . . . . . 71

Limitations of the study . . . . . . . 72

Precautions for Accuracy . . . . . . 73

IV CASE STUDY FINDINGS. . . . . . . . . . 75

Summary of Findings for the Variable of Politics. . . . . . . . . . . 78

Summary of Findings for the Variable of Special Groups. . . . . . . . . 88 
The Findings for the Variable of Leadership . . . . . . . . . . 91

The Findings for the Variable of Economics. . . . . . . . . . . 97

The Findings for the Variable of Research . . . . . . . . . . 104

The Barriers to Utilizing Research in Policy Development. . . . . . . 108

The Actual Process for the Final Legislation and Passage. . . . . . 125

V IMPLICATIONS AND RECOMMENDATIONS . . . . . . 134

General Recommendations for Policy Developers .......... . . 145

The Role of Politics and Leadership in Policy Development. . . . . . . . 147

The Importance of Leadership in Policy Development. . . . . . . . . . 151

Implications for the Use of Research . . . 153

Implications and Recommendations for the Legislature. . . . . . . . . . 157

Concluding Thoughts. . . . . . . . 159

REFERENCES. . . . . . . . . . . . . . . . 161 APPENDIX

A

CASE STUDY DATA. . . . . . . . . . . 170

B BUDGET NOTES . . . . . . . . . . 208 
CHAPTER I

\section{INTRODUCTION TO CASE STUDY OF POLICY DEVELOPMENT}

The purpose of any public policy is to solve problems for the citizens it serves. Oregon, a small state of three million, faced a public crisis in the early 1980s that required policy solutions. Clearly the problems of substance abuse had reached epidemic proportions. As there was no public policy for youth substance abuse, state leaders took the opportunity to develop one. It is the development of that precedent setting policy that is the focus of this study.

oregon's youth substance abuse problems were not fully recognized by the state's leaders until there was a dramatic increase in the crime rate, and citizens angrily turned to their political leaders for solutions. The cost of substance abuse was reported to be $\$ 716$ million in the early 1980 s (Kushner, 1983). There were at least 8,000 youth identified in oregon with such serious substance abuse problems they should receive treatment. Oregon also adopted some of the most liberal marijuana legislation in the United States prior to 1985 , which has had some impact on substance abuse in the state according to many experts. In the 1980s, high concentractions of illegal drugs were found in both 
rural and urban areas, and alcohol abuse was already a problem for many of Oregon's citizens.

The oregon Serious crime Commission ranked drug and alcohol abuse as the most serious crime facing underage oregonians for the fifth straight year in 1984 (Bellamy, 1984). Reports of fatal traffic accidents in the state involving teen-age drivers revealed that 50\% were abusing substances at the time (Bellamy, 1985).

The public outcry about substance abuse was particularly acknowleaged by then President of the Senate, Fred Heard, and then speaker of the House, Vera Katz. The Oregon legislature provided an important forum to express public concern during the biennial sessions of 1983 and 1985. Politicians were possibly more likely to respond because of the immediate feedback received if they did not support the demands of constituents. This feedback could easily result in a vote out of office.

In the early 1980s, it became apparent that millions of dollars had been spent by state agencies to solve substance abuse problems. There was little state agency coordination or even legislation that could create a meaningful holistic approach to this serious problem.

The many issues surrounding substance abuse created a unique situation in oregon. The issues included: a lack of coordinated policy about substance abuse, a conservative spending political climate, a high level of public concern, 
and a leadership committed to solving substance abuse problems. All these factors combined to create an environment receptive to policy solutions. Oregon, a state that did not have the burden of overpopulation or hopelessness about its ability to problem solve, was recognized as a state that worked hard at solving problems (J. Kushner, interview, November 20, 1990). Although this was an important variable in the success of oregon's legislation for substance abuse, it may also result in a situation where the findings in this study are not easily generalized to similar situations of policy development in large population states.

The high level of concern about substance abuse, and the potential resources, such as research, for carrying out policy development were significant in the early 1980 s. There were at least 10 researchers studying youth substance abuse issues in oregon prior to 1985. There were several National Institute of Drug Abuse grants being carried out, mostly within three research institutes.

The Governor's Task Force, mandated by a budget note from a subcommittee of Ways and Means, provided a means for development of policy, and demonstrated that oregon had routinely used public boards and commissions to oversee agencies and programs (see Appendix B). Although the use of public task forces was not unique to oregon, this form of citizen involvement in the bureaucratic process is regarded 
as a positive approach to solving social problems. It is said that development of policy may be hindered by the more narrow view of bureaucrats when programs are initiated and monitored by those closest to the process.

The process of policy development in substance abuse for youth and adults was initiated in 1983 by a vote of the legislative Ways and Means Sub Committee of Human Resources. A budget note directed the Director of Mental Health to appoint a blue ribbon panel to study the problems of substance abuse (see Appendix B). The group included: citizen membership, representatives of the judicial system, state agencies, the academic community, professionals in substance abuse, the health industry, and then speaker of the Oregon House of Representatives, Vera Katz.

The 1985 policy is carefully detailed in this case study to determine what was known about youth substance abuse prevention, how decisions were made to either include or abandon certain directions derived from research, what appeared to impact policy deliberations the most, what methods were available, and which methods were used.

In conclusion, there were important conditions and variables that affected oregon's development of substance abuse policy. This study focuses on the conditions and the variables that affected oregon's policy the most, with particular emphasis on the use of research, the methods of policy analysis available to administrators, and what was 
actually done in this case of policy development. An important outcome of $\mid$ this case study is the information for public administrators about methodology in policy development, why particular methods are used, and suggestions to improve this process.

\section{Focus of the study}

This study reviews the development of public policy in substance abuse prevention, focusing on youth. Case study is the method of analysis used to examine this policy development process. Some policy theorists would say that policy is built on a rational or scientific model, but the reality may be quite different due to the people involved, history, and many other variables. The study examines policy analysis methods available for the development of effective policy and those used in oregon's process.

This study also/determines how each of the following five variables affected policy development: the use of research, influence of politics, impact of special interest groups, leadership, and importance of resources to support programs. Decision making models used and available to policy makers in this case of policy development are also closely examined. 
Statement of the Problem

A great deal has been written about the need for outcome based processes that may result in successful strategies to reach solutions. simply stated, one could (in a perfect world) define the desired outcomes and create an array of methods to accomplish the task. Although regarded as desirable, the development of public policy to solve the problems of society is rarely a scientific or rational process.

This dissertation contains a review of the literature on social policy development and its fallibility that often results in an uncoordinated process rather than a scientific endeavor.

The goals of this study are the following:

1. To focus on the area of youth substance abuse and prevention in oregon's 1985 public policy development.

2. To determine the actual methods used in developing Oregon's substance abuse policy and to compare those with practices most commonly referred to in the literature of policy development (policy analysis).

3. To lend new understanding about the implications between actual practice and those perceived used in policy making.

4. To identify the factors that affect policy development, including the following:

a. Politics and milieu; 
b. Special interest groups;

c. Economics or resources available;

d. Research as a policy input;

e. Leadership.

since social policy is laden with perspectives and values that are difficult to quantify, this study is qualitative in nature. The study is based on interviews, reviews of historical records, and ex-post facto analysis of the setting in which policy was developed. This case study focuses on the 1983-1985 process for developing public policy in the prevention of youth substance abuse. The 1985 policy had a broader scope, including adult abuse and a review of the programs for treatment of youth and adults; but, this case study is attempting to focus only on youth. Although there was policy in substance abuse for adults dating from to the early 1940s, it is fair to say that there was little policy dedicated to youth abuse issues. This study reviews the time segment from the inception of serious public concern in the 1980 s to the legislature's response in the form of 1985 policy.

The study answers some of the following questions:

1. What were the methods available to public administrators in the development of this policy, and which were actually used?

2. What was known about prevention of substance abuse in the early 1980s? 
3. What was the process that determined recommendations and became final policy?

4. What is the distance between desired and actual practice in policy development?

5. What literature-defined variables most impact policy development?

This study presents knowledge in policy development through the review of one case study in oregon. All of the variables impacting this public policy from its identification as a social issue to the final legislation are thoroughly studied and related to the literature on policy development in public administration. The case study provides a unique opportunity to study an issue of public health and safety from its designation as a serious public problem to policy.

Substance Abuse Policy and Budgets Prior to 1985

oregon, similar to many states in the 1980s, was not prepared to deal with the multitude of social problems that substance abuse handed its citizens. clearly there was a need to develop policy to control substance abuse. There was also the necessity to increase coordination among the seven agencies who spent millions of dollars on this problem. Youth policy was necessarily separate from adult policy because there was a difference in treatment, and less 
was known about the control and treatment of youth substance abuse than about adult addiction.

Although concern existed about substance abuse before 1985, a major shift in the level of concern about the problem occurred in 1985. This new importance resulted in the budget note attached to the Mental Health Division's Appropriation Bill by the Ways and Means Committee (see Appendix B). Dr. Joe Treleaven, Director of the Mental Health Division, was charged with appointing a blue ribbon panel to study the problems of substance abuse. The 1985 legislative session would receive this committee's report and create policy from its recommendations.

The substance abuse problem in oregon was serious in the 1980s, in spite of millions of dollars spent by various agencies to solve it. Part of the problem emanated from little or no coordination of the budgets dedicated to the prevention of substance abuse. Budget concern appeared to some of the people involved, the goal of the legislation. One problem of the budget process was especially important to this legislation and to the final document presented to the Ways and Means committee of the legislature: agency budgets were reviewed by three or four analysts from several state agencies. In the case of substance abuse monies, analysts might look at the budget from several different perspectives. The agency's needs, the needs of the Human Resources' agency, the Governor's 
Office, and the Legislative Fiscal office were all considered. The final budget might be quite different in form and intent from the original proposed by the agency's director that could limit the possibility of solutions for the substance abuse problem (c. Campbell, interview, November 10,1989 ).

It became clear that a unified process to review budgets with substance abuse monies could solve problems and coordinate efforts by individuals and agencies. An umbrella agency dedicated to substance abuse problems was supported by several administrators and legislative leaders. Many administrators, however, did not agree that the Alcohol and Drug Abuse Program office should be moved out of the Mental Health Division. The fight that ensued almost overshadowed the potential for programs to solve the substance abuse crisis and streamline the budget process.

Federal substance abuse policy, though available, was not particularly important to solving problems in oregon. Prior to 1985, weak policy seemed to be created every year. According to Jeff Kushner (interview, November 20, 1990), "the Feds were liberal with the states, allowing local policy and goal setting."

\section{Research Efforts Prior to 1985}

It is important to note that oregon researchers were actively involved in research on substance abuse prior to 
development of the 1985 policy. Many researchers in substance abuse were nationally known for their efforts. For example, the oregon Social Learning Center in Eugene, directed by Dr. Gerry Patterson, nationally recognized expert on family and youth issues supervised several studies in the identification of risk factors for children, behavior modification programs for them, social competence models, survival training for first graders, and family interventions. The oregon Research Institute, also located in Eugene, directed several studies prior to 1985 in nicotine use as a gateway drug into other use and abuse, parenting, social skills and peer factors in groups. Both institutes were heavily funded by either the National Institute of Drug Abuse, National Institute of Health, or other federal grants.

There were other researchers in oregon in the early 1980s (Patterson, Dishion, \& Reid, 1988) who studied family dynamics and factors, drunk driving intervention models, and adolescent substance abuse risk factors. Many of these studies supported early intervention and identification of risk factors. From interviews, it became obvious there was a large volume of research available to policy makers in the area of youth and substance abuse. Dr. David Hawkins, an expert in risk factors at the University of Washington School of Social Work, was even hired as a consultant for the Governor's Task Force and the Alcohol and Drug Program 
office to provide knowledge about successful programs in adolescent substance abuse prevention.

Quite separate from the research available for youth substance abuse, the Governor's Task Force was appointed to review Alcohol and Drug programs in oregon and make decisions about future directions. As noted above, they were charged with making good decisions about policy directions by using all means available to them. The following section documents the Governor's Task Force appointments and membership.

\section{Appointment of the Governor's Task Force on Alcohol and Drug Abuse}

Victor Atiyeh served as Governor from 1982-1986. He directed Dr. Joe Treleaven, Director of the Mental Health Division, to appoint a blue ribbon task force to study substance abuse. Dr. Treleaven asked Jeff Kushner, Director of Alcohol and Drug Abuse Programs, to help him. The Sub Committee of Human Resources of the Ways and Means Committee was aware that a lot of money was being spent in various state agencies without much success in curbing youth substance abuse in oregon. It also became clear that there was little coordination between the state agencies in this area. The budget note from Ways and Means directed the following activities (see Appendix B):

1. An evaluation of alcohol and drug abuse program quality and effectiveness. 
2. An analysis of the service delivery systems for these programs.

3. An examination of related funding sources and formulas.

The following members were chosen to serve at the discretion of Governor Atiyeh:

1. Vera Katz, Speaker of the House of Representatives.

2. Tom Dargan, Station Manager for KATU Television in Portland.

3. Kristine Gebbie, Director of Oregon's Health Division.

4. Douglas Egan, Professor of Business, Lewis \& Clark College, Portland.

5. Judge William Beckett, Lane county circuit Court, Eugene.

6. Bob Yates, businessman from salem.

7. Spero Manson, Professor, Oregon Health Sciences University, Portland.

8. Robert Hatch, Alcohol and Drug Counselor, Gresham.

9. Hank Crawford, lobbyist for health care providers, salem.

The Governor's Task Force was the identified political body in this policy process, but it also involved several agencies that all had some stake in alcohol and drugs. 
Administration and Jurisdiction of Substance Abuse Policy

Agencies involved with some aspect of substance abuse and had budgeted monies were the following:

1. Adult and Family Services.

2. Children's Services Division.

3. Department of Education.

4. Health Division.

5. Juvenile Service Commission (now Youth Services Commission).

6. Mental Health Division.

7. *Traffic Safety Commission.

*This agency is not used in this study to provide more emphasis on social service agencies.

The Alcohol and Drug Abuse Program office was subsequently moved out of the Mental Health Division because of the 1985 legislation. As an umbrella agency, this office coordinated various budgets among the above agencies, but would incur other problems because of its new powerful role.

The move of Alcohol and Drug Programs out of Mental Health was partially an attempt to prevent a problem as serious as the expenditure of $\$ 43$ million in substance abuse by the above agencies prior to the 1985 legislation. Alcohol and drug monies were spent among at least seven agencies with little coordination or evaluation of activities funded. 
This problem was best characterized by the actions within the Department of Education. Then Superintendent of Public Instruction, Verne Duncan, believed that substance abuse was a family issue and should not be discussed in schools although the problem was reaching epidemic proportions. Schools were regarded by some as the first line of attack to prevent children from abusing substances. Recovering addicts often talked to school children about the horrors of substance abuse, and often held the student's interest.

Research, however, has shown this method to have little success in youth substance abuse (Hawkins, Lishner, Jenson, \& Catalano, 1986). Schools were often regarded as the most appropriate location for discussions about substance abuse, but a more successful intervention might have been, for example, substance abuse treatment for sex offenders or welfare parents within the various agencies' jurisdictions. Within the Mental Health Division, the Alcohol and Drug Abuse Program Office's issues were dwarfed by the overwhelming problems of running training institutions (Oregon state Hospital, Fairview Home, etc.). When clearly millions were spent in the various agencies with little coordination or policy guidance, legislative leaders decided to listen to the Alcohol and Drug Abuse Program office. It is safe to say that this small agency would still be a part of Mental Health if there had not been a serious concern for 
agency budget coordination, a goal far from the more critical one of substance-abuse prevention.

\section{Prevention of Youth Substance Abuse}

Prevention was a significant concern in youth substance abuse and deserves explanation. The difficulty of definition may point to the problems implicit in social policy. Prevention in substance abuse is difficult to define because of the many factors that affect attempts to modify individual behavior and addiction. During the 1980s, youth risk factors were understood in substance abuse, but programs to carry out prevention efforts with such a research basis were not evident in the final policy. The actual means for carrying out the policy were not defined until long after the policy was passed. Program managers had great latitude in terms of implementing the broad goals of the legislation.

The routine management of day to day problems in government often dominates the use of resources rather than progressive programs for preventing future problems. This may be the reason prevention is often considered in the first budget cutbacks and found less vital than other programmatic considerations. It may seem logical that monies would be directed toward early intervention, with goals focused on risk factors for youth substance abuse that did not happen. 
The reality was that the first monies cut in the 1980 s depressed state budget were for prevention. The word "prevention," although implicitly understood by administrators, often does not appear as such in policy. Some would say that prevention of substance abuse was the major goal of this policy, but other issues often clouded it. The interest in this policy appeared to shift from the goal of youth substance abuse prevention to the establishment of the Alcohol and Drug office separate from Mental Health, and the coordination of various substance abuse buldgets.

Oregon state agencies, such as Children's Services Division and Adult and Family Services, seemed to have little concern for prevention efforts when it came to substance abuse budgets ( $\mathrm{J}$. Kushner, interview, November 20 , 1990). A father who abused substances, for example, was highly at risk of abusing his children. Treatment for the primary problem of substance abuse might not be recognized because of a lack of trained personnel in the above-named agencies to detect it. The lack of staff awareness was a result of severely restricted funds for training in social service agencies, especially in this time of economic downturn. Because of the lack of funds or inattention to the problems associated with substance abuse, the fathers (or mothers) rather than receiving treatment, were allowed to remain in the home, tended to abuse their children more, 
created serious costs for the agency, and most important, caused great loss in the human dignity of the family.

$$
\text { Oregon's Political climate }
$$

The first variable, politics, was investigated for its effect on oregon's policy development in substarice abuse. oregon was deeply affected by an economic recession in the 1980s. The state's most important industry was lumber, which was seriously depressed due to log exports to Japan and too many trees cut. The result was fewer dollars।for legislative programs, and this affected the state's spending because of lowered tax revenues and may have resulted in less creative policy solutions.

Governor Atiyeh was known as the politician who said, "If it isn't broken, don't fix it." His administration was regarded as one where few innovative programs were started, but many good ones were left to progress without changes. Some programs thrived, but others simply never got started.

The appointment of the Governor's Task Force was la turning point for youth substance abuse and its political stature. It also allowed the administrator of Alcohol and Drug Programs to occupy a strong support role for the Governor's Task Force, which had political implications for this policy development.

In policy development, there are several levels of government through which legislation must pass. Oregon's 
substance abuse policy was involved in politics and took on several identities before passage as prevention of youth abuse.

\section{Special Interest Groups}

The second variable in the development of this policy was the special interest groups. As previously noted, this study chose to narrow the focus of special interest groups to stakeholders who were outside of agencies. Mothers Against Drunken Drivers (MADD) was especially well known and appeared to have access to leadership in this area. Another active special interest group was the county administrators for alcohol and drug programs, who resented their strong reliance on the state for monies and guidance. The health service providers, such as Blue Cross and Blue Shield of oregon, also entered this process with agendas and economic interests.

\section{Leadership}

Leadership is the third variable identified to review in policy development. There were more public members than agency personnel on the Governor's Task Force. The personality and leadership capabilities of certain members within this process seemed to make a distinct difference. Leadership is recognized as a powerful variable because of the perceived importancel of human relations. Jeff 
Kushner, Director of the Alcohol and Drug office, held a great deal of legitimate power in this process, as did vera Katz within the political structure of the Oregon legislature. Qualities of leadership may include intellect, political savvy, or possibly, access to information.

Is leadership simply charisma, access to information, important networks, or a combination of all these? The strength of the Governur's Task Force was well appreciated, but the importance of convincing legislative leaders by one of their own, Vera Katz, cannot be understated. A process is affected by those leading it, but resources to support programs also have significance.

\section{Economics or Resources}

Since oregon was suffering a serious decline in timber products, state revenues were at an all time low. The mood of the legislature, agency directors, and citizens was gloomy at best. There had not been a serious decline in revenues for quite a long time and politicians were ill prepared to deal with the shortfalls. The legislative committees of Ways and Means in 1981 recommended a 108 "across the board" cut in all state budgets. When a state is struggling to make ends meet, would innovative and new programs suffer? 
It is well understood in policy development that resources support innovative programs and without revenues, other decisions might be made.

\section{Use of Research in Policy Development}

The final variable is the use of research to support policy decisions. Research can be data from agencies or other sources and longitudinal studies. Because youth substance abuse was a fairly new topic in the 1980s for the research community, few longitudinal studies about treatments actually existed, and studies about youth abuse or risk factors were sometimes five to seven years old.

Most public administrators would agree that the use of research is desirable, but the actual use of it may not occur for a variety of reasons. In oregon, there were several researchers who were doing work in substance abuse and were largely ignored or undiscovered. Determining how much research was actually used or even reviewed is one goal of this paper.

In conclusion, the above variables were probably not equally important to the final policy passed. They were also those most often mentioned in the literature of policy development, sometimes in different vocabulary. This study uncovers other policy inputs that affected the process, and some were quite surprising. 
Substance Abuse Policy

Passed in 1985

The actual policy passed by the oregon Legislature in 1985, House Bill (HB) 2124, was the first major legislation in substance abuse since then Governor Mark Hatfield's Mental Health policy of 1959. Only youth policy was reviewed since that is the focus of this case study. The final policy passed by the 1985 legislation is summarized as follows:

1. Agencies shall coordinate resource distribution and avoid unnecessary duplication.

2. Standards in substance abuse must be met for prevention and early intervention programs.

3. Comprehensive community-based programs should include: parent support groups, school curriculum, formal school policies, student intervention strategies, and the increase of adolescent treatment capacity.

4. Intervention strategies should be priorities.

5. State funds to be expended on prevention strategies shall encourage no substance use.

6. Comprehensive studies shall be initiated to determine strategies for use in state institutions and youth care facilities. 


\section{Importance and Need for \\ the study}

Public policy is often developed in an imprecise and uncoordinated manner. Since social policy particularly is often based on soft data, it is important to attempt to define accountability in policy solutions. It is well accepted that there are difficulties in developing social policy because of the many variables present when the issues are defined and solutions sought. Public administrators have attempted to develop better methods for public policy development over the last 50 years. Faulty policy may be a result of the many variables and their apparent lack of controls.

An issue as important as substance abuse deserves solutions that are workable and realistic within the confines of resources and human potential. Creating social policy with goals and objectives that match the problems is difficult, but not impossible. The importance of firm statistics that validate the need for policy and support the direction and methodology are desired, but are often difficult to determine and carry out.

This study sheds light on the beliefs and practices of public administrators in the development of policy. There appears to be general agreement that using policy analysis methods to develop policy is desirable, but the actual practice may be quite different. The number of variables in 
social policy, the lack of resources to support policy, and many policy solutions to choose from all create serious problems for policy development.

Lindblom (1959) said that human nature seriously impedes logical and analytic processes for developing policy. Methods for policy development include policy analysis and decision making which are readily available to administrators. This dissertation uncovers some reasons that strict adherence to the methods and a more logical process are less practiced than reasoned minds would expect. Oregon HB 2124 (1985) had little previous policy on which to build. Programs, policy direction, and innovations are not created without some precedence. Lindblom (1959) noted that history is a large part of any policy. In Oregon's case of policy development, this did not appear to be the case to any great extent.

Finally, oregon HB 2124 (1985) is now nine years old. Was the research appropriate to the policy development? Did the policy fit the needs of the state? How successful were the methods used in terms of the final product? Was the methodology responsible for effective or ineffective programs?

\section{Limitations of the study}

A case study, by its nature, is not based on one hypothesis that is proved or rejected. Generalizations are 
not usually drawn in a study of this nature because a case only attempts to look at one example of policy development and does not necessarily generalize to others. There are other restrictions in a case study, including the following:

1. Data sources, including interviews, often rely on memory and perception of the people involved.

2. Human variables are difficult to quantify, and a case study is laden with them.

3. Nine years have passed since this legislation was developed. Previous ideas and purposes may be lost to human memory .

4. Biased reporting by those interviewed is possible, thus, results are skewed in favor of those comments.

5. Generalizing the results of this study to other policy development would be risky since this is a singular case with a preponderance of variables that might have effects only in this environment or set of circumstances.

6. Conceptually new policy, without precedence or historical background is rare, yet previous legislation for youth substance abuse was not in place to build on.

In conclusion, although there were limitations to this case study of one policy development process, as noted above, there are, nevertheless, important implications for policy makers. There was sincere desire by administrators and others involved in 1985 to develop good policy. What were the final variables that affected the process most, and 
did they inhibit or help the final legislation or policy to stem the tide of youth substance abuse? In an area with such importance to many states, this study could offer public administrators information that might improve their process, or underscore the problems implicit in any policy development. 
CHAPTER II

\section{LITERATURE REVIEW}

Public policy often has a lofty purpose in society that is beyond instituting rules, standards, and program practices. Social policy seeks to remediate the problems of society by the creation of programmatic solutions. A problem as serious as 8,000 oregon youth abusing drugs finally activated public officials in the early 1980 s. Policy development is more than finding solutions for problems of society, and can include values' clarification, finding resources to support programs, and understanding the elements of programs necessary to solve the problems.

The initial purpose of this chapter is to present the literature available in social policy development and the methods available. The second purpose of this chapter is to illuminate the literature about the five variables of policy development chosen for this study. The third purpose of this chapter is to present the history of substance abuse in oregon. The final purpose is to present the literature on risk factors that appeared to be the research base commonly supported by youth treatment experts in the early 1980 s. 
Social Policy Development and Methods Available

In the literature of policy development, there seems to be support and even acceptance for policy development that is less than logical or built on sound reason. Dunn (1981) alluded to some of the problems of social policy development when he identified logic and inquiry as areas that are often not present in the methods, or consciously sought. Social science knowledge is less verifiable and exacts less definition (Balmer, 1986).

one cannot discuss this case of social policy development without looking at the problems in finding solutions for human problems. Pal (1987) asked if policy is consciously made. He also wrote of the implicit reasons policy is either undefinable, unintentional, or fallible because of human intervention. He even asked why other factors impede a logical process to find solutions for serious social problems. This case of policy development in Oregon will seek to answer that question and others.

Dye (1983) said that public policy is whatever governments choose to do or not to do. It is the undefinable or less than empirical state of social policy development that makes it problematic. Heclo (1972) said that a policy may usefully be considered as a source of action or inaction rather than as a set of specific 
decisions or actions, and that such a course has to be perceived in a particular way by the analyst in question.

Policy making is a process of social learning as well as an institutional and intellectual phenomena (Balmer, 1986). Rose (1976) suggested that policy be considered a "long series of more-or-less related activities" (pp. 9-10) and their consequences for those concerned, rather than as a discrete decision. Policy is regarded as:

proposed course of action of a person, group, or government within a given environment providing obstacles and opportunities which the policy was proposed to utilize and overcome in an effort to reach a goal or realize an objective or purpose. (Anderson, 1994, p. 121)

Bureaucrats who create policy and then implement it are referred to in the literature of public administration. Pal (1987) said that policies may be unintentional when they are systematically and collectively perceived in a particular way by the people who are the objects of them. Bureaucrats who direct and implement policy appear to have a great deal of power and subjectivity in this process.

Heclo (1972) also said that policy is what the analyst defines and discerns, not necessarily what the actors perceive themselves doing. He wrote that the actors are aware of the reasons behind policy, but prefer to keep them hidden. His solution for this situation is allowing analysts to get behind the scenes to determine the actual reasons, rather than the perceived ones. A goal for this 
case study is to look at the actual practice of policy development rather than acceptance of those perceived.

A review of the literature uncovered methodology for policy development that may be unique to social policy. The lack of tested or empirical theories due to the many variables inherent in social problems results in theoretical constructs or practices for policy development rather than strictly rational or scientific models. The methodology in the current literature of public policy development is policy analysis that is a group of loosely integrated practices.

Lindblom (1959) wrote that the science of policy development is "muddling through" a process without a definition, or solely dependent upon preceding policy. This study examines that definitive statement from 1959 to determine its relevance almost 30 years later.

A definition of policy will contribute to an understanding of program development for social problems such as youth substance abuse. Policy is the authoritative allocation of values for the whole society, or for a portion of it. Policy can regulate citizens, distribute resources, and extract from larger issues to make sense of less significant ones; it is, therefore, quite subjective. Wildavsky (1979) said that public policy is a powerful reflector of values and of the tension between resources, objectives, planning, politics, skepticism, and dogma. Dye 
(1978) referred to a general lack of agreement on how to define problems in the beginning of a search for acceptable solutions. It appears a clear definition of problems would logically lead to the possibility of more effective solutions.

The process of policy development should begin with a general statement of goals or aims (Starling, 1988). Policy illuminates choices that require decisions. The choices are the point at which the public would like to know that the best decisions are made, based on cost, efficiency, and effectiveness. Policy choices, according to Dery (1984), evolve into a pattern of decisions over time.

Policy decisions may be a complex political process of incremental changes that are adaptive rather than products of major discrete decisions about values. In other words, incremental changes may be the mode of operation based on less than rational reasons with long-term goals or time commitments. This absence of defined boundaries, and the general lack of rational decision making because of the complexity of social problems, may be the reason policy development is an art rather than a pure science.

The following section presents the methods of policy analysis available to policy developers in oregon. 
Policy Analysis Methods

Policy analysis practices have developed over the last 50 years. In 1951, Lerner and Lasswell (1951) established policy analysis as a practical and special orientation within social science disciplines. Particular emphasis was placed upon the policy sciences of democracy, or the recognition of human dignity in theory and fact. This science has evolved into a more quantitative or data conscious practice in recent years.

Current practices in policy development have evolved to include professors and researchers from universities who are concerned with government policies. Pal (1987) stated that policy analysis is the disciplined application of intellect to public problems.

The methods of social policy development are constructs that serve as models for practice, but lack the empirical evidence of theories in some other disciplines. Policy analysis provides an array of methods for studying social problems and their possible solutions. Before a review of policy analysis methodologies, it is important to note the controversy regarding social science theory.

There are experts in policy who believe that the scientific or hypothesis setting model used in research studies is not appropriate for social issues. Some theorists believe that it is impossible to deal with the relation of facts to values in social science investigation. 
Others, such as Fischer (1980), believed that one can attempt to deal with this methodologically by using the principle of value neutrality along with the separation of facts and values. Weiss (1972) wrote that this can be dealt with by weighting different variables for the purpose of making analogies and comparisons.

Dunn (1981) described policy analysis as methodologies, or practices providing policy makers with information to be used in reasoned judgment for solutions to practical problems. Analysis is separating or decomposing problems into fundamental components. Policy analysts are concerned with knowing what are the facts of the problem, what is right (or correct to do), what are the values affecting decisions, and how to decide what to do to solve social problems. Policy analysis provides a process for determining the effectiveness, efficiency, adequacy, equity, responsiveness, and appropriateness of any possible solutions to social problems.

Even policy analysis is laden with inconsistencies and questions, according to Dunn (1981). He referred to the problems of the interdependency of variables, the subjectivity, and the artificiality or results of human beings making judgments about alterations in any policy development process.

Policy development has identifiable life stages that include: 
1. Problem definition.

2. Methods for determining solutions.

3. Implementation.

4. Monitoring of a program's success.

Policy analysis generally follows this procedure (Dunn, 1981):

1. The identification of stakeholders in the process.

2. The identification of assumptions by the

stakeholders about the problems isolated.

3. The identification or listing of problems.

4. The identification of recommendations to solve a social issue.

Anderson (1994) believed that policy often does not follow the above identified steps. The steps may not occur or can follow a new sequence.

Several methodologies are identified from the literature of policy analysis that include values clarification, data analysis and decision making. The methods are presented to further understanding about their potential use in policy development such as oregon's substance abuse process.

The Variables of Policy

Development

A more rational process for policy making is desired, but may rarely occur because of several factors that this study attempts to identify. Isolation of a few of the 
variables that affect policy, and determining their importance, seemed especially necessary in this case study.

Kroll, Fremont, and Shipman (1969) wrote about the variables that affect policies. They offered insight about decisions made for reasons that lack validity.

Kroll et al. (1969) also wrote of five categories or variables that provide the foundation or internal aspects of policies. They included power arrangements, historical dimensions, involvement and role of personalities, leadership, informal and formal prescriptions (or programs), and organizational instruments. Kroll et al. also referred to the meandering course of government that attempts to adjust to a reality that is rarely consistent or predictable.

For the purposes of this paper, five variables were extracted that appeared often in the literature of policy development. They include: the political milieu, special interest groups, economics or resources available, leadership, and research as policy input.

\section{Political Milieu}

The first variable chosen for this study is politics, which is analyzed for its importance to policy development. Several experts have written on the critical role of politics. Nagel (1978) said that "policy deals with legal, economic, and, most important, political values" (p. 93). 
Lasswell (1971) said that "politics is the process by which the irrational basis of society is brought into the open, and since policy is based on politics, it is key to the attainment of goals" (p. 1). Brewer and De leon (1983) wrote that:

policy underscores the most important decision actions supported by widespread approval or the threat of actions, which seems to affect the final outcome more than might be reasonably expected. (p. 95)

Politics is important in policy decisions since the layers or government bureaucracies affect decision making at several points rather than one central location. The role of the legislature as an arbitrator of policy rather than an initiator is also referred to by Dye (1985). Dye also asked if legislators are the most appropriate policy developers.

Dye (1992) pointed to the various levels of politics and decision making in policy development. They can include the legislative level with staff members who can be quite important, executive department, special interests, and citizens. Dye said that many policies are technical and cannot be independently acted upon because of the amateurism of the legislative political milieu. He said the Executive Department does not act alone. Although Dye included special interests in the levels of decision making, this dissertation narrows the focus to those outside of agencies. There are various decision-making models that affect policy and constitute an important aspect of politics. Dye 
(1992) referred to various models from political science to define various policy processes. He referred to the elite, rational, incremental, public choice, and process models. The Rational Comprehensive model referred to above is from James Buchanan, an economist who attempted to quantify the process of defining options in policy and purposefully weighing them against each other. Incrementalism is from the writings of Lindblom (1959) who believed that policy is built on previous ideas and changes little. Etzioni (1974) drew from both of the above models to create Mixed Scanning as a compromise decision making model.

Anderson (1994) said that policy is a product of a group struggle. He called the political system a "black box" that is identified as an interrelated institution. Anderson said that the institutional structures and arrangement procedures have important consequences for the adoption and the content of policy. He talked of the context for policy making and the effects of incomplete or imperfect information and also the uncertainty in this process.

Special Interest Groups

The second variable is the role of special interest groups, a sub category of the larger political environment. stakeholders can be agency personnel or special interest groups as diverse as health care providers, county service 
providers, or Mothers Against Drunken Drivers. This study narrows the focus of special interests to those in the larger political environments rather than agency personnel or those involved in state government.

Dye (cited in Majchrzac, 1984) believed that policy moves in the direction desired by those groups gaining influence and away from those who are losing it. Policy is clearly affected by the views of special interests. Doty (cited in Majchrzac, 1984), Etzioni (1974), and Dye believed that the ability of stakeholders or special interests to mobilize resources and their access to decision makers is key to the success of chosen policy values. These groups have more than a small interest in the organizing structure for implementation, the resources needed to support policy, and the actual mechanisms for the initiation of policies. Anderson (1994) believed that policies often arise out of conflicts among people with different information and desires. He referred to the importance of influence in special interest groups as a function of membership size, money, cohesiveness, skills of leadership, attitudes of officials toward them, and the site of decision making. Anderson also believed that government matters little to most citizens and that their commitment to values guide their interests. The private citizen is often neglected because of indifference or inertia. 


\section{Economics or Resources \\ for Policy}

Economics or resources available for policy development and implementation is the third variable identified. Pal (1987) referred to the causal forces and determinants of policy that begin with broad environmental forces such as the level of economic development. He also referred to government's reliance on resources for policy instruments: the information and the treasury or money available to pay for that information. Money is critical to carry out programs. Dye (1992) noted that policy often depends upon funds for implementation and even innovation.

Construedas (cited in Brewer \& De leon, 1983) believed that policy is a guide to choice or action that becomes an instrument applying a structure to a particular choice. He also believed that rational judgment cannot quantify the goals, but that the allocation of dollars seems to provide that support. Wildavsky (1979) referred to policy as the tension between resources, objectives, planning, politics, skepticism, and dogma. He wrote, "Promise always underlies public policy" (p. 84).

Dye (1992) wrote that policy outputs (in a study of 50 states) reveal that the level of economic development dominates the influence on programs and implementation in policy. Anderson (1994) said that a failure to act in policy matters is believed to be due to recalcitrance and 
unresponsiveness rather than limited resources. Anderson also noted that resources for policy are responsible often for innovative programs.

Leadership

Leadership is the third variable chosen for this study and the one that appears consistently in all of the literature of policy development. Kroll et al. (1969) noted that leadership is very important to the policy process. They said that an individual in leadership might possess some of the following attributes:

1. A specialized capacity that provides distinctive effectiveness in a policy field.

2. A moderating ability that reconciles competing forces.

3. A tone or force of dominance for a segment or approach within a policy field.

4. A type of administrative leadership that includes the mechanisms and instruments for final development.

Kroll et al. (1969) also discussed the system of values and behaviors that characterize a public policy. They believed that the actors and manipulators change and that this dynamism and fluidity are essential and common to all policies. Kroll et al. believed that the identification of general features and dynamics of the policy environment is 
critical, and that particular factors appear to have a direct bearing on the policy.

Bales (1950) talked of two types of leaders: task and socioemotional. One provides ideas, gives information and opinions, coordinates and energizes the group, while the other praises, mediates, and encourages the group process. Likert (1961) talked of four behaviors that characterize effective leaders: supportive, set high performance goals, supervise groups, and serve as spokespersons.

\section{Research as a Policy Input}

Research as a policy input is the final and most important variable (for the purposes of this paper) analyzed for its use in policy development. Administrators can be pragmatic in their approach to the job of policy development, but surveys in this case study suggest that agency directors believe that research is an important variable. The actual use of research, though highly regarded, is a foundational question of this study.

Etzioni (1967) described policy research as mapping alternate approaches to a problem while specifying potential for different intentions, effects, and costs. Policy research translates problems from the real world into scientific investigation, then back again. It is usually conducted using one or more of the following methods: the focused synthesis of conversations and literature reviews, 
focus groups, interviews, participative observations, qualitative surveys, case and cost benefit studies.

Doty (1980) referred to two methodological approaches in policy research. The first was the moral, philosophical think tank method that selectively reviews and synthesizes theoretical literature and data that support a certain point of view. The second was empirical and emphasized the collection and analysis of data rather than the interpretation through one perspective and the prejudices by one analyst.

The potential for improved policy development through the use of research is spoken to in the literature of public administration. Lawler (1985) referred to the common sense of policy research while Laver (1986) believed that policy research and evaluation can cut down on waste and useless programs.

There are problems with social science policy research, which Coleman (1972) referred to as operating on the boundaries of existing methodology because there is not one framework to guide it. Majchrzac (1984) believed that social science researchers often find themselves adapting, combining, and improvising as they study a problem. Policy research can often find itself addressing decision makers and their ambitious questions rather than the realities of social problems. 
Social science, by its own design, lacks hypothesis setting and often finds itself addressing social problems and then attempting empirically to induce concepts and causative theories as the study evolves. Majchrzac (1984) referred to the following problems in social science research: lack of design experiences, hidden information and lies, observations are mass-aggregated, fallible instruments, and the lack of appropriate time frames. Experts also point to the complex array of indicators and the number of variables as difficult to measure.

Brewer and De leon (1983) also referred to the problems of social science theory, such as the lack of quantification due to the large number of variables in human perception and the values inherent in society. They believed that social science offers theoretical solutions that are often blind to realistic possibilities that seek to simplify and confine the problems to be solved. Social science often cannot produce a unified set of causal laws (Bobrow \& Dryzak, 1987) because of the number of variables affecting human behavior. The problem of variables in substance abuse creates a serious problem for policy development because of their wide ranging perspectives. In this case study, the knowledge base of substance abuse prevention and treatment, though large, is difficult to define and segregate into one collective belief system. 
There are other problems with research in policy. As an input for decision making, it may not add much to the data base if the information is not rationally scrutinized (Majone, 1980). Another problem exists when the researcher is deeply attached to a chosen paradigm or course of study (Kuhn, 1970). Finally, social science research is often built on soft data and may result in faulty conclusions. Think tanks often provide policy information and usually represent a particular bias (Anderson, 1994). University staff members sometimes offer information of direct use to policy makers.

Although research is one of many possible policy inputs, this variable is particularly important to this paper. There were many researchers in oregon and elsewhere carrying out significant studies in youth substance abuse in the early 1980s. Youth risk factors offered a sound body of research for policy developers. Research, while generally highly regarded by administrators and abundantly available, was not highly used in this case study. The barriers to the use of policy research are identified in this study.

\section{Methods for Values}

clarification

The most complex areas of social science policy are problem identification and values clarification. Policy analysis provides theoretical constructs for determining the variables involved and for prioritizing them with regard for 
the special and public interests. This might involve identification of all relevant objectives for the policy and stakeholders affected (Dunn, 1981). It could include a listing of the value premises that underlie the stakeholders' commitment to the objectives of the policy and classifying them as an explanation of the objectives. The outcome could be determination of value expressions, statements, and judgments about the policy solutions. Policy analysis provides the means for challenging assumptions or systematically comparing the pros and cons of problem solutions. It also provides methods such as assumption pooling or negotiating rather than prioritizing recommendations for the relative certainty and importance to stakeholders, which are then followed by making necessary agreements.

Analycentric models are also available that are based on systems analysis or simple explanatory methods such as cause and effect, value clarification, and critical ethics (consideration of the rightness or wrongness of policy claims). The models are concerned with the motivation, beliefs, values, and interests of the stakeholders. Ethical systems provide tools to review and determine what makes sense and is appropriate for policy (Pal, 1987). 
Data Analysis Methods

Policy analysis also offers methodology for gathering information about the original problem and possible solutions relative to costs and statistical data. Consideration of costs for programs is crucial in any discussion of policy solutions, especially in light of tax payer attitudes about the high cost of government. Cost benefit analysis, for example, is a practice that offers a method to review the internal costs, such as those incurred by an agency to run a program versus external costs, or those required if the program is operated by others outside the agency $(\mathrm{Pal}, 1987)$. One could reveal the intangible or possible unreasonable costs versus the tangible or necessary costs for solutions. Decision making could be assisted by a review of direct costs versus the indirect ones to determine the bottom line in program expenses.

Cost benefit analysis attempts to measure all costs, review the economic rationality or the resources to project whether the private marketplace rather than a public agency would be more cost effective, and could uncover the social cost benefits (Dunn, 1981). Social cost benefits refers to the price for public programs compared to the actual improvements for society. Cost benefits may be problematic because there are difficulties expressing all outcomes in dollar terms, and some may be neglected because they cannot be converted to money amounts. 
Theoretical Constructs in

Decision Making

Several constructs provide methods for more rational decision making. MacRae (1982) wrote that forecasting is one method that attempts to determine the consequences of existing policies and new ones, to predict the content of new policies, and to note the behavior of stake holders toward the policy. The forecasts can be based on trend extrapolation, theoretical assumptions, and subjective judgments (Dunn, 1981). Policy analysis could provide assumption synthesis or synthetic solutions for a composite set that could serve as a basis for the creation of new problem conceptualizations without first living through the consequences.

Another method of policy analysis is the Delphi technique used to aid decision making. Delphi is a process of issues specification, the design of questionnaires to find out important information, the analysis of results, and possibly, the refocus of subsequent questionnaires to obtain more or different information. This process is commonly used in the evaluation of programs and allows information transformation about policy alternatives into possible policy action (Dunn, 1981).

Assumptional Theory (Brewer \& de Leon, 1983) is an example of a theoretical construct or practice that assumes policy is based on the assumptions of one policy maker, but 
lacks a systematic method to look at other views and solutions. Beach and Mitchell (1990) believed that the self-effacing character of those in charge of policy development makes it difficult to challenge the current formulation of problems because of their prejudices or perspectives.

Dunn (1981) wrote about a problem of policy development that happens when surface characteristics or criteria are used to assess the adequacy of problems rather than looking deeper at the underlying ones and then conceptualizing them. Serious issues may escape study because the surface characteristics are misleading when further study might uncover all facets.

Another theoretical construct to assist with decision making is Simon's (cited in Dunn, 1981) Bounded Rationality, which attempts to explain situations when the available information and alternatives are so great that an individual cannot approximate rationality. "Satisficing" occurs when there is a consensus for action that is "just good enough." Incremental Theory is a construct that attempts to define the status quo, or the current practice that occurs most frequently in policy, and the objectives that differ incrementally from that beginning point (Brewer \& De leon, 1983). Lindblom (1959) referred to this common government practice as "muddling through." Lindblom believed: policy development is a process of problems, continuously reformulated, based on changes or 
adjustments in goals, objectives, and alternatives as new information is acquired. (p. 80)

As a result, social problems are frequently remedied rather

than completely solved at one point in time.

Etzioni (1967) proposed Mixed Scanning as an

alternative to dependence upon the status quo, which he

believed ultimately dulls the creative process of public

administrators. A sociologist, Etzioni proposed that

comprehensive rational choices are appropriate for strategic

problems while incremental choices are appropriate for

operational ones. He believed that creativity in policy

development is often prevented in defense of the status quo.

Etzioni believed that the most powerful forces in society

often make choices to maintain the stacus quo because they

have the most to gain by little or no change in policy. He

also pointed out that strategic decisions are different from

day-to-day operational ones. Powerful forces may affect

policy from different milieus, sometimes those who are left

in charge because of a particular expertise.

Another method to assist decision making is referred to as Rational or Comprehension Theory that accounts for all goals, objectives, policy alternatives, and identifies their resulting consequences (Brewer \& De leon, 1983).

Comparisons are formulated, based on the consequences of the attainment for each goal, and coordinated with the desired outcome alternatives. This is accomplished while maximizing the attainment of objectives. In a rational world of policy 
making, the Rational approach could provide a structure to review all of the possible solutions and their consequences before implementation. The process is straightforward and logical and provides a method to compare with oregon's actual development of policy.

Reviewing parallel cases of policy elsewhere provides a method for gathering information to improve the process. Analogies with other policies provided another structure for deciding upon possible policy solutions. A review of other states, for example, might provide data for improved policy decisions (Pal, 1987).

Dunn (1981) referred to the importance of authoritative experts; those knowledgeable in a particular area and the importance of insights from decision makers. The Governor's Task Force was charged with determining goals and program objectives for youth substance abuse during 1983 to 1985 . Their personal and individual expertise was important in this process, but they did receive input from a variety of sources over the course of their deliberations.

Since policy development relies upon decision making, it is helpful to understand that there are methods to improve the process that have consistency and implications for practice. The above array of methodologies was available to policy makers in the 1980 s and provided methods to compare with those used in Oregon's process. 
Would more explicit methods improve policy development? This case study sets out to determine if simply a structure could improve the process, or if are there other considerations that are equally important.

\section{History of Substance Abuse in Oregon}

Although the history of substance abuse in oregon may not appear to lend support for the importance of this case study, it seemed necessary since the 1985 policy had little precedent. In public policy, previous legislation provides a foundation on which to build. The foundation of this study appeared to be incomplete without more understanding of the history of substance abuse treatment and prevention in oregon.

The early attention to substance abuse in oregon was initiated with the development of a mental health system to serve all citizens. Alcoholics, however, were confined to mental institutions or prisons for incarceration and sometimes, treatment. Historically, oregon was not particularly noted for innovations in mental health, but as a state was not unresponsive or inhumane to those considered mentally ill, insane, or "Pelton Kloochman" (a Native American name for one who is demented). The first hospital for the insane was built in 1880 (Dickel, 1977), and led to the building of several more institutions over the years for the mentally ill. 
In 1959, then Governor Mark Hatfield determined that mental health programs needed review, centralization, and innovation. He appointed an eight-member committee to review the state's role in mental health programs (Mental Health Advisory Committee, 1960). The Committee recognized the state's responsibility for care of the mentally ill, which then included alcoholics, those categorically regarded as "mentally deficient," and the aged. The recommendations from this study focused on the importance of community resources and local control in mental health issues. Sixtyfive councils were then established statewide to deal with mental health issues and alcoholism.

The oregon Community Mental Health Plan of 1962 (Oregon Mental Health Division, 1964a) recommended that a Program of Alcoholic Education and Rehabilitation should be a part of mental health rather than a separate unit of government. According to 1960 statistics, there were 55,000 alcoholics in oregon.

In 1964, Trelevean presented a report from the Mental Health Planning Board for the Mental Health Division that outlined a comprehensive plan for oregon. Care was available in mental health facilities for those diagnosed as alcoholics, delinquents, the aged, and disturbed children. The recommendations for prevention of alcoholism included educating oregon's school children about its dangers. This report also carefully detailed alcohol abuse as a major 
health issue. Prevention was identified as a major goal for "good mental health procedures" and relied heavily on mental health centers for dissemination of information (Oregon Mental Health Division, 1964b).

As early as 1959, there was concern about education and early intervention in substance abuse. Prevention was mentioned in a 1973 report as a component of policy in substance abuse (J. Treleaven, interview, June 13, 1991). Inservice education was provided for agency staffs, juvenile courts, schools, and child guidance clinics in cooperation with the oregon Alcohol Education Committee. Alcohol education and rehabilitation services were proposed at the community level. Early intervention and training were first mentioned in 1937 for traveling Child Guidance clinics (Dickel, 1977).

In 1970, a grant from the U.S. Office of Health, Education, and Welfare to the oregon Division of Mental Health funded the study of young drug addicts in order to evaluate the effectiveness of three methods of treatment ( $J$. Treleaven, interview, June 13, 1991). The methods included: individual counseling, group therapy, and "mini-marathon" group therapy. The purpose was to assist youth in becoming useful citizens, in obtaining employment, in making better use of leisure time, and in reducing criminal behavior (Oregon Mental Health Division, 1973). 
In 1973, community education programs were included in five field offices around oregon in order to provide alcohol and drug prevention for the public. The offices were created to expand public awareness and understanding of the problems caused by the abuse of alcohol and drugs. The field offices provided consultation for the development of detoxification programs, halfway houses, and referral centers. The centers were located in Burns, Newport, Salem, Eugene, and Portland. That same year, there were 20 regional councils on alcoholism and drug addiction established state wide to ensure educational programs for schools, businesses, professional groups in communities, detoxification centers, and residential living centers for substance abusers (Oregon Mental Health Division, 1973). The mental health system handled large numbers of alcoholics in the 1970s. Statistics from that time revealed that $11 \%$ of mental health clinic patients had alcoholrelated problems. During 1971, about $22 \%$ of admissions to Oregon's three state hospitals for the mentally ill were diagnosed as alcoholics or problem drinkers (Oregon Mental Health Division, 1973). By 1974, drugs were included in public policy as Oregon's Senate Bill 544 was passed that declared drug dependency to be a mental illness.

On March 8, 1982, Dr. Joseph Treleaven, Director of the Mental Health Division, delivered a state of affairs in mental health speech to the oregon legislature. He spoke of 
the need for county and state partnerships. Dr. Treleaven stated that mental health issues were family matters, and he pointed out that money was still a major problem in spite of the recovering econorny. One recommendation in his speech was an analysis of prevention in substance abuse. He said that substance abuse problems were as serious as child abuse, crime, juvenile delinquency, family breakdown, and economic dependency. The prevention theme is still relevant.

Treleaven's (1982) speech was historically significant since it was the first time the oregon Health Division was mentioned in relation to substance abuse. This demonstrated a paradigm shift from a time when it was perceived as criminal behavior or mental illness.

Prevention histarically was considered in most deliberations about substance abuse policy. Dr. Treleaven (interview, June 13, 1991) of the Mental Health Division, for example, never lost sight of the importance of prevention in his agency. He noted, "Although the budget note might not have indicated prevention, there was always an understanding of its importance in all policy."

In conclusion, substance abuse concern in oregon was first recorded around 1937. By 1959, concern was more evident and referred to in most mental health reports. Drugs were not acknowledged until the 1970s when concern grew rapidly. 
Historically, youth have been referred to in policy decisions, and specifically in 1959 when education was viewed as the primary method for prevention and intervention. Risk factors (see Appendix A, Exhibit 20), an example of specific focus on youth, were not recognized until the 1980s. Over the last 50 years, substance abuse understanding has changed dramatically. The disease concept, for example, has gained acceptance since the 1940s, and resulted in treatment for addicts rather than punishment, or incarceration.

\section{Research on Risk Factors for Youth}

A review of the literature for this case study uncovered an abundance of research available in substance abuse risk factors for youth. In the early 1980s, the experts pointed to certain behaviors and predispositions to substance abuse called risk factors. Several researchers contributed to this research base for adolescents since it was apparent that adult addiction had different characteristics.

Risk factors included deviant behaviors, sensationseeking, aggressiveness, alienation, impulsivity, issues of self esteem, locus of control, and family cohesion. Although risk factors appeared to be one of the most promising research bases for youth substance abuse, some felt it should not be the only focus. Battjes and Bell 
(1985) believed there is little validity in targeting substance abuse on the basis of these variables alone. There are several problems in the identification of youth abuse, including: the transitory nature of abuse (Jessor \& Jessor, 1977), the difficulty of pinpointing central target problems and sorting them out, the lack of a standard assessment of abuse, and the problem identifying short-term experimenters from those who abuse (Winters, 1988). Little work was done in the area of depression and substance abuse in youth prior to the passage of the legislation, but held promise for a segment of the population even then (Jaffe, 1984). In the 1990s, a substantial amount of work has been done in this area of psychiatrically affected youth.

Jessor and Jessor (1977) provided important research with their problem behavior theory that stated that youth substance abuse is socially learned, purposive, and functional behavior that is the result of the interplay of social-environmental and personal factors. They believe it is a learned behavior through a process of modeling and reinforcement that is mediated by personal factors such as cognitions, attitudes, and beliefs. They also mention the importance of peers, which is an area that a great deal of research has been accomplished.

The concept of teaching refusal skills to youth who might enter into substance abuse was derived from Jessor and 
Jessor's initial studies (Botvin \& Willis, 1985). There were many possible avenues for prevention available in the early 1980s. The skills might include communication, problem solving, parent contingency management skills, contracting skills, self management, school and communitybased skill programs (Patterson, Reid, \& Dishion, 1985).

Bry (1988) and Patterson et al. (1985) and many others believed that family systems in disorder were predictive of youth who might abuse. They talked about the flexibility of interactions, the importance of authoritative models of parenting, clarity, permeability of boundaries, proximity of family members, the autonomy of family parts, degrees of interdependence, and seriousness of disruption. Family therapy was mentioned often as a preventive measure.

There were other possible models presented for prevention that included early identification of children who were aggressive or antisocial at school and home (Robins, 1978), delinquent behavior that always led to drug use, poor school performance, and poor coping skills (Kandel, 1978). Shore (1985) reported several ideas for prevention based on research. An important finding is the importance of family modeling and parent attitudes for youth who abuse substances (Bushing \& Bromley, 1975), and others in the early 1980s found out similar information. Peers are viewed as major contributors to youth involvement in 
substances, and risk factors increase with peer use and support for abuse (Patterson et al., 1985).

Research also points to the high correlation between economic deprivation, parents and family in low status professions (i.e., service industry), community disorganization because of poverty and crime, and the propensity for at-risk youth to be involved in substance abuse (Hawkins et al., 1986). Children at risk of substance abuse are readily identifiable in the early grades; and they differ in discipline contacts: physical, verbal, and aggressive behaviors (Walker, Shinn, O'Neill, \& Ramsey, 1985).

Most research on risk factors for youth substance abuse make a compelling case for early identification and social skills training as an early intervention. This information would logically offer policy solutions that include schools, agencies, and communities for intervention with those at risk (see Appendix A, Exhibit 15 for more risk factors). Although treatment is not a focus of this study, the use of the Alcoholics Anonymous model and the 12-step program is important to discuss because of its prevalence in Oregon's Alcohol and Drug Treatment office perspective on treatment.

There was a large scale research project carried out in the early 1980s, which was the Treatment outcome Prospective study (TOPS). This longitudinal project was set up to study 
various treatment models. TOPS was carried out from 1979 to 1981, and found that treatment models were difficult to compare and outcomes were difficult to quantify.

At least two programs reviewed in the 1980 s were built on the Alcoholics Anonymous model and found to be successful. The problems of validation for success were caused because of the many undefinable variables that affect adolescent use and abuse (Grenier, 1985).

Catalano, Hall, and Hawkins (1983) reported that there is not enough information to rate one method more successful than another. Adolescent relapse is also quite high. Catalano et al. reported that any treatment program was better than none. Friedman (1983) also reported that no treatment models were clearly out in front.

At least two programs reviewed in the early 1980 s were built on the Alcoholics Anonymous model and were rated as successful, but it was apparently difficult to substantiate because of the many undefinable variables that affect adolescent use and abuse (Grenier, 1985).

The importance of recognizing that no programs were substantially effective in curbing or treating substance abuse forms a basis for this study, including those Alcoholics Anonymous models. Since Jeff Kushner (interview, November 20, 1990), Director of Alcohol and Drug Programs strongly believed in the Alcoholics Anonymous model as a 
paradigm for his office and direction for policy, this information is particularly important.

In conclusion, a great deal was known about youth substance abuse that was critical to policy development in the early 1980s. There were several studies that could have offered direction for policy in prevention and treatment. Policy analysis provided a variety of methods or practices to support decision making and excellence.

In conclusion, what policy development model, if any, was followed in oregon? If none of the more generally accepted practices were followed, why not? This dissertation will compare one instance of policy development with the perceived rational or desired methods in policy development. Some conclusions from that comparison may provide necessary insights for public administration, and possibly, more rational methods which could improve policy solutions. 
CHAPTER III

\section{METHODOLOGY FOR CASE STUDY}

The purpose of this chapter is to present the methodology for this ex-post facto case study of oregon's development of public policy for youth substance abuse in the early 1980s. Governor Atiyeh and legislative leaders of oregon were faced with a serious social problem in the early 1980s, and their response to the problems of youth substance abuse form the foundation of this study.

The development of Oregon's 1985 public policy offers opportunities to look at what was understood about youth substance abuse, what goals were developed to solve the problems, how the process was carried out and why, and finally, what was the distance between desired policy development and the actual practice, as well as the barriers to an improved process?

A case study attempts to portray an event, situation, or a "slice of life." The imprecise practices that characterize public policy development submit more readily to qualitative analysis and may even confound the conclusions of experts who report problems with such methodology. Coleman (1972) believed that there are problems with social science research because of the lack of 
a single framework to guide it. The same could be said of policy development that is built on practices rather than empirical theories. The practices of policy analysis methods provide models for policy development, and are laden with inconsistencies and questions (Dunn, 1981).

This case study examines policy development ex-post facto through interviews, surveys, archival records, and other documentation of this policy process that was carried out from 1983 to 1985. A foundation of this study is to better understand why rational methods for policy development are abandoned for politically expedient ones. A case or descriptive study attempts to recreate a historical period, which, in this case, is the years between approximately 1980 to 1985. The case study method attempts to gain new knowledge from the thorough review of an existing program, agency, or policy, and to reveal the properties or characteristics of this policy development (Yin, 1989). In the case of development of substance abuse prevention policy, there are certain properties that characterize it, such as a soft research base from which to determine solutions with promise. Pal (1987) stated that there are many problems with social policy and also pointed out that some of the reasons policy is either undefinable, unintentional and fallible is because of human intervention or other factors that get in the way of a strictly logical 
process to find a course of action for problem solving. This perspective is important to the focus of this study.

A case or descriptive study is an empirical inquiry that investigates a contemporary phenomenon "within its real-life context," determines the boundaries between context and phenomenon when they are not clearly evident, and also prescribes that multiple sources of evidence to be used (Yin, 1989).

The purpose of descriptive studies includes the following (Yin, 1989):

1. To develop a register of facts or events in the order they occurred.

2. To depict or characterize a situation.

3. To teach or give knowledge about the situation.

4. To test or prove a hypothesis.

A descriptive or case study attempts to answer questions that begin with how or why. These questions are explanatory in nature and require different tools to probe them. Schramm (1971) described a case or descriptive study asks why the steps were taken, how they were implemented, and with what result. In this study, the questions include:

1. How is public policy developed? Are rational methods used or is "muddling through" (Lindblom, 1959) the traditional model? How were policy analysis methods used in decision making? 
2. Are certain variables or conditions (i.e., politics, special interests, etc.) more important in the policy process than others, and how did they impact the final outcome or policy?

3. How much was known about the prevention of youth substance abuse, and how was that information used? How were decisions made for policy goals in light of the research available? What were the barriers to the use of research?

While this study does not posit a hypothesis, there exists a perception among public administrators that methods for improved decision making are available and desirable. Although the methods are available, their use is questionable in most policy development. The use of research studies to develop better policy is one of the methods that appears to be appreciated and desired by administrators, but is still little used. The improvement of policy development through utilization of more structured methods is a point this study regards as important.

\section{Research Methods}

The research methods used in this case analysis are qualitative in nature, allowing for a variety of perspectives with the hope of capturing the diversity and convergence of actions. The methods allowed for freedom of response by numerous participants who were interviewed or 
surveyed. Survey questions became more focused as the study progressed, but always allowed for individual perspectives that were not necessarily introduced through the questioning process. Interviews allowed individual expression, but focused on specific information to initiate interest and attention. Ideas were formulated that were a part of an evolutionary process that was based on interviews with necessarily broad questions. It became apparent that interviewees felt this study was important and they responded with honesty, a degree of enthusiasm, and at a high rate of response.

\section{Interviews}

Interviews or surveys from five of the nine members living or accessible of the Governor's Task Force provided information for the policy development aspect of the study (see Exhibit 1 in the Appendix A). The initial interviews contained a set of questions about the process of policy development derived from the literature review, and allowed for expression of other related matters of importance by each task force member. This resulted in information that later became integrated into the goals of the study as it became apparent that there were certain variables and conditions which had particular importance in the literature of policy development. 
The variables of policy development were chosen and modified from a general listing written by Kroll et al. (1969). The variables included: politics, economics, leadership, special interest groups, and the use of research.

The members interviewed or surveyed include:

1. Judge William Beckett, Lane county circuit court.

2. Dr. Doug Egan, Department of Business. Administration, Lewis \& Clark College.

3. The Honorable Vera Katz, Representative, Oregon House of Representatives.

4. Kristine Gebbie, then Director of the oregon Health Division.

5. Dr. Spero Manson, formerly of oregon Health Sciences University.

Members of the Governor's Task Force who were not interviewed include the following. (The first two were deceased, and the last two either did not return phone calls or were unable to be located.)

1. Tom Dargan, KATU Television.

2. Hank Crawford, Lobbyist of health industry (i.e. Blue Cross, etc.).

3. Robert Hatch, Substance Abuse Counselor.

4. Bob Yates, Salem Businessman.

Governor Victor Atiyeh was also interviewed as he was important to the policy process. Dr. Joe Treleaven, former 
Director of Mental Health was interviewed two times. He offered an important historical perspective and his own archival records, which gave the study greater breadth and understanding because he was close to the policy development issues of that time.

There were also interviews held with eight agency administrators of oregon's social service agencies who were not involved in the policy development except for one (Jeff Kushner) (see Appendix A, Exhibit 2), two legislative leaders (see Appendix A, Exhibit 3), and three alcohol and drug experts (see Appendix A, Exhibit 10). The interviews were face to face and uncovered a great deal of information about the development of public policy and especially the utilization of research. The protocol for each of the interviews is available in the appendix of this dissertation.

The greatest amount of time interviewing was spent with the two administrators for the Alcohol and Drug Program Office who were intimately involved with the process of formulating substance abuse policy in the 1980s. For the sake of confidentiality, the names of the other interviewees are not presented in the body of this study. The interviews allowed indirect answers and provided secondary information that proved to be quite helpful. As with any study, the questions became more focused as the data was gathered. 
In order to determine the research base for substance abuse, interviews were only one source of information. Three experts were identified for interviews because of their experience in adolescent and adult substance abuse in Oregon (see Exhibit 10 in Appendix A).

The interviews provided information to determine if the chosen policy goals were consistent with expert opinions about prevention and treatment for the policy. Dr. David Hawkins did not respond to a survey, however, his attendance at a conference in 1989, organized by the office of Educational Policy and Planning, provided ample evidence for support of risk factors.

\section{Survey Data}

Three different surveys were sent to participants who were involved with the process of policy development. The first participants surveyed included five administrators of state agencies in 1989, and the second group included three other administrators who specifically dealt with substance abuse issues. Questions included their use of research in building policy and their knowledge of substance abuse issues for this task (see Appendix A, Exhibit 5). The third group, surveyed in 1990, consisted of 13 oregon researchers who had studied youth substance abuse in order to determine what information was available for policy developers within the state (see Appendix A, Exhibit 6). 
The fourth survey evolved from the first two phases of the study and was returned by five of the nine members of the Governor's Task Force in 1991. The purpose was to determine their perception of the effect of five selected variables on the policy process. (The matrix for this survey is found in Exhibit 7 of the Appendix A.)

\section{Archival Records}

There were public records of the proceedings and private archival ones that provided important documentation of the actual proceedings and read to increase understanding of the entire process. The archival records included historical documents, speeches, and reports that were given to various political leaders and agencies (Exhibit 8 in the Appendix A). Dr. Joe Treleaven, Director of Mental Health in the early 1980s, provided his own documents for examination by this author. They were particularly helpful to the review of the evolution of Oregon's substance abuse policy dating from the early 1930s.

\section{Secondary Sources}

Substance abuse policy manuals and studies from the Federal Government and researchers were used for the study. Research studies from a variety of researchers within oregon were reviewed, as well as those from Dr. David Hawkins of the University of Washington. There were at least 100 
studies by researchers from the United States and internationally that were read to determine a body of knowledge that policy developers might have used. Information particularly about risk factors focused the study and correlated with the information given by substance abuse experts during the process.

Resources for research in substance abuse treatment and prevention were acquired from the National Institute of Drug and Alcohol, the Center for Substance Abuse Treatment, both in washington, DC. The University of Washington library for Alcohol and Drug Resources and Oregon's Alcohol and Drug Resource Center provided documentation of research studies that were available to policy planners prior to 1985 . Doty (1982) referred to the above procedures as a review of relevant studies from a variety of researchers as a form of research for policy.

study sources are limited to public and private archival records, research studies, government policy manuals, and the memory of participants. Documentation of information sources used is available in Exhibit 8 of the Appendix $A$ and in the references.

$$
\text { Analysis of Data }
$$

In order to analyze the data from surveys, interviews, and literature, it is necessary to report the findings in a narrative form. The five variables of policy development 
used for analysis are rated for their relative importance by task force members. The ratings of importance to the process are reported in a narrative manner in the study as well as represented by an array in the appendix that allows for comparisons of the various variables and sub categories. Findings are presented in a narrative form with listings of barriers to the use of research in policy and barriers to the utilization of the methods of policy analysis. Chapter $V$, the final chapter, provides possibilities for further study in policy analysis and decision-making models. The alliance between future study directions and the methods of policy analysis resulted because there was simply little in the policy development process to suggest these methods were even recognized, much less used. Without their use in the process, findings were non-existent and only pointed to their use in the future.

\section{Limitations of the study}

This study is not free from the normal limitations of descriptive research. The data were largely gathered from the memories and perceptions of those involved. This is a limitation that cannot adequately be calculated, but which may be considerable. This policy process occurred several years ago and eliminated the participation of several key individuals because they have become inaccessible. This limited response to surveys and interviews could result in a 
lack of certain perceptions and points of view in this study.

The study period is from 1980 to 1985, which creates problems for locating both archival materials and individuals who had the greatest impact on the policy development. A sincere attempt was made to involve key members, but there are some who probably impacted the process a great deal and yet were not identified or who were impossible to locate, as in the case of some agency administrators and four members of the Governor's Task Force.

\section{Precautions for Accuracy}

The bias the author brought to this study became more apparent over time. Studies read in the beginning became fact rather than ideas since perspectives were difficult to pinpoint and memory faded. In other words, there was so much public|policy information to interpret that some categorization and self-selection became necessary that does not necessarily yield the truth. Some original assumptions, for example, became lessened as factors, while other ones seriously changed the course of the study. It may be true that the author of this study might retain and might utilize certain perspectives more than others due to the time spent with certain ideas, memory, and the influence of participants who had certain biases or beliefs. 
A problem for this study became the many possible directions to pursue and also the abundance of findings. The areas that were identified included: the perceived and the reality of policy development, the use of policy analysis methods, the use of research in public policy, research in youth substance abuse prevention and treatment, and the many barriers to effective practices in policy development. Each of these areas provided a separate study in themselves and made the findings difficult to report simply and clearly.

In conclusion, a sincere attempt was made in this study to maintain neutrality and reflect not only ethical but highly professional research methods. That attempt may not have been entirely possible in a process dealing with human behavior and interpretation. 
CHAPTER IV

\section{CASE STUDY FINDINGS}

This chapter draws conclusions based on the findings derived from surveys and interviews of five members of the Governor's Task Force (including Jeff Kushner, Director of Alcohol and Drug Programs), then Governor Atiyeh, Rick Bauman, former oregon Representative and Chair of the Sub Committee for Human Resources of Ways and Means, seven social service agency directors, and members of oregon's research community. This case study is intended to inform policy developers about oregon's attempt to create solutions for the serious problems of youth alcohol and drug abuse. This study should offer some ideas for the development of public policy. Chapter V presents several ideas for further study in the use of policy analysis methods that may even further enlighten public administrators. Wildavsky (1979) referred to policy as the tension between resources, objectives, planning, politics, skepticism, and dogma. Construedas (cited in Brewer \& De leon, 1983) stated that policy becomes a guide to action, which then becomes an instrument applying a structure to a particular choice.

The questions this study set out to answer include: 
1. What were the methods available to public administrators in the development of this policy, and which were actually used?

2. What was actually known about the prevention of youth substance abuse in the early 1980s?

3. What was the process used to determine the recommendations that finally became this policy?

4. In public policy development, to what degree is the distance between actual practice and theoretical constructs within acceptable limits?

5. What variables impacted policy development the most?

The findings include an abundance of information for policy development. At least $70 \%$ of the Governor's Task Force responded to interviews and surveys that attempted to measure the impact of variables in this case of policy development. All of Oregon's social service agency administrators shared information in 1989 for this study about their policy practices, but only two were active during the actual substance abuse policy development. One social service agency administrator is still active in oregon's bureaucracy, and that is Jeff Kushner of Alcohol and Drug Programs. All the other administrators directly involved in 1985's policy development were not available for this study except Dr. Joe Treleaven, former administrator of 
Mental Health who led the agency up to the point of the policy process.

oregon's research community also contributed information about their work with policy developers after 1985 since their work was not used in the formulation of this policy. It is important to recognize that the conclusions provide an ex-post facto integration of information about deliberations between 1983 and 1985 . Information previous to 1985 would have been preferable, but was not always possible in some cases such as from social service agency directors and researchers.

The following findings are general in nature and are integrated into this chapter:

1. There is general. confusion about the difference between data (numerical data about clients who received interventions for substance abuse) and study results that involve careful, systematic client study by agencies. Terminology is a problem with agencies who appear to interchange the words data and longitudinal studies of clients.

2. There are longitudinal studies and research in youth substance abuse that reflect risk factors for prevention, however, treatment procedures are not as conclusive. 
3. There are differing attitudes about the use of research among agency administrators, task force members, and researchers.

4. There is a problem with research that is devoted to issues different than the needs of policy developers.

5. There are conflicting research paradigms.

6. There is a lack of understanding about the importance of research for the work of agencies.

7. There are different comfort levels about the use of research in agencies.

8. There is a lack of familiarity with literature and research in substance abuse outside of the Alcohol and Drug Program office.

9. There is a general lack of experience in utilizing the research community and understanding the barriers to it.

10. There is a reliance on previous policy or the status quo rather than a broader view of the future.

The next sections review the findings from the Governor's Task Force specifically related to the five variables in policy development.

\section{Summary of Findings for the \\ Variable of Politics}

Politics are important to any discussion of policy development, and they affected this case from its inception. Several political entities are involved in this policy process and affected deliberations and the progress. It is 
important to note that any of the political entities through which this policy found its way were in some manner a special interest group. The term, however, as a variable of policy development for this study has a different meaning and is retained as such. Special interests affected this policy from beginning to end, and were, in some sense, broader than organized groups such as Mothers Against Drunken Drivers. This dissertation makes a clear distinction between those groups and stakeholders in the various levels of the bureaucracy.

Politics is the art and science of governing and should be dedicated to the improvement of the public good. Politics is the work of people involved in such a process of policy development; the way they interact and make decisions.

In the relevant literature, there is much about the role of politics in policy development. Nagel (1978) wrote that policy deals with legal, economic, and most important, political values. Lasswell (1971) referred to the policy process as one where the irrational basis of society is brought into the open, and is influenced by politics and is key to the attainment of goals.

Dye (1985) wrote about the many entities policy must pass through in a legislative process that all affect the final product, and probably hinder the process and the final product. The entities of government will remain in the 
domain of politics rather than special interests which are spoken to in the next section.

Probably the largest domain or level of government is the people in a state such as oregon. Doug Egan (interview, May 15, 1990) of the Governor's Task Force believed that the public understands the problems of substance abuse, but politicians give it visibility. He believed, for example, that school boards were not able to accomplish this policy by themselves since youth substance abuse required the credibility and status of a state issue before it received proper attention in schools.

Kristine Gebbie (survey, June 14, 1990) referred to the elevation of substance abuse as a health issue through the policy development process. The threat of actions and approval underscore the important decision actions of policy (Brewer \& De leon, 1983).

one political aspect of task forces such as the Governor's was the inclusion of representatives of agencies, special interests, and the public in its membership. The Governor's Task Force provides a good forum to hear a variety of perspectives. The literature of public administration regards the use of task forces as desirable in blending the interests of public and government officials. The task force, with a variety of perspectives represented, was an attempt to balance biases which can be a problem in policy development. 
Kristine Gebbie (survey, June 14, 1990) of the Governor's Task Force believed the policy that emerged was a good compromise of interests. The task force was a blend of political perspectives on substance abuse. Several members of the task force note that compromise was often the result of their deliberations because of the give and take among members in their discussions. Good relationships in the Governor's Task Force characterized its work, but this may also have contributed to a policy that was too broad, eliminating major disagreement or controversial solutions, and resulting in goals that allowed many interpretations.

There were at least six milieus involved in this study: the legislature, state human service agencies, then Governor Atiyeh's office, the Governor's Task Force, special interests or stakeholders (separate from government entities), and oregon's citizens. The social service agencies of state government with the greatest stake in policy for youth substance abuse included: Adult and Family Services, Children's Services Division, Department of Education, Mental Health, Health Division, Youth Services Commission Office, and the oregon Traffic Safety Commission. Each of these agencies has some relation to substance abuse, but generally deferred to the Alcohol and Drug Program Office for important decisions. The Alcohol and Drug Program Office and Jeff Kushner were consistently important to this policy development process. 
Each of the political entities affected this process at a different point, and sometimes joined forces. Doug Egan (interview, May 15, 1990) stated that issues of turf or self interest by agencies are serious, and there is little knowledge about how to treat the controversies as they arise. A major issue in this policy development process appears to be the Division of Mental Health's loss of control over Alcohol and Drug Program's budget when it was removed from their jurisdiction. The possibility that alcohol and drug issues might be confined to one agency created contentious battles among agency administrators. Administrators appeared, at times, to abandon the problems of substance abuse and focused more on streamlining the budgets of agencies with alcohol and drug monies. The public, meanwhile, was anxious for solutions since the numbers of Oregonians abusing substances in the 1980 s were growing.

Governor Atiyeh's office was critical to the success of the policy. When surveyed about which variables most affected the policy, four members of the Governor's Task Force believe that the Governor's office was important to the passage of the legislation. Two members believe that the office was not at all important to the final process. Two members of the Alcohol and Drug staff commend Governor Atiyeh for his interest in substance abuse and his support of the task force (members were actually chosen by Jeff 
Kushner). Doug Egan (interview, May 15, 1990) believed that Governor Atiyeh became more interested over time, and his support was important to the policy.

Governor Atiyeh's interest in this legislation appeared to be a factor in its success because his office gave the task force credibility as well as free reign to make decisions. Then Governor Atiyeh (interview, May 22, 1990) characterized his managerial style when he spoke of the need to protect his agency directors and their autonomy. Although he held some power in this process, Governor Atiyeh trusted his administrators to be innovative; thus, he left them alone to do just that. For this position, he was often roundly criticized as a "do nothing governor."

The citizens of oregon were another political entity that directly affected this policy process. Public perception was rated important by four members of the Governor's Task Force, while two felt the public's concern was not at all important to the legislation. Two members were apparently unaware of the public outcry over substance abuse in the state. Spero Manson (survey, May 3, 1994), Task Force member said it was impossible to separate policy from public perception since both made a significant contribution to the process. He believed the public made policy changes possible and also monitored the entire process. 
For the purpose of this study, special interest groups include only organized groups for the purpose of lobbying such as Mothers Against Drunk Driving, health care, and county alcohol and drug personnel. One could make the case that special interests include any of the entities mentioned within the variable of politics. In order to facilitate a clear distinction of special interests, a narrower view is maintained in this dissertation.

The legislature is an important political body because of its legitimate role in policy development. Four respondents of the Governor's Task Force rate the legislature and its committee process as important, while two believe it was not at all important to the process. Two respondents believe policy development and passage are not successful due to the work of the legislature. The body did provide a meeting ground for various political entities, a forum for spirited discussion, and a neutral location to present some winning and losing policy concepts.

Policy is a confluence of values that also must pass through various layers or milieus of government before final enactment. The layers within the legislative process include the Human Resources Committee, Ways and Means and sub committees, the legislative fiscal office, various budget analysts, and key representatives and senators who vote both in committees and on the floor of their respective houses. At many points in the process, particular 
perspectives, personalities, and political agendas command attention.

Networks and alliances in the legislature appeared to impact the policy development significantly. Task force members and agency personnel who impacted the legislative process the most appeared to have established networks there. There were members of the oregon House and Senate, separate from the Governor's Task Force, who were influential to the policy process. Legislative membership was rated very high in the success of the policy by five respondents, while one felt it was not at all important. The importance of membership in the oregon House of Representatives by Vera Katz, also a member of the Governor's Task Force, impacted policy development. The legislature is a political body and knowledge about it is significant to this policy formation. In terms of politics and leadership, Vera Katz, then Speaker of the House, was mentioned by respondents more often than any person as important to the process. Vera Katz (interview, July 1, 1990) was regarded by task force members as a politician who understands the legislative process and cleared the way for the policy rather than pushing her own political agenda. Vera Katz was also the only person to mention that politics is not important to the passage of the legislation.

One member of the Governor's Task Force, the late Hank Crawford, was a lobbyist for the health care providers (Blue 
Cross and Blue Shield) and he also knew the legislative process well. Hank apparently provided important networking in the legislature for this policy, which is noted by two members of the Governor's Task Force. He had important alliances within the legislature, and he also understood the means and the necessity for political maneuvering. Doug Egan (interview, May 15, 1990) recalled that Hank Crawford sometimes stood diametrically opposed to his own lobbying interests in the substance abuse policy development. clark Campbell (interview, November 10, 1989) noted that when the legislature puts its seal of approval on policy, it is necessary to "grease the way."

Judge Beckett (interview, June 15, 1990) believed that the give and take of the legislature and the agencies helped pass the legislation. The legislature is an important and complex milieu in which to work, and perhaps understanding legislative networks is more important than selling the policy concepts.

Convincing those who are the final arbitrators and explaining the issues of policy for a variety of perspectives and self interests is a task required for passage. Various members of the task force and the legislature were important to policy passage. Some were either recovering from their own addictions to substances or had some relationship to the problems of abuse. Personal experience and connection to this issue must have had an 
impact on deliberations and final outcomes in policy since various individuals mention either their own or others involved who had some problem with substance abuse.

Doug Egan (interview, May 15, 1990) believed that clark Campbell, Jeff Kushner's Deputy Assistant, was particularly helpful to the process by his guidance of the policy through the legislative process. He had several contacts in the agencies and legislature. The importance of networking cannot be understated in policy development, particularly in light of the legislative process.

Dr. Joe Treleaven (interview, June 13, 1991), former Director of Mental Health, referred to the legislature as "the final arbitrator that utilizes interpretations, impressions, and must work with data up front." This data includes the cost estimates provided by agencies to demonstrate how much money is used for agency programs. Doug Egan (interview, May 15, 1990) referred to the "stacks of testimony" the task force received from all around the state. The testimony was from stakeholders including experts in substance abuse, concerned citizens, and county service personnel. No members of Oregon's research community testified during this time.

There appears to be a split between survey respondents about whether previous legislation affected the 1985 policy. Doug Egan (interview, May 15, 1990) said that the previous legislative session passed legislation to provide treatment 
that he believed helped the policy's passage. Three respondents believe that previous legislation was either highly or somewhat important to passage, while three believe that previous policy was not at all important. All survey respondents believe the previous legislative leadership and attitudes toward adolescents highly affected this legislation.

In conclusion, Oregon's development of policy for adolescent substance abuse prevention was significantly influenced by politics at both the legislative and agency level. Vera Katz, then Speaker of the House, affected the policy process, especially in the legislature. The support of Governor Atiyeh and his office was also important to passage of this policy. Jeff kushner exerted a great deal of political influence in this policy process, which is further expanded in the next section on leadership since it is difficult to separate politics from the personalities involved.

$$
\begin{gathered}
\text { Summary of Findings for the Variable } \\
\text { of Special Groups }
\end{gathered}
$$

Although any of the above political entities might be considered special interests, the variable chosen for this study specifically refers to groups outside of oregon's agencies or government. Recently, concern has become more serious regarding special interest lobbying in the affairs of government. Many believe that lobbying may ultimately 
cause inequities and bias in government because of too much access to power. The special interest groups of the 1980s, however, were fairly benign and as diverse as Mothers Against Drunken Drivers, county alcohol and drug personnel, and health care providers.

Dye (1985) wrote that policy moves in the direction desired by groups gaining influence and moves away from those losing it. Several experts, including Doty (1980), Etzioni (1974), and Dye wrote that the ability of stakeholders or special interests to mobilize resources, and their access to decision makers is key to the success of policy values.

This case study finds that the special interest groups noted above do have some impact on policy development, but it is not clearly significant. Their presence, though noted by almost all respondents, was not impactful to the policy development in surveys from the Governor's Task Force. It also became evident in this dissertation that the narrow focus of special interest groups limited understanding about the role of stakeholders in general.

Five respondents believed that special interest groups are somewhat to highly important to the process. One respondent believed that special interests are not at all important to the policy development. Judge Beckett (interview, June 15, 1990) believed there were many special interest groups present during the $1980 \mathrm{~s}$ and their interest 
was genuine. Doug Egan (interview, May 15, 1990) noted there are so many groups to deal with, it is difficult to make sense of them all. Both members of the task force may be referring to a more broad interpretation of special interests or stakeholders to include agency personnel and layers of government.

Doug Egan (interview, May 15, 1990) referred to Roseanne Creighton of the Drug Initiative, Mothers Against Drunken Drivers, and others such as health care providers. Governor Atiyeh (interview, May 22, 1990) also referred to Mothers Against Drunken Drivers as the only active group; and he believed they were not always helpful. Spero Manson (survey, May 3, 1994) also referred to Mothers Against Drunken Drivers as the only special interest group pertinent to substance abuse.

County service providers "blocked the process" according to Clark Campbell (interview, November 10, 1989) and are regarded as highly important to the process by one respondent, while three task force members believe they are only somewhat important to the process. One respondent believed that the county service providers are not at all important to the process.

This lack of support for one special interest and apparent admiration for another such as Mothers Against Drunken Drivers can lead to an understanding about stakeholders. It appears the larger the distance from 
government and agency involvement a group is perceived to be, the more respectfully it is regarded in the process. Jeff Kushner (interview, November 20, 1990) believed that special interest groups concerned with substance abuse would be more helpful in upcoming sessions, and that has proven to be the case in the 1990s. One may postulate reasons the special interest groups, as we know them in the 1990s, may not have been so important in the 1980s. The legislation may have been perceived to be so benign, so broad, or lacking in programs that a strong lobbying effort was not necessary.

In conclusion, the public perception of special interest groups unfairly influencing government is not substantiated in this case study. The narrow definition of special interest groups in this study appeared to conform to the views of task force members. Almost all members of the task force mentioned certain special interest groups, but do not ultimately regard them important to the policy process.

The lobbying efforts of these groups appeared to be minimal and not particularly well organized. The groups presented testimony to the task force and were acknowledged but had little impact on the final policy.

\section{The Findings for the Variable} of Leadership

The leadership variable in this case study are the qualities that certain individuals brought to this policy 
development. At least three people are identified who impacted this policy development significantly because of their leadership skills. Of the five chosen policy variables, leadership is the one that appears to impact Oregon's policy development the most.

Kroll et al. (1969) described the attributes of leadership: a specialized capacity for providing distinctive effectiveness, a moderating ability for competing forces, a tone or force of dominance for a segment or approach, and a type of administrative leadership including mechanisms and instruments for final development. Kroll et al. (1969) also referred to the importance of dynamism and fluidity when actors and manipulators change. This point is especially important to underscore in oregon's policy development since the leadership role changed as the process evolved. At certain times, different members of the Governor's Task Force took the reigns of leadership as the process made use of their knowledge of a system or their abilities to create consensus. The staff of Alcohol and Drug Programs was ultimately the most visible and active of all those involved in the process.

Bales (1950) and Likert (1961) referred to the leadership qualities of data gatherer, keeping the process on track, and providing reinforcement and support. Interestingly, the qualities of charisma and personality do 
not necessarily equate with good leadership (Stephan \& Stephan, 1985).

Survey respondents all rated the Alcohol and Drug Program staff's leadership important to the policy. Four of the Governor's Task Force members believed this agency's leadership is highly important, while one believed that it is somewhat important. Every respondent in the Governor's Task Force believed the Alcohol and Drug Program staff is important to the policy because of their knowledge of the legislative process and their grasp of substance abuse.

In a review of archival files, letters from the Alcohol and Drug Program office to members of the task force reflected appreciation for their work. This kind of positive communication probably contributed to Alcohol and Drug Program's perceived leadership in this policy development. The archival letters also indicated that Alcohol and Drug Programs nudged the process along in the legislature and in agencies. Each member of the task force had a full time position in his or her respective careers and depended upon this agency to keep the policy process moving toward completion. The Alcohol and Drug Program office appeared to accomplish this by serving as a liaison with the legislature and the task force. They consistently had more informaticn and access in the policy process than the task force or anyone else that impacted almost every aspect of development. 
Leadership is a major factor in this policy development.' Four survey respondents rate the Governor's Task Force members very high in leadership, and one believed they are somewhat important. Leadership by the legislature is also perceived to be very important to the process by five respondents whilie one felt it is somewhat important. The legislature provided a location for debate of the final policy.

Leadership qualities include individual access to the legislature, charisma, collaboration skills, and goodproblem solving, which were all demonstrated by the Honorable Vera Katz. All members of the task force, Governor Atiyeh, Fick Bauman of ways and Means, and three agency personnel all referred to the importance of her leadership. The traits mentioned are probably not as important as her "shepherding role," according to clark Campbell (interview, November 10, 1989). In surveys and interviews, visibility and understanding the legislature are regarded as more important than charisma.

Hank Crawford, health care provider lobbyist, also demonstrated neutrality and an understanding of the legislative process that gained the attention of two members of the Governor's Task Force in interviews and surveys ( $K$. Gebbie interview, June 14, 1990; Doug Egan interview, May $15,1990)$. 
Tom Dargan, late Director of KATU Television in Portland, demonstrated good problem-solving and communication skills that appeared to serve him well. Governor Atiyeh noted (interview, May 22, 1990) that Tom Dargan was a member of the news media, and it was unusual for such an individual to take part in policy development. Doug Egan (interview, May 15, 1990) talked about how he and Tom Dargan would drive from Portland to salem and make decisions about the next steps in task force deliberations or policy steps.

Tom Dargan (interview with c. Campbell, November 10, 1989) had personal experience with substance abuse, which may have affected his motivation and interest. Three interviewees mentioned his charisma, verbal skills, and ability to pull divergent forces together as important to the process. One interviewee mentioned that Tom's leadership was due to his stature in television and Portland politics, an investment in substance abuse, and an ability to keep the issue on track. Vera Katz (interview, July 1, 1990) especially appreciated him for working through the process in a logical manner as well as for his political savvy in working out turf battles.

One can only postulate about the political alliances and other reasons for the views of certain Task Force members. Kristine Gebbie (survey, June 14, 1990) noted that she enjoys working with Vera katz. At the time of the 
survey, Kristine Gebbie was the director of Oregon's Health Division, and it is fair to say that she probably had an investment in a good relationship with the speaker of the House of Representatives. Overall, the responses from task force members point to a cooperative and collaborative spirit among them that appeared to affect their deliberations and success in passing legislation while possibly avoiding difficult decisions and conflict.

Jeff Kushner's perceived leadership appears to be the result of his guidance and information gathering for the task force. Comments from those involved in the process focus on his characteristics as a good problem solver and as one who provides excellent staff work and data just when it is needed. From archival records examined, it appears that he was especially good at letting the task force know about his work with the legislature and agencies. Four respondents believe he is the most important member of the Alcohol and Drug staff while one noted that clark Campbell (Jeff Kushner's assistant) is the most influential. Survey respondents believe there is equal leadership demonstrated by the task force and legislature. The task force members depend upon the legislature for final decision making, but they believe their own ability to digest a great deal of information and arrive at policy solutions is equally important. The leadership of agencies is rated very high by four respondents while two respondents believe the 
agencies are somewhat important. The social service agency rated as most important by all members is Alcohol and Drug Programs.

In conclusion, leadership has certain definable characteristics that impacted this policy process significantly. Leadership is defined by those who provide information, have access to the legislature, and keep a process on track. The leadership qualities of three people in the process are particularly notable. Jeff Kushner probably had the greatest legitimate power in this process because of his access to information about substance abuse and his role of facilitator, but he was assisted by at least two others in this policy development. It appears that vera Katz, then speaker of the House, provided political access to the legislature, and the late Tom Dargan provided the ability to keep the task force focused on their policy goal with a measure of good humor and grace.

The Findings for the Variable of Economics

Any study of government programs and policy recognizes that resources are necessary to support them. Innovativeness in the actual programs of policy depends upon the adequacy of resources. The streamlining of government agencies, especially through budget processes and reporting procedures, affected this policy development and almost overshadowed the policy for substance abuse prevention. 
The lack of money for programs had a serious effect upon policy development in the 1980 s because of cutbacks in state budgets. A struggling state economy with timber production at an all time low were major causes of the state's budget deficit. oregonians had been long dependent upon timber, tourism, and farming (Bryson \& Levine, 1989). According to then Governor Atiyeh (interview, May 22, 1990) as the economic climate changed due to timber shortages, Oregonians were slow to respond, possibly because they had little experience with severe budget shortfalls. Interventions came too little and too late, resulting in all time low revenues.

Politicians and administrators were not familiar with managing state government with deficits, and the entire system was reeling from the effects. Little money for new programs or innovations and legislative leaders sparring with agency directors about funding combined to make the 1985 legislative session less than spectacular, particularly for substance abuse.

Economics can affect other areas indirectly. Policy development, for example, can often be improved by utilizing the expertise of researchers, but that requires funding. Pal (1987) wrote about government's reliance on resources for policy instruments and the information needed to make good decisions. Policy research can provide such services, and oregon's research community might have provided a range 
of studies related to substance abuse policy decisions, which, of course, did not occur. Researchers all mentioned the importance of reparation for their services.

It is reasonable to believe that low state revenues affected this policy significantly, but this does not appear to be the case. One task force member believed that the impact of economics on the process is very high, while five respond that the availability of state tax revenues is only somewhat important. Six respondents regard the attitude of the legislature toward spending as only somewhat important to the process.

The state's forced austerity did affect the substance abuse policy proceedings. Dr. Joe Treleaven (interview, June 13, 1991), Director of Mental Health, referred to the lack of dollars for programs. He also believed that research and prevention are limited by a lack of dollars. Clark Campbell (interview, November 10, 1989) referred to the "sinking raft" of state budgets that had been severely cut since the 1980s. He noted there were no program dollars left to cut. It became obvious early in the policy development that adding expensive programs to solve problems would be exceedingly difficult. The serious lack of dollars appeared to result in political maneuvering that stopped or scaled down program alternatives.

Clark Campbell (interview, November 10, 1989) referred to the budget note or memo from ways and Means in 1983 as a 
directive to do a study of substance abuse. He believed this provided an effective method to study alcohol and drug services. The Ways and Means Committee in the oregon legislature has a great deal of power in the legislative process. Their decision making for agencies in the budgeting process is an expression of values when applied to their programs, and provides the bottom line in all deliberations.

Ways and Means provides a committee structure in which to debate issues such as program coordination between agencies and also expenditures. Rick Bauman (interview, 1989), Vice Chair of the sub Committee of ways and Means for Human Resources in the 1985 legislative Session, said that budgets are not well understood and do not always reflect need. He also noted that agencies often use bureaucratic manipulations such as hiding monies or classifying them under categories such as alcohol and drug, which creates greater complexity in understanding budgets.

The desire to streamline the budget process often seems to be more important than the legislation itself, just as moving Alcohol and Drug Programs out of Mental Health dominated the process rather than focusing on substance abuse. The legislative concern for streamlining government by better management of budgets in the various agencies and coordinating them appears to be counter productive to the passage of policy for prevention of substance abuse. Rather 
than focusing on innovative program goals and the issues of substance abuse, budgets and political expediency appeared to dominate many discussions.

A problem with public policy development appears to be the result of many levels of government through which it passes. Many of these levels have a small investment in the original purpose, which may even lack original clear intention. It is possible that some in the legislature, or even agencies, never embraced the goal to prevent youth substance abuse. It appears that some regarded the final legislation as an opportunity to save money and look more efficient to taxpayers.

It is fair to say that policy development was initiated by Speaker of the House of Representatives, Vera Katz, and Senate President, Fred Heard, because of their concern about the lack of accounting procedures in the social service agencies with alcohol and drug monies. This concern was probably equal to their perception of the public's concern about the serious problems of substance abuse. Pal (1987) wrote that the legislature responds to problems rather than initiates them.

The Governor's Task Force often mentioned concern about budgets. There appears to be equal concern for availability of resources as there is for improved budget procedures. Tom Dargan spoke of the need for a "better handle on 
budgets" or determining where the monies were going (D. Egan interview, May 15, 1990).

An area of deficiency regarding funding was the lack of cost and performance data from agencies. More than one task force member commented about this situation. The data provided a "bottom line" of budget dollars with which to make informed decisions about continuation of programs. The budget process provides an arena to use in looking at programs and outcomes which were a result of the $\$ 40$ million spent for alcohol and drug abuse. Four respondents mentioned that data in the form of numbers from agencies provided numerical information rather than any research analysis. Some agencies provided better data than others for the task force. Dr. Joe Treleaven (interview, June 13, 1991) said there is a need for agencies to generate better data and noted the legislature utilizes it through interpretations, impressions, and simply working with statistics up front.

Jeff Kushner (interview, November 20, 1990) referred to the policy created by agencies and the resulting interest groups. He believed that the layers created by seven agencies is a serious problem. Doug Egan (interview, May 15, 1990) said that substance abuse is not the "bread and butter" of most of the agencies. This may be the reason information was so varied between agencies and was probably the first time many of the agencies were forced to provide 
much information about their alcohol and drug programs. This is also referred to in the literature of policy development as a serious problem of legislature's creating policy and the many political entities that must affect it. Beyond statistical data in agencies, few interpretations of client information about what could work to solve the problems of substance abuse were available. Evaluation departments were not available in all agencies, and this could have been responsible for little research on client treatments. The data could have included findings from longitudinal studies of programs that had previously been implemented in these agencies (optimum outcome or research evaluation). Survey respondents were asked to reflect on the policy as representative of the best methods available for prevention of substance abuse. The responses are varied and reflect that the best methods were not represented, but it was believed that the policy was politically appropriate for the times. Prevention is not supported in the final legislation, but some members of the task force believed that political and resource allocations would take care of this later in the process (W. Beckett interview, June 15, 1990).

In conclusion, the actual content of the substance abuse legislation was sometimes overshadowed by the need to streamline budgets for alcohol and drug programs. There were mixed attitudes about the power of the economic 
variable in the process. Limited funds probably affected program development, but economics, though notable, was not the most important variable in this policy development.

The Findings for the Variable of Research

It is impossible to talk about the use of research without referring again to the implicit problems of social policy. Coleman (1972) believed that social policy operates on the boundaries of existing methodology because there is not a single framework to guide it. Social policy may be less than satisfactory to those who support scientific hypothesis setting because it lacks a systematic basis, and designs can also be less than satisfactory. Social policy often addresses human problems and also then attempts empirically to induce concepts and causative theories as the study evolves (Brewer \& De leon, 1983).

Majchrzac (1984) believed that social researchers often find themselves adapting, combining, and improvising as they study a problem. Adaptation and improvisation appear to be common to this case study. The problems of substance abuse may be clearly defined, but the process of responding to such problems is diffused by efforts such as improvement of the budget process, moving Alcohol and Drug Programs out of Mental Health, and determining how to best support county programs. This inability to focus on actual programmatic 
solutions appears to be a serious problem in this policy development process.

Majchrzac (1984) referred to the many problems of social research, including lack of design experiences, hidden information, fallible instruments, and lack of appropriate time frames. Clark Campbell (interview, November 10,1989 ) also referred to the problem of research not interfacing with the period of time that services are provided. Oregon's researchers also refer to the problem of time lines and longitudinal studies. There were few longitudinal studies in youth substance abuse available to review, and this lack of studies is documented by administrators and researchers in the $1980 \mathrm{~s}$.

Research can map alternative approaches to a problem while specifying potential for different intentions, effects, and costs (Etzioni, 1974). There are two methodological approaches in policy research (Doty, 1982). The first is the moral, philosophical, think tank method of selectively reviewing and synthesizing theoretical literature and data that support a certain point of view. This methodology reflects the work of Dr. David Hawkins who assembled research in the area of risk factors in youth substance abuse.

The second methodological approach is empirical, emphasizing the collection and analysis of data rather than interpretation from one perspective. In this study, 
administrators appear to perceive data collection and research as the same product. Agency personnel who store and analyze data are often regarded as researchers by their peers and by the legislature. There is a vast difference between longitudinal studies that atiempt to control the effects of substance abuse by various treatments and that of data presentation that simply demonstrates a drop or rise in the number of clients abusing (within agencies) without any validation of what interventions worked or did not, and why. The problem of social science research built on soft data is a factor in policy development. There are also many causative variables in social issues that are difficult to isolate. In substance abuse, the variables could include family dynamics and genetic history, environment or cultural norms, disease or mental health theories of predisposition, and even more. The list may even differ between youth and adults. Actual programs for solving the abuses of substances must account for several variables before decisions are made about which variable affected the problem at the highest rate and was then controlled. Even the most sophisticated statistical model cannot account for all the variables involved in substance abuse.

The use of research for studying policy options before deciding on final program solutions is reasonable, yet it appears that the perception and intention to use research by many administrators does not match the actual process of 
their policy development. Most policy administrators indicate that research is very important to policy development, but is definitely not used to the extent it is valued.

Several experts speak of the benefits of policy research lending common sense to the process (Lawler, 1985). Laver (1986) believed that research can cut down on waste and useless programs. This view is reasonable and acceptable to most agency administrators in oregon. Their actual practice, however, belies their commitment to this theoretical construct. Nine social service administrators believe the use of research is valuable, but do not utilize it.

Jeff Kushner (interview, November 20, 1990) believed that research is "narrow-minded and control groups limit creativity." He may be referring to the fact that some substance abuse research is carried out on animals, or sample sizes are small or ungeneralizable to oregon's population. He noted that little research has been done in the area of youth substance abuse treatment. This statement has not proven to be the case from careful review of the literature. Research available on treatment programs prior to policy passage reveals that a variety of treatment models had some success, but none had remarkable outcomes for youth (Tims \& Ludford, 1984). 
It is important to note that Jeff Kushner's somewhat narrow view of successful treatment is substantiated by three Oregon experts in youth substance abuse who were interviewed for this study (see Appendix A, Exhibit 4). The Alcoholics Anonymous model used by some treatment facilities had some success but not outstanding. Since Jeff Kushner was particularly favorable to this model, his view may not reflect the information about treatment in the early 1980 s.

There were several researchers doing studies in the early and late 1980s. Jeff Kushner's comments were especially interesting in light of the fact that Dr. David Hawkins was hired by him as a consultant for the substance abuse policy process. Dr. Hawkins' own research and those he pulled together in risk factors include relevant studies that could have provided actual programmatic solutions for this policy.

The overwhelming number of researchers surveyed believed that their work was available to oregon policy makers in substance abuse and was little used. Their interest in this topic is represented by a $90 \%$ return response rate to surveys and interviews.

The Barriers to Utilizing Research in Policy Development

At least 10 barriers to using research for the formulation of successful programs are defined from the conclusions of respondents and include the Governor's Task 
Force, Agency Administrators, and from Oregon's research community (dedicated to substance abuse issues). The 10 barriers are detailed in this section beginning with the confusion about data and research studies.

The first barrier is the consistent misunderstanding by some respondents about the difference between statistical data and the actual research studies that reviewed different treatments models. Six respondents from the Governor's Task Force rank data from agencies as high to somewhat important to policy development. It is not clear if this is statistical data about clients with or without program intervention, or research studies which include actual data about treatments and documentation of their success. Rick Bauman (interview, November 10, 1990), Chair of Ways and Means interpreted research as data from agencies. Dr. Spero Manson (survey, May 3, 1994) of the Governor's Task Force, a university academician, is one of two respondents who differentiates between research as academic studies and data as statistical or quantifiable information.

Three social service agency directors report that they use research frequently, while two say they use it only somewhat. Again, because administrators do not always discriminate between data and numbers of clients and careful, systematic study of treatment variables, it is difficult to determine if they actually use research studies. 
The perceived lack of longitudinal studies in youth substance abuse has been referred to before. The issue is the second barrier to the utilization of research. Oregon's research community reflects several concerns that may lend understanding to the general lack of research studies having been used. At least 60 researchers and agency personnel attended a conference to create possible alliances in the matters of youth policy that was held in salem, oregon, November 1989. Governor Neil Goldschmidt's Office of Educational Policy and Planning sponsored this important meeting.

Agency personnel and researchers voiced concerns about the gaps in research knowledge of youth issues, a lack of lead time to incorporate research by agencies, and the reproductibility of research results in public settings. Tom Dishion (interview, March 12, 1989) of the oregon Learning Center in Eugene, Oregon believed that we knew a great deal about predictors of drug and alcohol abuse. He noted that "we simply don't know what to do about it." Tom Dishion believed that there was a lack of longitudinal research related to youth because of the urgency and currency of the problem, and that developmental stages were difficult to assess. Gerry Patterson, Director of the Oregon Social Learning Center, reported there is little or no research on children who abuse drugs and alcohol before the age of 10 (Patterson, Dishion, \& Reid, 1988). 
The Oregon Social Learning Center was involved in a project to work with middle school children to screen at-risk predictors by a multiple-gating device. Teachers and peers were highly important in this process, and this institute was working on a treatment plan for those identified to involve parents, peers, family, and to utilize problem-solving techniques. Oregon appeared to be carrying out "cutting-edge" substance abuse research. oregon's research community reported that it was difficult to access and to integrate with relevant agency issues. Many researchers experienced problems in the determination of what research was needed or how agencies might use the information effectively. They believed that agencies were not willing to risk changes in policy directions. Oregon researchers also said that money and staff for research included different priorities than that of their work.

Divergent attitudes about the use of research may have contributed to the general lack of access to studies by Oregon's researchers. The importance of Oregon's research community to the final policy is rated very high by one respondent of the Governor's Task Force, while one member believed this variable is somewhat important to the process. Others did not respond to this question. It appears that dependence upon the Alcohol and Drug Program staff, though 
reasonable, did not result in policy that used research from Dr. David Hawkins and from Oregon's research community. Governor Atiyeh (interview, May 22, 1990) believed that research is not the problem, but utilization is. He noted the lack of longitudinal studies and coordination of information in youth substance abuse. Governor Atiyeh is among at least two others who believe that commori sense and knowledge in substance abuse are more important than research.

The third barrier to the use of research is individual attitudes about research itself. Jeff Kushner's (interview, November 20,1990 ) view of research as narrow minded and lacking creativity may have affected the research used in the development of this policy. Social service directors differ in their use of research. They use federally funded research exclusively if there is a mandated government program in their agencies. One agency director indicated that he does not use research at all because of $\mathrm{his}$ dependence upon federal policy mandates and federally funded research in his agency.

Dr. David Hawkins is closely aligned with oregon's research community and is recognized as a leader in adolescent substance abuse issues (risk factors). As a consultant on youth substance abuse policy development, it is remarkable that none of his specific programs ever found 
their way into this policy despite his stature nationally and also his close work with Jeff Kushner.

Results from a conference held for agency administrators and oregon's researchers indicated a problem in the use of research in policy making. Researchers believe that the politics in substance abuse are often adverse and being the "lone voice in the wilderness" is not always valued, (G. Patterson interview, March 20, 1988). This group also noted that getting the individual practitioner, in this case the agencies who might support programs, to change or to try new ideas is not a simple task:

Members of the Governor's Task Force appear to have varied opinions about how they utilize research and what they study during the policy deliberations. Kristine Gebbie (survey, June 14, 1990) depended upon Jeff Kushner to give her appropriate research because she regarded him as the expert in the area of substance abuse (as most of the task force did). Doug Egan (interview, May 15, 1990) reported that the task force was given research by the Alcohol and Drug Program staff, but they also brought their own research studies and journal readings to share among themselves. Judge Beckett (interview, June 15, 1990) said that he had read studies in substance abuse, but he uses his own practical experience to make judgments. Judge Beckett had personally watched the ravages of substance abuse on the 
many people who came before him during his many years as part of the court system. He has a great deal of frustration because of this. Rick Bauman (interview, November 13, 1989), Chair of Ways and Means Human Resources sub committee believed that research is a "gut level' feeling." He believed that research is evolving and can be theoretical and practical at the same time. clark campbell (interview, November 10,1989 ) also noted that task force members were knowledgeable and had common sense, both of which he finds more valuable than research.

In this case study, there appears to be no real benefit to youth substance abuse policy from the use of research although it was difficult to ascertain how much and what types of research studies were given to various nembers. Spero Manson (survey, May 3, 1994) believed that little academic research was used. clark Campbell (interview, November 10,1989 ) said that the research used was original and literature based. The task force used research to a limited degree, and no common research findings about treatments or programs (such as risk factors) emerged from their deliberations or their studies of research. The use of research from outside of oregon is rated very highly by one respondent to somewhat important by four respondents. The fourth barrier to the use of research is that the research studies available are dedicated to issues that did not match the needs of various agencies. Several members of 
oregon's research community said that their research could not be correlated with agency or policy needs. Economics is the major factor related to this barrier since many researchers depend upon federal grants that often did not correlate with oregon's perceived needs. The lack of agreement about what research was needed, in an appropriate time frame, stalled or stopped most collaborations. The fifth barrier relates to conflicting research paradigms as well as to different comfort levels among agencies in the use of research. Kuhn (1970) wrote that researchers who attach to a particular paradigm are often unable to change perspectives. Jeff Kushner of Alcohol and Drug Programs is attached to the paradigm of Alcoholics Anonymous Twelve step Program model. Although policy decisions must have been affected by his perspective, there was not even unanimity in the substance abuse community about the causes or treatment of youth substance abuse. The disease model is the foundation Jeff Kushner supports in his agency. The effect of this paradigm is difficult to determine in the final product.

The sixth barrier relates to the problems of divergent timelines between researchers and policy developers. The time to carry out research and to look at outcomes is far longer than agency personnel can accommodate. Several researchers and agency personnel referred to the problem of finding time to carry out collaborations and the importance 
of their own time constraints in research studies. clark Campbell (interview, November 10, 1989) referred to the problem of research not interfacing with the period of time that services are provided.

oregon's researchers also referred to the problem of time lines and longitudinal studies. This problem may have impacted the number of longitudinal studies that looked at outcomes and programmatic solutions in substance abuse. The lack of youth substance abuse research was expressed as a real problem, yet several studies were available, especially from oregon researchers.

Social service administrators were surveyed, and they generally indicated a desire to use research and researchers in program planning. They complained that a lack of time or knowledge about how to network with this group, the turnaround of contracts, and funding were serious factors in preventing them from utilizing research findings. Two administrators reported that working with researchers was profitable but time consuming. One administrator reported that alliances with researchers were informal. Three administrators also stated that they would like more collaborative efforts with researchers in the future.

The seventh barrier to the use of research is the agency administrators' understandings about the issues of substance abuse as it relates to the service of their agencies. In a survey of agency directors, half of the 
respondents reported that research in substance abuse was not applicable to their agency because they lacked specific policy for substance abuse. This point is remarkable because all the agencies are dedicated to social programs, and substance abuse is a problem for many of the families they serve. Children's Service Division, for example, had no policy relating either to its employees or the clients it served. There was a perceived lack of importance for the Alcohol and Drug Program office or a limited understanding about the relevance of substance abuse to their clients. Agency administrators were asked if alcohol and drug policies were present or successful in their agencies. Survey findings suggest that administrators utilize different methodologies to create policies, if they have developed policies in their agencies. One administrator referred to a variety of outcome indicators for both prevention and treatment programs in his agency's programs while another administrator used patient records, and two administrators reported that policies did not exist in his agency or follow-up research was not available.

Agency administrators were asked whether their policy in youth substance abuse had a research base. One agency director said that youth substance abuse policy in his agency was based on research while another reported that there was little research for treatment of psychiatrically hospitalized youth. He noted that agency policy related to 
all aspects of client's disabilities, rather than just substance abuse. One administrator reported that no policy in the agency was based on research, while another said that adult clients, not youth were required to have treatment.

Interest was apparent from surveys when administrators spoke of future alliances with researchers. Only one administrator said that there were no plans for further work in prevention or youth substance abuse. Two administrators indicated their interest for effective programs that would be specific to the work of their agencies. One administrator said that his agency was increasing research capabilities in the next biennium of the legislature. Overall, all administrators believe that research is important, and they planned to use it more in the future. Agency administrators varied in their responses to the importance of substance abuse research and policy in their agency. Only one administrator indicated research and policy were not important compared to child protection. The notion that child protection did not include prevention efforts was troublesome.

A lack of commitment or deep understanding about substance abuse may exist because of staff and administrative turnovers in oregon's government. The frequent reorganization of government agencies because of changes in leadership, namely new governors, create several problems for policy development. It appears there is not 
always the understanding or historical background to provide the continuity necessary. Legislative committee staff, for example, has only a small understanding of the needs in agencies or resulting policies. Governor Atiyeh (interview, May 22, 1990) referred to his staff assistant as invaluable for providing historical memory in the affairs of government. It appeared that policy is often shaped by those with only limited access to information or even interest in the issue.

The lack of continuity in government because of political appointments affected this case study. An attempt was made to contact all administrators involved in the process. Because of retirements, moves out of the state, and political changes, only Jeff Kushner followed the legislation from the inception to implementation. Some agency administrators who responded to surveys were not directly involved with the previous policy development, but they shed important light on their use of research in the 1980 s.

The eighth barrier is the lack of familiarity with literature and research in youth substance abuse. It became apparent that one agency, Alcohol and Drug Programs, had more access to research in this area while other agencies either deferred to that agency or were controlled by their respective federal research mandates. The only program that existed for substance abuse in most social service agencies 
was training for employees to detect abuse by other employees or by clients.

Half of the administrators reported that they either read research reports about youth substance abuse or relied on peers for information. The Alcohol and Drug Program staff responded that publications, literature reviews, networking, and conferences provided them access to new research. This agency was far more knowledgeable in substance abuse research than other agencies were, and their expertise is a factor in policy development.

A good example of this lack of information in substance abuse is reflected in the literature reported by the Director of Mental Health (R. Lippincott survey, May 14, 1989), as compared to those used by the Director of Alcohol and Drug Programs. The Mental Health Director appropriately reviewed literature specific to his area rather than journals dedicated to substance abuse. The number and specificity of resources dedicated to substance abuse used by the Alcohol and Drug Program staff lends understanding for the general dependence upon that office for information. For example, the Director of Mental Health listed the following resources he used:

1. Journal of Clinical Psychiatry;

2. Consulting and Clinical Psychology;

3. Adolescent and Child Psychiatry;

4. The Psychiatric Hospital; 
5. American Journal of Orthopsychiatry. Compare the above list of journals to the specificity of those read by the Alcohol and Drug Programs:

1. Abstracts on Drinking and Driving;

2. Alcohol Health and Research World;

3. The Alcoholism Report;

4. Alcoholism and Addiction;

5. Hospital and Community Psychiatry;

6. Drug Abuse Update;

7. Journal of Studies on Alcohol;

8. National Indian Health Board;

9. Prevention Forum and Pipeline;

10. Professional Counselor;

11. Recovery Magazine;

12. Chemical People Newsletter.

The ninth barrier to the use of research is the lack of experience of administrators working with oregon's research community. This relationship has been mentioned previously in terms of timelines and networking. When administrators were asked whether they had worked with oregon researchers, two administrators said they had no experience with oregon's research community, while one administrator said he had worked with this group to a limited degree, and another said he had worked extensively with the oregon Social Learning Center in Eugene. 
The tenth barrier is more difficult to define, but one that appears to hamper the efforts of research utilization. A general lack of a strong working relationship between agencies and the oregon research community appears to be the result of reliance (by certain agencies) upon federal grants. There are two nationally recognized research institutes in oregon that depend almost exclusively on federal grants. Researchers in these institutions said they rarely, if ever, work with state agencies on any programs. Networking appears to work better within the federal bureaucracy than at the state level.

Surveys indicate that federal research is especially prominent in at least two agencies. Two administrators said that national conferences and federal money dictated most research and collaborative efforts in their agencies. One administrator said that national research is the basis of general policy decisions in his agency. This case study found that the administrators who used research the most depended upon federally mandated programs. Their reliance on federal research tends to restrict utilization of local research, but often that research is more progressive, demonstrates a thorough understanding of the issues, and academically well respected.

The eleventh barrier to the use of research in policy development is an over reliance on previcus policy. Two agency administrators reported that decisions about policy 
emanated from analysis of their programs and from previous policies. Two other administrators reported that new programs were possible because of previous policy. The theory of "muddling through" that Lindblom (1959) believed underlies most policy actions may be relevant to this case study. He believed that a reliance on previous policy almost always occurs, and that this is responsible for the lack of creativity or rationality when policy makers decide to find solutions.

Kristine Gebbie (survey, June 14, 1990), Director of the Health Division and member of the Governor's Task Force, referred to one aspect of the status quo in policy deliberation when she said that the policy was a good compromise for both those who wanted to take Alcohol and Drugs out of Human Resources in order to illuminate its importance and those who were not entirely sure that the status quo needed alteration. Although most of oregon's youth substance abuse policy was not built on previous legislation since little existed, there was still some historical precedence. Archival records from Dr. Joe Treleaven (interview, June 13, 1991) documented programs as early as the 1940s that determined that families were a major risk factor in youth substance abuse.

Possibly the agency identified most often with activity in the area of youth substance abuse is the Department of Education. This agency could have instituted precedent 
setting policy but chose to deal with this issue in a different manner in the 1970s and 1980s. Officials at the Department of Education (survey, August 14, 1989) reported that substance abuse was handled at the Seaside Health Conference where educators from around the state were trained to focus on healthy life skills, which rejected the notion of substance use or abuse. Substance abuse policy did not actually appear in the Department of Education until after 1989 .

There are some clear directions for policy makers to pursue in this case study. From the first survey to agency administrators, it became clear that substance abuse policy was scarce in almost all agencies except for Alcohol and Drug Programs and the Traffic Commission. There is a general lack of understanding about the importance of substance abuse to all the agencies, except the two listed above, since other issues received more dollars in budgets. Agency administrators regarded the use of research as worthwhile and planned to use it more in the future, but they were not currently using any studies. There is little unanimity on the methods by which policy outcomes are determined to create new policy or even much understanding about the importance of such research.

It is abundantly clear that Alcohol and Drug Programs are regarded as the experts in this area. Only half of the administrators read research in this area, regardless of how 
much substance abuse affected their clients. The Alcohol and Drug Program staff is well endowed with publications, literature reviews, networking, and conference attendance, which allows them access to more current research. This knowledge base allows them latitude, but also may prevent others from using research in their agencies, reading it, or understanding the programmatic solutions that are valuable for their substance abusing youth clients.

Finally, this case study points to the general agreement between agency administrators and policy developers about the importance of research and the many barriers to utilizing it. All administrators in this study reported that they are committed to using research more and understand its benefit, but they rarely use it. Research did not find its way into this policy except in the broadest sense. Logic and rationality, though desired for successful policy formulation and well appreciated, are not always practiced by administrators.

\section{The Actual Process for the Final}

Legislation and Passage

The broad implications of decision making in the process of policy development can only be captured in a case study. One must carefully review the various developmental stages of this policy development where agreement was sought among a number of individuals, entities, and budgetary requirements. There are even a variety of perspectives 
among those interviewed for this case study about how the final policy document was actually crafted.

Politics and budgets are especially important to the final process according to Clark Campbell (interview, November 10, 1989). Clark reported that he and Leo Hegstrom, Director of Human Resources, finally "hammered out the final policy in an all night session" for the Governor's Task Force. Leo Hegstrom had little to do with the initial work in this policy, but he had a lot to do with the budgets of the agencies that would manage this policy. Rick Bauman (interview, November 13, 1989), former Chair of Human Resources in Ways and Means, said that Leo Hegstrom usually made "final policy decisions."

The portrayal by clark Campbell of the final process to deliver policy was probably the most accurate. This final process is probably perceived as far more formal and scientific by many of those involved policy development. The actual passage within the legislature was probably due to the craftwork of Vera Katz and her important networks in that body. Hank Crawford added important lobbying to this effort behind the scenes. Hank Crawford died shortly before the author was able to interview him for this case study. Public policy development is a complex process that may not lend itself to high structure or predictability. The many stages, entities, and perspectives in this policy process underscore the difficulty of policy development and 
even the potential use of methods (such as policy analysis) which might clarify and enable the process to run more efficiently. Oregon's policy process was not standardized, scientific, nor logical. There are few theoretical constructs or methods used in this case development of policy, and that is an important outcome of this study. The uneven evolution of the policy, opposite perspectives about the final process for creating the actual legislation, and a process that was far from rational and standardized appear to characterize oregon's policy development in youth substance abuse in the 1980 s.

This case study observed ex-post facto policy development whose designers had no preconceived notion of the final product and used very few public administration methods. There were serious barriers to the utilization of rational methods that included:

1. There was information on treatment models and prevention, but none were found to be useful to the policy. 2. There were decisions made through several levels of bureaucracy.

3. There were budgetary problems and declining revenues that had a major impact on decisions. 4. There were agencies and experts who saw substance abuse problems differently. 
5. There were several other issues that often overshadowed the importance of substance abuse in this process.

Policy development is a complex and massive undertaking, typically as big as the problems it hopes to solve. It is made even more complex when a number of government entities are involved. The actual implementation process may occur several years down the road, well after the policy is passed. This policy is broad in scope and allowed for latitude in implementation, and had limited revenues. It appears that an array of programmatic solutions from Dr. David Hawkins and other accessible researchers in the state was disregarded.

Overall, the process appears inconsistent and dependent upon the direction of the Alcohol and Drug Program staff. It concluded, finally, with an informal session of two key administrators who "hammered out policy goals one night," almost dispelling the notion of policy development as a science.

The study makes clear that federal research is generally more future oriented and used if the agency has mandated programs and funding. Networking at the federal level is only found in agencies where there are clear lines to Washington, DC because of the mandated programs. Several researchers met agency personnel in Washington, DC rather than within oregon's government agencies. There is value in 
working with the high quality of research generally available because of the federally mandated programs. The questions the author of this study set out to answer uncovered conclusions that were often surprising. The first question was:

1. What were the methods available to public administrators in the development of this policy, and which were actually used?

The findings in this study determined that few or no methods of policy development, defined as policy analysis in public administration, were used by administrators in this case. Politics seemed to drive the process, rather than rational methods that might have provided more specificity for the final document in terms of programs to solve the problems of youth substance abuse. Broad policy goals provided non specific solutions that appeared to be the result of political maneuvering rather than the utilization of theoretical constructs or utilizing the methods that might have created outstanding policy with promising programs for treatments and prevention.

2. What was actually known about the prevention of youth substance abuse in the 1980s?

This was more difficult to ascertain since there were longitudinal studies available in youth substance abuse at that time, but the perception by administrators (namely Jeff Kushner) did not support that. There were many studies 
nationwide and some even begun within oregon that could have provided specific program solutions for youth substance abuse. The studies never found their way into policy. Especially notable was the lack of utilization of Oregon's research community in this policy development. Dr. David Hawkins of the University of Washington provided several important studies and models of substance abuse treatment and prevention for the Governor's Task Force. A strategy paper from the Office of Alcohol and Drug Program in June of 1985 listed specific programs and research derived from Dr. Hawkins and others. The focus was on social competency behavior theory and far more detailed than the policy document. Its appearance well after passage of the policy is interesting and notable.

When interviewed, three experts in youth substance abuse appeared to have disagreements among themselves as to what constitutes excellent research or commonly held notions in this area.

3. What was the process used to determine the recommendations which finally became policy?

The process used to write the final policy lacked a rational methodology, it was informal, and dispelled the notion that policy development is a science. Two administrators "hammered out the policy in an all night session." There were several broad recommendations from the Governor's Task Force that found their way into the final 
policy. The mounds of testimony, some quite specific, were condensed into broad goals, which may have been intentional for later implementation. overall, the process was politically driven, lacked specific methodology, and generally left out any programmatic solutions that demonstrated choices of specific treatments or any controversy.

4. In public policy development, to what degree is the distance between actual practice and theoretical constructs within acceptable limits?

The distance between actual practice in public administration and recommended methods such as policy analysis is especially far in this case of policy development. Methods that could have provided structured decision making are almost absent from this process. From the results of this case study, public administrators or agency personnel respect rational methods, want to utilize them more for decision making in the future (especially research), but used almost none in this policy development.

5. What variables affected this policy process the most?

The variables chosen from the literature of public policy were politics, economics, special interest groups, leadership, and the use of research. It appears that the variables impacting this policy development most are leadership and politics. Economics, though important to the 
final document, are difficult to capture, and from the conclusions of this study, are not as important.

Special interests were narrowly defined in this study to include stakeholders outside agencies. The groups had some effect on the policy, but did not significantly impact the process. It became obvious that it is difficult to clearly delineate the difference between politics and special interest groups. Some members of the Governor's Task Force appeared to view special interests in this narrow manner as well since none indicated agencies or any other political entities the policy passed through in this regard. The use of research in policy development is recognized as important by almost all of the respondents in this case study, but was little used for a variety of reasons.

This case of policy development appeared to be informal and changeable, relied on few methods of policy analysis for decision making, and was managed by Jeff Kushner of Alcohol and Drug Programs and the Governor's Task Force. The final process was almost incongruous with the expectations one might have about policy development.

After stacks of expert testimony, consultation, expert research, and a high level of collaboration among the Governor's Task Force, one might have predicted outstanding policy. It appeared that the final policy was bereft of specific programs to prevent substance abuse and resulted in broad goals that left a great deal to interpretation by 
those who would carry it out, namely Jeff Kushner of Alcohol and Drug Programs.

Review of the research available (prior to 1985 passage of the policy) to Jeff Kushner and other policy developers reveals that social competency models including family identification for dysfunction and intervention, early intervention for high risk children, focus on school achievement, and attention to the serious problems in identification of adolescents who experiment or become abusers might have resulted in non specific policy goals.

Finally, in 1994, the policy has not been updated to a great extent, and youth substance abuse is still a serious problem. Vera Katz (interview, July 1, 1990) indicated problems with the policy implementation when she posed the question, "I would like to know more about how Jeff is actually carrying this policy out." state Auditor, Don Waggoner reported in September of 1994, that poor bookkeeping practices allowed people to leave alcohol and drug programs early, and allowed others to stay too long (Manzano, 1994b). Jeff Kushner defended a purported $\$ 1.1$ million loss to faulty bookkeeping and poor management of clients in programs, both intended goals of the 1985 policy. 
CHAPTER V

\section{IMPLICATIONS AND RECOMMENDATIONS}

Several implications emerge from the findings of this dissertation that could serve as important recommendations for improved policy development at the state level. The essential act of policy development typically involves several different entities of government including administrative agencies, the governor's office, the legislature, task forces that study problems, and special interest groups. This dissertation explains the importance of leadership and politics in policy development, and illuminates the use of research as an effective variable for the formation of public policy.

As this case study evolved, it became apparent that public policy could be improved through the use of rational methods, including research. It also became apparent that personal biases and politics affect the complex process of policy development to such an extent that simple solutions became less realistic. The implications for future practice hold promise, but do not offer the panaceas for the resolution of social problems that many citizens believe exist. 
The literature of public policy development offers more information on the importance of politics in the process than any other variable. This case study offers important information about state policy development since federal policy development is often the focus of the literature. The National Association of state Legislatures and the Clearinghouse for Alcohol and Drug Abuse are two avenues for researching the number of case studies of state policy development to determine if this study is unique. The previous literature on policy variables is often dated, supporting the possibility that a good dissertation topic would be state policy development in the 1990s.

This study supports the general conclusions of the literature on policy development that note the problems of politics in the process, the absolute necessity for it, and some ways to control it, namely policy analysis. Literature that supports the use of research in policy development, though particularly difficult to find, does generally align with the conclusions of this study. This study determined that the use of research is helpful in policy development, and that there are several barriers to accomplishing that purpose. The barriers uncovered were almost exactly the ones noted in the literature.

An argument can be put forth that the 1985 policy (oregon HB 2124) has not been particularly successful in the prevention of youth substance abuse, lending added 
importance to the recommendations from this dissertation. A review of the status of the 1985 policy shows that prevention of youth substance abuse appeared to be marginal late in 1992, seven years after its passage. Reporter Nora Lehnhoff (1992b) wrote in response to a question on policy effectiveness, "Oregonians need to be clear about the state's goals and what it is trying to accomplish with drug and alcohol mandates" (p. P4). The question of effective treatment models is still a significant issue, pointing to the importance of establishing a good research base for policy development.

To further clarify the lingering issues of the ineffective policy, Phil Manzano (1994a) reviewed nine years of substance abuse policy, including a follow-up survey for oregon's students that determined that substance abuse had declined among eighth and eleventh graders; but the rate of decline had almost stopped for eighth graders (Hallan \& Egan, 1985, 1989). An indictment of the policy's ineffectiveness was even voiced by Larry Didier (cited in Manzano, 1994a), staff person in the office of Drug and Alcohol Program. He reported that substance abuse had not reached the record levels of the 1970s, but "it's a message we need to continually get out front" (p. A10).

This chapter has several purposes that relate further study or practice in policy development to the most important findings in this dissertation: 
1. The documentation of various constructs in policy analysis that lead to improved and more rational methods for policy development that match the social problems to effective solutions.

2. The presentation of several general recommendations to improve the policy process for those involved in solving social problems, transcending several levels of state government.

3. The definition of leadership and politics as important variables in policy development and how they might be used or better understood to create programmatic solutions.

4. The recognition that research in the various substantive policy areas holds great promise for policy development and potential for alliances between those who study social problems and those who write policy to solve them.

5. The recognition that the legislature is vital to policy development and methods for improvement of the process that might be shaped to increase effectiveness and decision making, especially through increased knowledge in policy problems.

Implications from this dissertation seem particularly appropriate for higher education faculty and students who historically have not worked in policy development but who nonetheless have many opportunities to do so because of the 
multitude of social problems. The role of higher education in policy development, especially departments outside of public administration, provides uncharted territory for involvement of students and staff. Increasing problems of funding, the growing complexity of serious social problems that cross all disciplines, and the possible integration of various arms of state government (to save important budget dollars) in policy all present opportunities for collaboration.

The first section documents the key findings of this dissertation, offering clear suggestions for improved policy development practices. The possibilities for policy analysis methods are explained in this final chapter to further clarify implications for future practice or study. Key findings in this dissertation, aligned with recommendations for improved methods in policy development, include the following:

1. The lack of singular purpose for the policy and problem identification that appear to be diffused throughout the process.

2. The knowledge about youth substance abuse that evolved during the policy deliberations and depended upon several substance abuse paradigms or research bases, rather than one (i.e., risk factors). 
3. The broad policy goals that lacked program specificity and gave administrators great latitude for implementation.

4. The effects of the budgetary process on policy development.

5. The problems of various levels for decision making including the legislature, seven agencies, the Governor's Task Force, and special interest groups.

The audiences with the greatest need for improved methods in policy development are the governor and agency staff who attempt to solve problems through policy statements. There are also several other entities of state government that also affect such a process. The methods of policy analysis offer theoretical constructs to create a more rational policy development process since they present a structure that defines various options and the pros and cons of each. Constructs more accurately describe theory in social policy development because of the many variables that affect human problems.

Problem identification appears to be an issue in this case of policy development. Brewer and de Leon (1983) wrote of the need to answer questions in policy development relating to: goals, origination of the problem, trends, driving factors, events or developments without interventions, and changes needed to achieve more desired goals. Since the various levels of government deal with 
policy development, each stage of the process must be clearly identified and understood to benefit policy development.

stricter adherence to the steps of policy analysis outlined above may have improved the process by better control over the many variables that appeared to affect the process and even overshadow the key problem of youth substance abuse prevention, including turf battles and budgetary fights. The evolutionary nature of this policy process may have been assisted by this structure. A strong recommendation from this dissertation is training for agency staffs, legislative committee members, task forces (if used) and the governor's staff in the methods of policy analysis. Policy analysis methods do not offer all the answers for policy development. The many variables and entities involved in this case of policy development validate the fact that policy development is difficult to control completely with any methodology, and that is an important implication from this study. This also does not give license for the apparent lack of control that characterized this policy process. In this case of policy development, it appears that politics negatively affected the process when rational structures were lacking for decision making. An implication of this dissertation appears to be that controlling politics or willful abuse of power by those in 
leadership positions can be assisted by rational policy analysis methods.

Broad policy goals characterized the final legislation that leads to the recommendation that methods such as those used in Assumption Theory (Brewer \& de Leon, 1983) could offer structures to systematically review a variety of programs and determine the best fit between problems and solutions. Policy analysis offers the structural methods to look at various options, weigh outcomes and create rational discussions that could all affect policy. Implications for practice might involve several other constituencies, both outside and within government, to offer solutions and a structure to clarify or weight the most effective alternatives.

The problems of budgets and politics adversely affecting policy points to the need for improved data analysis in policy development. Another problem was the lack of specific outcomes in this policy to be later evaluated. Data analysis methods in policy analysis involve specific procedures to weigh different options and review client data to define successful outcomes. Implications for practice include the opportunity to involve higher education students in the creation of quantitative and qualitative evaluation projects secondarily using client data, for example, in different state agencies to improve policy development and thereby, program effectiveness. 
Decision making in this policy process occurred in several locations and had an insecure base of research to support policy formulations. Policy analysis offers several options for decision making, including Bounded Rationality (Dunn, 1981), which offers options in situations when the available information and alternatives are so great that rational behavior is not possible. Five-foot tall stacks of testimony resulted in policy that was possibly "just good enough" when time and resources prevent in depth study of problems. A definitive process to review all relevant information and the creation of appropriate program options could improve a policy process. A possible dissertation or research study could provide a delivery system for such a process and determine if the final product was a better match between needs and outcomes.

Determination of a course of action was further complicated by the problems resulting from the reliance upon a single paradigm in substance abuse, the Alcoholics Anonymous model, favored by Jeff Kushner, the administrator who held the greatest power and political clout. Implications for practice again point to a decision making process that is more rational and less politically driven, especially by the narrow view of one administrator who in this case developed policy and then implemented it.

A promising practice might involve students from higher education who could research a problem area and also review 
the testimony given. An improved process to include service providers and those knowledgeable in a policy area (including researchers) has merit. There are endless opportunities for dissertation or research projects and collaborations between universities and state government in many social science problem issues. Students from education might look at youth at risk, schooling practices, and policy development. Graduate and undergraduate students from other academic disciplines including counselors, social workers, public administrators, and those involved in health studies could research a variety of issue areas.

The study of public policy has often been relegated to departments of public administration rather than at the location of greatest need. Education has a stake in the welfare of Oregon's students and could participate in a variety of policy issues to the improvement of their own discipline, the multitude of issues that affect at risk youth and also provide future job insights and opportunities. Recommendations for dissertation and research topics will be presented later in this chapter. Sharing the results of this case study with agency directors in state government and offering a model for weighing alternatives to create more rational and appropriate policy, could only improve the process. Rational Comprehension Theory (Dunn, 1981) offers such a structure to look at goals, objectives, and policy 
alternatives with appropriate consequences noted. The use of Dr. Hawkins' risk factors could have provided an excellent listing of possible paradigms or options to compare alternative program objectives and possibilities. The findings in this dissertation point to the good working relationship between the Governor's Task Force and the staff of the Alcohol and Drug Programs. The possibility of "group think" in cooperative groups appears to have negative implications for policy development. Further study might compare the current avenues for studying policy problems, which often include task forces, legislative committees, or even agency policy planners (who must later implement the policy they design). Comparative studies of those involved in such study might uncover the entity that would most be qualified to do so. This might also uncover the possibility that neutral parties are the best to uncover relevant research or information and formulate possible decision packages to administrators, etc.

Another problem recognized by this dissertation affects decision makers (such as the task force, legislative committees, legislators, or agency personnel) who may not be aware of all the alternatives for policy because they do not have access to all the information needed. In this instance, it appears that certain research information did not reach the final decision makers. A recommendation of this dissertation is judicious study of all the avenues|for 
good policy information in an area such as substance abuse or at-risk youth issues, and make sure they are used.

Streamlining the process of policy development is an important recommendation from this study. The alignment of interested policy parties, good communication, and screening out unimportant information would all be part of this overhaul. An excellent dissertation topic would review the current policy development process and recommend an improved model that eliminates unnecessary entities of government or recognition of the most important one.

What are the problems of policy formation and implementation conducted by the same people? A study might determine if innovative programs suffer because an administrator is too concerned about budgets or other issues of implementation. The comparison of policy developed by neutral parties and those more intimately involved in an issue area might be helpful to the improvement of policy. Another study might compare the narrow $/$ view of administrators who control the information sources and know (or fear) the budgetary or other requirements that accompany implementation.

\section{General Recommendations for Policy Developers}

More general recommendations for policy developers from the findings in this dissertation that lappear to have promise for improved social policy include the following: 
1. Carefully define the problems that policy will solve and commit only to solving those that are most amenable to resolution.

2. Use the methods of policy analysis to control politics and other agendas from interfering with the policy development.

3. Define the leadership needs, research base, outcomes, economics and goals at the inception to offer optimum possibilities for well crafted or innovative policy. Review alternative solutions in a manner that offers structure for improved decision making.

4. Create a location in state government to accommodate collaborations between researchers and policy planners.

5. Outline specific programs in policy rather than broad goals allowing for broad interpretation in implementation.

6. Stress the separation of roles for administrators who make and then implement policy.

7. Use task forces that demonstrate a good understanding of the issues and represent a broad range of expertise.

8. Make provisions for agency specialization in particular issue areas by the provision of control over budgets, policy, and expertise in one location. 
9. Make policy related training available for agency personnel to include problem solving, decision making, leadership functions, and provision of structures for debating policy perspectives.

10. Establish evaluation procedures at the inception of the policy to accommodate longitudinal research studies, data analysis, and outcomes to validate the success of policies and provide for alterations in programs.

11. Review the process of policy development to streamline and improve it at all government levels.

12. Determine the possible variables involved in any social problem and further understanding about the implicit problems of program solutions.

13. Involve higher education, experts and other groups in policy development at ail levels through education and improved accessibility to the process.

The Role of Politics and Leadership in Policy Development

This dissertation determined that leadership and politics affect policy more significantly than other identified variables. The findings have potential for the improvement of policy development because understanding the traits that positively affected this process can assist future proceedings.

Politics is the first variable uncovered in this dissertation, and although well known as an aspect of policy 
development, it is the control of politics that becomes the greatest obstacle to a more rational process. The various levels of government through which this policy passed presented several political problems. Turf issues, lack of understanding or commitment about substance abuse, differing perspectives about the problem, or views of budgets and implementation affected this policy. Implications for improved practice might include streamlining the process, creating improved transitions from one level to another, and the possible prevention of administrators designing policy who must later implement it.

The problem of the legislature acting as the final "arbitrator" in policy has implications for improved practice. It appears that legislative committees must be better trained in policy analysis methods, using research to improve policy, or requiring more specificity and comparison of policy programs before passage. Committee staffs have a great deal of power in such a process and they must be appropriately trained and selected for the important roles, instead of political appointments driving the process.

Citizens and interest groups must be trained in the workings of the legislature to better impact the process. It appears that knowledge of the legislature is ultimately important to the policy process, and few appear to have access to such information. Improved knowledge in policy development is a recommendation of this dissertation. To 
accomplish that purpose, wider audiences must be involved in the process. Special interest groups have organization and access to the legislative process, but they do not hold all the information necessary for well-designed policy solutions.

wider audiences for policy development could include service providers and researchers in various social problems who could expand the knowledge base to create more appropriate policy. The current dissatisfaction with government by citizens might be improved through access to the avenues of policy development, which could increase their knowledge base and opportunities to offer differing perspectives on policy interest areas.

Higher education classes in education, social work, counseling, public administration, and health might look at the problems to be solved within their own issue areas through policy development and determine different avenues for solving them. Educational leadership classes might, as a result of this dissertation, focus more on the control of politics in every educational arena, rather than dismissing it. Students might benefit from the results of this study in terms of leadership in policy development, which is applicable to all who must lead. A deep understanding of systems, understanding a subject particularly well, and exercising controls as appropriate seem worthwhile goals for all leaders. 
Higher education classes, or even high school social studies classes, could work in a specific social problem area to better understand the legislative process, contribute to the goals of oregon HB 3565 (1991)-Certificate of Initial Mastery and Certificate of Advanced Mastery, and demonstrate citizen participation in solving the serious social problems that affect all entities in government and education.

The knowledge and support of the governor's office were important to this policy development. A recommendation for future policy development is to involve the governor's office early in the process in order to be successful. Possibly, an even more important recommendation to the governor is to understand the importance of policy analysis methods, and further to encourage the hiring of agency personnel with public administration training. A future research study might compare the effectiveness of agencies led by administrators who have public administration training and those who do not. The understanding of theoretical constructs in public administration became of interest to the author over the course of interviewing agency administrators and even governors.

The governor's office has legitimate power in the workings of state government. A critical review of institutional structures for streamlining the process of government responses to social problems seems particularly 
relevant as oregonians have recently elected a new governor. Legislative mandates for streamlining the process would be required, but perhaps it is time for all aspects of policy development and government delivery systems to be reviewed. Finally, politics is difficult to capture in any policy process, but management of it is also important. Rational methods in decision making, prohibiting those in charge of policy development from later implementing it, increasing the amount of information through increased participation in policy matters, and streamlining or overhauling the process all have implications for practice and further study.

The Importance of Leadership in Policy Development

Several implications for practice further result from the finding that leadership was important to this policy. The findings in this dissertation defined the characteristics of successful leaders. Leaders in this process reflected exceptional knowledge of the issue, demonstrated ability to moderate and to keep the process on track, or understood how policy was finally enacted through the legislature.

The implications for future practice are training of agency personnel and other identified individuals (committee staff, etc.) in the value of knowledge and related behaviors for leadership. The possibility for organizational development and human resource or empowerment training for 
agency or legislative staffs seems essential. The governor could institute seminars in leadership training for identified individuals who have major policy development roles. This process would correlate with the recommended review of the policy process in state government to determine who should have the intended influence and how that might be better managed.

since the process of clarifying problems and defining solutions can educate and inform those involved, the final legislation may be a secondary product. In this case, involvement by representatives of the several entities involved in youth substance abuse could have contributed to later implementation and ownership in the programs to prevent substance abuse. The involvement of several agencies, for example, leads to problems of ownership of the problem and diffusion of energy in a singular issue such as youth substance abuse.

There were problems with defining and sharing an appropriate knowledge base in substance abuse for those involved in this policy development. Knowledge about social issues can be derived from client data in agencies, research outside of agencies, and by action research studies. At least one agency director reported there was a tremendous amount of client information in their files. client data bases could provide students in higher education many potential rewarding and helpful studies to support policy. 
It also appears that better training of agency evaluation departments to increase research might provide information for policy development.

Finally, leadership by Jeff Kushner of the Alcohol and Drug Program office affected this policy significantly. A result of this study is the recommendation that activities related to a single policy (such as substance abuse) reside in one office. Confining the activities of an issue to one office may be limiting, but in this case, it also created more cohesiveness within youth substance abuse. It appeared that the singular purpose of this office contributed to improved policy development in terms of legislative passage and consensus building.

\section{Implications for the Use of Research}

Opportunities for the use of research uncovered in this study are numerous in policy. There are also formidable barriers to use of research by agencies and the legislature, but great rewards if overcome. This section offers possible research projects in substance abuse to increase agency and researchers' collaborations. The recommendations from this dissertation have great promise since researchers and agency policy planners surveyed agree that further collaborations are desirable.

The development of delivery systems to involve and increase the use of research for policy is a strong 
recommendation from the findings of this dissertation. Possible collaborations between any of the following entities could involve researchers in academic institutions, higher education departments, policy planners, think tanks, and the legislature to provide necessary research for policy. Researchers might be hired for a single policy area, maintaining their neutrality and remaining in a consultative position rather than state employees.

A promising recommendation of this study is also the creation of a separate or neutral office for policy research. This office might be available to all agencies or outside sources to provide important data for policy decisions, and neutrality is ultimately important. An expert in policy development with a highly motivated staff would have the support of all agencies and the governor to create new avenues of collaborations, review the current system, and offer institute type seminars to focus on improved methods and knowledge in policy matters. This office could provide internships for students in higher education to carry out research and facilitate training sessions.

Within the above office of policy development, the creation of cohorts of researchers, students and faculty of higher education, and policy planners to create improved policy solutions for social problems is a recommendation of this dissertation. The cohorts could provide models for 
dealing with the severe cutbacks in funding because of oregon Ballot Measure \#5 (1990).

The array of possibilities for policy development in several higher education disciplines has been previously referred to in this paper. The recognition that each discipline has a stake in social policy issues is obvious, but the collaborations have not been effective or even existent within state government. Education, for example, has defined effective practices that meet the needs of at risk students. Policy programs that reflect such goals could be the focus of realistic class projects in educational administration. Oregon HB 3565 (1991)--the Oregon Educational Act for the 21st Century, for example, offers many avenues for improved school practices that have policy implications.

Agency directors maintain files of client data that could provide university classes of evaluation, statistics, research design, or doctoral students seeking dissertation proposals with unlimited opportunities. Think tanks exist all over this country that research areas of policy. Higher education has the human resources to enrich state government in all policy areas. The collaborations within such a structure would be beneficial and possible by a new governor and staff assistants who view this as valuable.

Implications for the importance of collaborations with researchers in oregon have been referred to several times in 
this dissertation. The barriers to those collaborations appear serious, but an office to coordinate time schedules, grant monies, and interest areas could help to overcome the obstacles and would be profitable for policy improvement. The legislature could improve its knowledge base considerably by receiving testimony, for example, from experts and researchers in specific areas. This study found that the most knowledgeable experts in substance abuse did not appear before the legislature because they were unable to access the process. Determining the means for increasing the use of experts in policy areas, and support for academicians to collaborate with policy makers is a strong recommendation from this study.

Although we know a great deal about youth substance abuse, the knowledge base is constantly changing. Access to research is an important implication of this dissertation, but also there need to be opportunities for students in higher education for dissertations and projects using data from agencies on specific social problems. An area that is receiving even more attention in youth substance abuse research circles today, for example, relates to resiliency theory (Benard, 1991). A comparison of risk factor programs and those supporting the new paradigm of resiliency could provide an excellent dissertation topic. The list of topics for study is endless. An interested graduate student in counseling, social work, or education could conduct a 
thorough review of expert opinions in youth substance abuse on treatment models, including the Alcoholics Anonymous model to determine highest effectiveness and return for program dollars.

F'inally, higher education, the legislature, policy planners, researchers, the new governor, and experts in various social problem issues have common concerns that should lead to important collaborations. The groups are disparate and have very different perspectives on issues, but the goal is to create policy solutions. The simple proposition to meet face-to-face may be one of the easiest recommendations to accommodate from the findings of this dissertation.

\section{Implications and Recommendations for the Legislature}

The oregon legislature maintains the important role as the final arbitrator for policy. Understanding the legislature's workings by key individuals in this policy process assisted formulation of the 1985 policy (Oregon HB 2124). This dissertation uncovered the difficulty of effectively informing several entities within government, invaluable in policy development. Possibly the most complex entity is the legislative process and deserves even more explanation.

The committee staff in the legislature is an appropriate point for improving the policy process since 
they are instrumental in defining the final legislation, and ultimately affect the intent of the policy. This dissertation recommends training in the methods of policy analysis for committee staffs. Joint meetings of staff and policy planners to ensure rational methods for defining alternatives and identification of research to support policy are necessary. The possible "office of research in policy" offers one location for these important collaboration.

The problem of information overload for legislators, policy planners, and committee staff appears to be a major barrier to rational choices. Identification of committee staff in the legislature to follow a policy from the research stage to legislation appears to be a promising practice. The role of university students in this process appears to offer opportunities in all aspects of government and students would benefit from following problems through to the final policy.

A recommendation for accomplishing the above collaborations might lie with the President of the Senate, the speaker of the House, committee chairs, agency policy planners, and university representatives meeting together to outline the possibilities for using human resources. It also appears that a neutral body to study policy research is necessary and realistic if the collaborations are to occur. 


\section{Concluding Thoughts}

with any exhaustive study, one looks back and recognizes mistakes and missed opportunities. The value of this dissertation for policy planners, the legislature, the research community, and higher education appear to be numerous. The advent of a new governor in January 1995 increases the potential for implementation of the recommendations from this study. The Chief of staff for newly elected Governor John Kitzhaber, Tom Imeson, will be contacted in the near future to discuss the possibilities.

This study was carried out by an educator who also understands public administration and the importance of an understanding of politics and the value of academia in all areas of society. The blend of academic and educational system understanding with politics, state government, and more rational. systems for solving the problems of youth substance abuse evolved from an internship at the office of Educational Policy and Planning where researchers combined with agency administrators to look at collaborations in all areas of at riskness. The uniqueness of the study and the possibility for melding state government with higher education, especially educators, is hopeful and innovative.

This case study provides policy planners, researchers, and legislators a hopeful message that encourages an increased reliance on the methods of policy analysis, more alliances with the research community, and expanding the 
base of policy development to higher education, citizens, and other experts who offer important perspectives about our serious and complex social problems. It appears that oregon state officials have nothing to lose and everything to gain by the improvement of policy development in these troubled times. 


\section{REFERENCES}

Anderson, J. (1994). Public policymaking. Boston: Houghton-Mifflin Publishing.

Bales, R. F. (1950). A set of categories for the analysis of small group interaction. American Sociological Review, 15, 257-263.

Balmer, M. (1986). Social science and social policy. London: Lavela-Allen University.

Bass, B. M. (1981). Survey of literature. In W. Stogdill (Ed.), stogdill's handbook of leadership (pp. 121-125). New York: Free Press.

Battjes, R. J., \& Bell, C. S. (1985). Overview of drug abuse prevention research (National Institute on Drug Abuse Research Monograph No. 63). Rockville, MD: National Institute on Drug Abuse.

Baumrind, D. (1985). Familial antecedents of adolescent drug use: A developmental perspective (National Institute on Drug Abuse Research Monograph No. 56) . Rockville, MD: National Institute on Drug Abuse.

Beach, L. R., \& Mitchell, T. R. (1978). A contingency model for the selection of decision strategies. Academy of Management Review, 4 (92), 235-240.

Beach, L. R., \& Mitchell, T. R. (1990). Image theory: A behavioral theory of decision-making in organizations. Research in Organizational Behavior, 12(8), 1-41.

Bellamy, G. (1984). Oregon Serious crime Commission report. Salem: oregon state Printing office.

Bellamy, G. (1985). Oregon Traffic Safety Commission report. Salem: oregon state Printing office.

Benard, B. (1991). Fostering resiliency in kids: protective factors in the family, school, and community. Portland, OR: Northwest Regional Educational Laboratory.

Bobrow, D. \& Dryzak, J. (1987). Policy analysis by design. Pittsburgh: University of Pittsburgh Press. 
Botvin, G. J., \& Willis, T. A. (1985). Personal and social skills training: Cognitive-behavioral approaches to substance abuse prevention (National Institute on Drug Abuse Research Monograph No. 63). Rockville, MD: National Institute on Drug Abuse.

Brewer, P., \& De leon, P. (1983). Foundations of policy analysis. Homewood, IL: Dorsey Press.

Bry, B. (1988). Family-based approaches to reducing adolescent substance abuse: Theories, techniques, and findings (National Institute of Drug Abuse Monograph No. 56). Rockville, MD: National Institute on Drug Abuse.

Bryson, T., \& Levine, C. (Eds.). (1989). Oregon Blue Book. Salem: Oregon state printing office.

Bushing, B. C., \& Bromley, D. G. (1975). Sources of nonmedicinal drug use: A test of the drug-oriented society explanation. Journal of Health and Social Behavior, 1 16$)$, 50-62.

Catalano, R. F., Hall, J. A., \& Hawkins, J. D. (1983, November 12). Assessment and treatment of social skill deficits of substance abusers. Paper presented at the 1983 Annual Meeting of the Association of Behavioral Analysis, Milwaukee, WI.

Catalano, R. F., Hawkins, J. D., Wells, E. A., \& Miller, J. (1990). Evaluation of the effectiveness of adolescent drug abuse treatment, assessment of risks for relapse, and promising approaches for relapse prevention. The International Journal of the Addictions, 25 (9A \& 10A), 1085-1140.

Center for Substance Abuse Treatment. (1993). Screening and assessment of alcohol and other drug abusing adolescents. Rockville, MD: Author.

Children of Alcoholics Foundation. (1985). Children of Alcoholics Foundation report. Washington, DC: Author.

Coleman, J. S. (1972). Policy research in the social sciences. Morristown, NJ: General Learning Press.

Dery, D. (1984). Pjoblem definition in policy analysis. Kansas City, MO: Kansas University Press. 
Dickel, C. T. (Ed.). (1977). H. A. Dickel's history of psychiatry in oregon (Monograph, H. A. Dickel Lectureship through Department of Psychiatry, University of Oregon Health Sciences Center). Portland: University of Oregon Health Science Center.

Dickel, H., \& Treleaven, J. (1963, September 24-27). History of mental health in oregon. Paper presented at the 89th Annual Meeting of the Oregon State Medical Society House of Delegates in Portland, OR.

Dishion, T., Reid, J., \& Patterson, G. (1986). Empixical guidelines for a family intervention for adolescent drug use: Family context of adolescent drug use. San Francisco: Haworth Press.

Donovan, J. E., Jessor, R., \& Jessor, S. (1983). Problem drinking in adolescence and young adulthood. Journal of Studies on Alcohol, 44(1), 121-125.

Doty, P. (1980). Guided change of the American health system: Where the levers are. New York: Human Sciences Press.

Doty, P. (1982). The role of the evaluation research broker. In L. Saxe \& D. Kroetz (Eds.), New directions for program evaluation (pp. 1-18). San Francisco: Jossey-Bass.

Dunn, w. N. (1981). Public policy analysis. Englewood cliffs, NJ: Prentice-Hall.

Dye, R. T. (1978). Understanding public policy (3rd ed.). Englewood Cliffs, NJ: Prentice-Hall.

Dye, T. (1985). Politics in states and communities. Englewood cliffs, NJ: Prentice-Hall.

Dye, T. (1992). Understanding public policy. Englewood cliffs, NJ: prentice-Hall.

Dye, T., \& Zeigler, L. M. (1983). American politics in the media age. Monterey, CA: Brooks/Cole Publishing company.

Etzioni, A. (1967, December). Mixed-scanning: A third approach to decision making. Public Administration Review, 27, 385-392.

Etzioni, A. (1974, May). Policy research: Mapping alternative agendas. Education in Urban Society, $7(3)$, 47-50. 
Fischer, F. (1980). Political values and public policy: Problems of methodology. Boulder, CO: Westview Publishing.

Fleming, J. P., Kellam, S. G., \& Brown, C. H. (1982). Early predictors of first use of alcohol, marijuana, and cigarettes. Drug and Alcohol Dependence Journal, $12(9), 285-303$.

Friedman, A. S. (1983). High school drug abuse clients: Treatment research notes, division of clinical research National Institute on Drug Abuse Research Monograph No. 56). Rockville, MD: National Institute on Drug Abuse.

Gardner, J. (1990). On leadership. New York: Free Press.

Goodwin, D. W. (1985). Alcoholism and genetics: The sins of fathers. Archives of General Psychiatry, $\underline{8}$ (25), 56-61.

Grenier, P. (1985). Childhood predictors and prevention of adolescent substance abuse (National Institute of Drug Abuse Monograph No. 56). Rockville, MD: National Institute of Drug Abuse.

Hallan, J. J., \& Egan, D. M. (1985). Drug use by oregon public school students. Portland, OR: Halprin, Inc.

Hallan, J. J., \& Egan, D. M. (1989). Drug use by oregon public school students. Portland, OR: Halprin, Inc.

Hawkins, D. (1984, September 6-7). Executive summary of OJJDP/ADAMHA practitioner's conference on juvenile offenders with serious drug, alcohol and mental health problems, Washington, DC.

Hawkins, D., \& Brown, B. (1979). Reintegration of street drug abusers in community roles. Addicts and after

care. Beverly Hills: Sage Publications.

Hawkins, D., Lishner, D., Jenson B. \& Catalano, R. (1986). Delinquents and drugs: What the research suggests about prevention programs. Seattle: University of Hashington Press.

Heclo, H. (1972, January). Policy analysis. British Journal of Political Science, 82 .

Hindelang, M. (1973). Causes of delinquency: A partial replication and extension. Social Problems, $I(20)$, $471-487$. 
Hirschi, T. (1969) - Causes of delinquency. Berkeley: University of California Press.

Jaffe, J. H. (1984). Evaluating drug abuse treatment: $A$ comment on the state of the art (National Institute on Drug Abuse Research Monograph No. 77). Rockville, MD: National Institute on Drug Abuse.

Jessor, R., Chase, J. A. \& Donovan, J. E. (1980). Psychosocial correlates of marijuana use and problem drinking in a national sample of adolescents. American Journal of Public Health, $5(70), 609-613$.

Jessor, R., \& Jessor, S. L. (1977). Problem behavior and psychosocial development. New York: Academic Press.

Kandel, D. B. (Ed.). (1978). Longitudinal research on drug use. Washington, DC: Hemisphere-Wiley.

Kaplan, H. B., Martin, S., \& Robbins, C. (1982). Applications of a general theory of deviant behavior. Journal of Health and Social Behavior, 23(4), 274-294.

Kroll, M., Fremont, L., \& Shipman, G. (1969). Policies, decisions, and organization. New York: Appleton, Century \& Crofts.

Kuhn, T. (1970). The structure of scientific revolutions. Chicago: University of Chicago Press.

Kushner, J. (1983). Report to oregon legislature: January 10, 1983. Salem: Oregon Mental Health Division.

Kushner, J. (1985). Strategy paper on alcohol and drug abuse. Salem: Oregon office of Alcohol and Drug Abuse Programs, Oregon state Printing office.

Kushner, J. (1989, April 12). Drug and alcohol abuse in oregon. Testimony presented to the oregon House of Representatives Human Resources Committee, Salem, OR.

Lasswell, H. D. (1971) . A pre-view of policy sciences. New York: American Elsevier Publishing Company.

Laver, M. (1986). Social choice and public policy. New York: Basil and Blackwell.

Lawler, M. (1985). Doing research that is useful and practical for theory and practice. Policy studies Review, $4(18), 39-46$. 
Lehnhoff, N. (1992a, March 22). Alice's story: Hard drinking led to the gutter. The oregonian, p. P4 .

Lehnhoff, N. (1992b, March 22). Drying out. The oregonian, pp. P1, P4.

Lerner, D. \& \& Lasswell, H. (1951). The policy orientation in the policy sciences: Recent developments in scope and method. Stanford, CA: Stanford University Press.

Lerner, J. V., \& Vicary, J. R. (1984). Difficult temperament of drug use. Journal of Drug Education, $13(1), 99-108$.

Likert, R. (1961). New patterns of management. New York: MCGraw-Hill.

Lindblom, c. (1959). Science of muddling through. Public Administration Review, 19(1), 79-88.

MacRae, D. (1982). Concepts and methods in policy analysis. In F. Lane (Ed.), current issues in public administration (pp. 379-389). New York: St. Martin's Press.

Majchrzac, A. (1984). Methods for policy research. Beverly Hills: Sage Publications.

Majone, G. (1980). Policies as theories. Omega: The International Journal of Management Sciences, $\underline{8}(2)$, 56-71.

Manzano, P. (1994a, February 1). In Oregon the struggle continues. The oregonian, p. Alo.

Manzano, P. (1994b, November 14). Prison blues. oregonian, pp. A1, A8.

Mental Health Advisory Committee. (1960). A report to Mental health in Oregon: A report to Governor Mark Hatfield. Salem: state of Oregon Printing office.

Nagel, S. (1978, May/June). Finding an optimum choice level or mix in public policy analysis. Policy Analysis, $\underline{3}(38), 88-98$.

National Drug Control Policy, office of. (1989). National drug control strategy. Washington, DC: United States Printing office.

Oregon Ballot Measure \#5 (1990). 
Oregon House Bill 2124, 63rd Oregon Legislative Assembly-1985 Regular Session (1985).

Oregon House Bill 3565, 66th Oregon Legislative Assembly-1991 Regular Session (1991).

Oregon Mental Health Division. (1963). Mental health problems in oregon: Exhibit a through $\mathrm{m}$. Oregon: oregon state Printing office.

oregon Mental Health Division. (1964a). Oregon Community Mental Health Plan. Salem: Oregon state Printing Office.

oregon Mental Health Division. (1964b). The ultimate goal: Comprehensive plan for a mental health program in oregon. Salem: oregon state Printing office.

Oregon Mental Health Division. (1973). A turning point for mental health programs in oregon. Salem: state of Oregon Printing office.

Oregon Senate Bill 544, 57th Oregon Legislative Assembly-1974 Regular Session (1974).

Oregon Senate Bill 1112, 65th Oregon Legislative Assembly-1989 Regular Session (1989).

Pal, L. (1987). Public policy analysis: An introduction. Ontario, Canada: Methuen Publications.

Patterson, G., Dishion, T., \& Reid, J. (1988). A social learning approach to family intervention. National Institute on Drug Abuse Research Monograph No. 77). Rockville, MD: National Institute on Drug Abuse.

Patterson, G. R., Reid, J. B., \& Dishion, T. J. (1985). $\underline{A}$ social learning approach: Vol. 4. A coercion model. Eugene, OR: Castilia.

Penning, M. , \& Barnes, G. E. (1982). Adolescent marijuana use. International Journal of Addictions, $\underline{2}$ (17), $749-751$.

Robins, L. N. (1978). The natural history of drug abuse: Evaluation and treatment of drug abusers. A.C.T.A. Psychiatra Scandinavia, 62(284), 92-108.

Rose, R. (Ed.). (1976). The dynamics of public policy: A comparative analysis. Beverly Hills: Sage Publishing. 
Schramm, w. (1971). Notes on case studies of instructional media projects. Washington, DC: Academy of Educational Development.

Schuckit, M. A., Parker, D. C., \& Rossman, L. R. (1983). Ethanol-related prolaction responses and risk for alcoholism. Biological psychiatry, 18(10), 38-58.

Shore, M. (1985). Correlates and concepts: Are we chasing our tails? (National Institute on Drug Abuse Research Monograph 56). Rockville, MD: National Institute on Drug Abuse.

Smith, G. M., \& Fogg, C. P. (1978). Psychological predictors of early use, late use, and non-use of marijuana among teenage students. In D. B. Kandel (Ed.), Longitudinal research on drug use (pp. 80-90). Washington, DC: Hemisphere-Wiley.

starling, G. (1988). Strategies for policy making. Chicago: Dorsey Press.

Stephan, C. W., \& stephan, W. (1985). Two social psychologies. Homewood, IL: The Doresey Press.

Tims, F. M., \& Ludford, J. P. (Eds.). (1984). Drug abuse treatment evaluation: strategies, progress, and prospects (National Institute on Drug Abuse Research Monograph No. 51). Rockville, MD: National Institute on Drug Abuse.

Treleaven, J. (1964). First biennial report of the Mental Health Division: For period ending June $30,1964$. Salem: oregon state printing office.

Treleaven, J. (1982). Testimony to oregon state Legislature, Ways and Means Committee, March $8,1982$. Salem: Oregon state Printing office.

Walker, H., Shinn, B., O'Neill, C., \& Ramsey, B. (1985). Longitudinal assessment of developing antisocial behavior in boys. Remedial and special Education, $19(8), 34-39$.

Weiss, C. (1972). Evaluation research. Englewood Cliffs, NJ: Prentice-Hall.

Wildavsky, A. (1979). Speaking truth to power: The art and the craft of policy analysis. Boston: Little-Brown. 
winters, K. (1988). Assessment of adolescent substance abusers (National Institute of Drug Abuse Monograph No. 77). Rockville, MD: National Institute of Drug Abuse.

Yin, R. (1989). Case study research designs and methods. Beverly Hills: Sage Publications. 
APPENDIX A

CASE STUDY DATA 
Case study Data

Exhibit 1

\section{Interview Questions for Governor's Task Force Members}

\section{Members and Dates Interviewed:}

Dr. Doug Egan, Lewis \& Clark College, 5/15/90

Governor victor Atiyeh, 5/22/90

Judge william Beckett, Lane County circuit Court, 6/15/90

Vera Katz, speaker of the Oregon state House, 7/1/90

Kristine Gebbie, former Administrator Health Division, (interview by mail) $6 / 90$

Dr. Spero Manson, formerly of OHSU, now Professor of Psychiatry, University of Colorado, Denver (interview by mail) $3 / 94$

Unable to be contacted:

Robert Hatch, Alcohol and Drug Counselor

Bob Yates, Salem Businessman

Deceased:

Tom Dargan, KATU Television

Hank Crawford, Lobbyist for Health Industry

Questions utilized in interviews:

1) What was your interest in this issue in 1984?

2) Who did you consider to be the key players in this legislation's development?

3) How did you know about research to use in this area?

4) How helpful were the agencies and their personnel to your task?

5) What was the climate for legislation in this area at this time? 
6) What did you feel best about in terms of your participation in this process?

7) Did you feel the legislation dealt best with the major issues concerning you?

8) How do you feel about the implementation of this policy?

9) Did you feel that the legislation was good compromise for the issues and groups? 
Case Study Data

Exhibit 2

\section{Interviews held with Alcohol and Drug \\ Abuse Program Administrators}

Jeff Kushner, November 1989

Clark Campbell, Assistant Director November 1989 and July 1990

Interview Questions:

1) How much did you utilize published research findings in the 1985 legislation?

2) How did you decide which to utilize?

3) What are the sources of research, i.e. publications?

4) How did you disseminate research to the Governor's Task Force?

5) What are the problems with utilizing research?

6) Why is research often not utilized?

7) How much did you utilize researchers from within oregon?

8) What was the actual process to make final decisions for final policy?

9) What was the decision making process, and who made final ones?

10) How well did you work with the legislature?

11) To what do you attribute your success in the final passage of the legislation?

12) What is now occurring with implementation? 
Case Study Data

Exhibit 3

Experts in Youth Substance Abuso

(chosen by author for background and credibility in community)

Telephone Interviews held with three experts:

Oren Bolstad, then Director, Morrison Center, Portland, Oregon May 1989

Ann Miller, Director, A Minor Miracle, Portland, Oregon, May 1989

Jay Renaud, then Director, New Day Center, Portland, Oregon, May 1989

Interview Questions:

1) How valid is the research that oregon's policy for youth substance abuse is built on?

2) How valid is research in youth substance abuse overall?

3) What constitutes excellent prevention?

4) What is the difference between adult and youth prevention models?

5) How effective is Oregon's drug and alcohol policy?

6) What is the research you regard as cutting edge?

7) How were you involved in the legislation, or were you? 
Case Study Data

Exhibit 4

\section{Timeline of Events in Oregon's 1985 Policy Development}

oregon's development of policy directed toward substance abuse followed approximately the following timeline:

\section{Novamber 1983}

The oregon State Legislature (specifically the Sub-Committee of Human Resources in Ways and Means) directed Governor Atiyeh to appoint a Task Force (Goverxor's Task Force) to do the following:

1) Evaluate alcohol and drug programs in the state for quality and effectiveness.

2) Study of alcohol and drug programs in various agencies.

3) Analysis of the service delivery system for these programs.

4) Examine related funding sources and formulas.

December 1983

Governor Atiyeh asked Dr. Joe Treleaven to appoint nine members to the Governor's Task Force on Alcohol and Drug Abuse.

The members included the following:

Judge William Beckett of the circuit court, Eugene, Oregon Hank Crawford, Lobbyist for Health Care Providers (now deceased)

Tom Dargan, Executive with KATU Television (now deceased)

Dr. Doug Egan, Business Department Chair, Lewis \& Clark College

Kristine Gebbie, Administrator oregon State Health Department

Robert Hatch, Mental Health and Substance Abuse expert (unable to be contacted)

Vera Katz, Speaker of the Oregon House of Representatives 
Spero Manson, Oregon Health Sciences University, Dept. of Psychiatry

Robert Yates, Salem area businessman (unable to be contacted)

september 1984

Report given to Emergency Board of Oregon State Legislature from Governor's Task Force findings.

July 1985

House Bill 2124 adopted by Oregon State Legislature with major inclusions from Governor's Task Force

November 1985

Policy decisions made in two day session by clark Campbell, Alcohol and Drug Programs with Leo Hegstrom, Director of Human Resources Agency, State of oregon.

Key Players in Policy Development included:

Jeff Kushner, Director of Alcohol and Drug Abuse Programs, state of oregon

Clark Campbell, Assistant Director of Alcohol and Drug Abuse Programs

Governor Victor Atiyeh of oregon

Members of Governor's Task Force (Special Committee) 
Case Study Data

Exhibit 5

\section{Agency Directors on Ose of Research}

Agency Directors who responded to survey:

Kevin Concannon, Director, Human Resources, State of Oregon

Dr. Richard Lippincott, Director, Mental Health Division, State of Oregon

David Fuchs, Director, Youth Services Commission, state of Oregon

Freddye Petett, Director, Adult \& Family Services, state of Oregon

Jeff Kushner, Director, Alcohol \& Drug Abuse Programs, State of Oregon

Dr. Joseph Treleaven, former Director Mental Health, State of Oregon

\section{Survey questions:}

1) What research do you use in determining policy for your agency in youth substance abuse?

2) How much policy do you have in your agency for youth substance abuse?

3) Do you have any measures for determining if the policy is working?

4) What are your plans for this area of policy for later study?

5) Have you worked with any oregon researchers in this area?

6) Would you be interested in any research in this area?

7) How important is this area to the work of your agency? 
Case Study Data

Exhibit 6

\section{survey and Names of substance Abuse Researchers within oregon}

John Crabbe, Oregon Health Sciences University, Portland, oregon

Anthony Biglan, Oregon Research Institute, Eugene, Oregon

Chris Cunningham, Oregon Health Sciences University, Portland, Oregon

Dan Dickinson, Kaicer Permanente, Portland, Oregon

Tom Dishion, oregon Social Learning Center, Eugene, oregon

Doug Egan, Lewis \& Clark College, Dept. of Business, Portland, Oregon

J. B. Hallan, Oregon State University, Corvallis, Oregon

Linda Magnuson, Orin Bolstad, Morrison Center for Children, Portland, Oregon

J. D. Matarazzo, Oregon Health Sciences University, Portland, Oregon

Gerry Patterson, oregon Social Learning Center, Eugene, oregon

Steve Ungerleider, Integrated Research Services, Inc., Eugene, Oregon

Hill Walker, University of Oregon Special Services Department, Eugene, Oregon

Arthur Wiens, Oregon Health Sciences University, Portland, oregon

\section{Survey Question:}

Research Projects on substance abuse prior to 1985 (available to agency administrators) that you participated in:

Give a little background and some important findings that might impact state policy for youth substance abuse: 
Case Study Data

Exhibit 7

\section{Analytical Table of Defined Variables Affecting Policy Development in oregon's Process}

Variable Effect on Policy Development

Very High somewhat Not At All

Political climate

1) Public Perception

2) Oregon's Legislature

3) Membership of Committee

4) Effect of the Governor's Office

Resources \& Economic Environment

1) State Tax Revenues

2) Attitude of Legislature toward spending

\section{Special Interest Groups}

1) Organized groups (such as Mothers Against Drunken Drivers)

2) Health Care Providers (others)

3) County Service Providers

Importance of Research as a Policy Input

1) Research from outside oregon

2) Research from within oregon

3) Data from agencies

4) Federal data

Importance of Leadership

1) Governor's Task Force

2) Legislative Leaders

3) State Agency Administrators 
Case Study Data

Exhibit 8

\section{Archival Records otilized in study}

Dickel, Charles T. (1977) H. A. Dickel's History of Psychiatry in oregon.

Governor's Task Force Committee proceedings, 1983-1985.

Kushner, Jeffrey (1989) Testimony presented to oregon House of Representatives, Human Resources sub Committee of Ways and Means.

Oregon Serious Crime Commission Report (1984) Oregon State Document.

Testimony to Governor's Task Force, 1983-1985.

Treleaven, Dr. Joe (1982) Testimony from Division of Mental Health to oregon Legislature, Ways \& Means Committee.

Treleaven, Dr. Joe (1964) First Biennial Report of Mental Health Division. 
Case study Data

Exhibit 9

\section{Studies Available from Oregon's Research Community Prior to 1985 Legislation}

Following is an analysis of research that was either available or initiated from Oregon's research community prior to the development and passage of substancelabuse policy in 1985. The oregon researchers who were doing substantive work in this area were willing to participate in this study (return rate on surveys was $90 \%$ ). The community of researchers also participated at a high rate for interviews and conferences which led to this case study.

John Crabbe of the oregon Health Sciences University in Portland was involved in understanding about genes and the predisposition sensitivity to the effects of alcohol. This could include the prediction of an individual risks for alcoholism in their life span.

Anthony Biglan of the Oregon Research Institute in Eugene, Oregon studied the use of tobacco by adolescents. I He concluded that youth who use tobacco are more likely to abuse substances since it appeared to be a gateway drug. Dr. Biglan and the Institute also did work in the areas of family training, various psychological theories, teens and peer modeling, communication training, and other behavioral change techniques.

Linda Magnuson and Orin Bolstad of the Morrison Center in Portland, Oregon were involved in the evaluation of child and mental health programs. An outcome of their studies included the analysis of stress factors and the structure of 2,500 families. The also studied family communication, dysfunctions, and stressors.

Tom Dishion of the oregon Social Learning Center in Eugene, oregon was involved in child rearing practices

identification and peer characteristics associated with substance abusing adolescents. He was particularly interested in peer modeling in treatment and initial use by youth.

Dr. Gerry Patterson directs the oregon Social Learning Center in Eugene, Oregon. He is a nationally recognized expert in family communication and training. The Institute was involved in several research projects that included: techniques for hyperactive children, treatment of ischool phobias, parent training, social learning, behavior modification techniques for the control of aggressive boys 
in classrooms, working with out-of-control children, prevention of child abuse, family and delinquent studies, and the utilization of multiple gating assessments for identification of youths at risk for delinquency.

Dr. David Hawkins of the University of Washington Social Work Department, Seattle Washington, was hired as a consultant for the substance abuse policy. He had done a great deal of work on social skills' training for youth as well as risk factors.

Dr. Dan Dickinson of Kaiser Permanente in Portland, Oregon worked on program outcome data on substance abuse. Kaiser had developed a well-respected research program but had little contact with the Alcohol and Drug Program office because of their perceived business nature, according to $\mathrm{Dr}$. Dickinson (interview, 1989).

Finally, of the 25 oregon researchers contacted, few were actually working in the area of youth issues. Only those listed above directly related to youth substance abuse. Many of the studies, especially those of the oregon Social Learning Center and oregon Research Institute (both in Eugene, oregon) were cited in substance abuse reports from the National Institute on Drug and Alcohol and other federal agencies in the early 1980s. Good research was available during the development of the policy, although much of it was in the early stages rather than definitive. 
Case Study Data

Exhibit 10

\section{Research Considered Excellent by Alcohol and Drug Experts}

Three experts from oregon's youth substance abuse community were interviewed about research they considered excellent in the 1980s. The three were chosen because they represented different treatment models, and were regarded with respect by the substance abuse community and the author. The interviews were held in 1989, four years after the policy was passed. It was difficult to ascertain what was actually considered excellent research previous and during the policy development. The interviewees were asked to reflect, as best they could on what constituted good research in the early 1980s. The data from these experts shed light on the differences of opinion about what excellent research was, and how difficult it would be to establish one particular view on a social issue such as substance abuse.

Interestingly, each expert knew the work of Dr. David Hawkins, consultant hired from the University of Washington School of Social Work, but each one questioned the validity of some of his research views.

The first expert in youth substance abuse believed that Dr. Hawkins' research was faulty since he merely lifted research from others and did not produce much of his own. There was a belief that the research studies gathered by Dr. Hawkins were not proven models of treatment or prevention. He also believed that the general lack of longitudinal studies in youth substance abuse was a serious problem.

The policy in Oregon was built on the Alcoholics Anonymous model, in the opinion of this expert, without much validity. Although this treatment had a great many followers in the substance abuse community, he believed that the model was descriptive and lacked quantitative methodology to validate it. This variance in opinion seemed to characterize a general rift among substance abuse treatment experts about successful programs for prevention and interventions.

Risk factors (Dr. David Hawkins' contributions) were also questioned by this treatment expert. He felt that 21 risk factors was high and unmanageable, and that two or three was adequate to treat therapeutically. This person referred to the importance of beta weights or incremental predictors for risk factors because of the difficulty of determining which factors are most related to substance abuse. Some factors 
would require more weight to form comparison with others to determine their relative importance to substance abuse.

This expert also believed there was a lack of comparison groups for families with substance abusers since the profile of a functional family simply did not exist. He believed also there was a lack of research in comparison groups for dysfunctional families.

The second expert in youth substance abuse did not believe there was good research in this area for either treatment or prevention. She believed that research was carried out only when there were facilities set up for such purposes. There was also concern about the high number of delinquent adolescents in Dr. Hawkins' research as compared to the potential for middle class families and girls to be represented. She believed that the tendency to regard boys as more predisposed to substance abuse needed to be challenged. Research in the late 1980 s pointed to an everincreasing number of girls abusing.

The treatment expert pointed out that chemical treatment programs had only existed since 1982. Little research about treatment or prevention was possible because of a general lack of information in this field. She noted that changing cultural values and more acceptance of substance use occurred later in the 1980s.

Both of the experts interviewed referred to the disease model of substance abuse and agreed that it may not be valid. The second treatment expert believed that the disease model might be reevaluated in light of new findings and attitudes about youth substance abuse.

The second expert also believed that the National Institute of Drug and Alcohol Abuse Prevention was self-serving in research projects. She believed that new directions needed to be pursued but were often prevented by NIDA. This treatment expert believed that research was desirable in treatment and prevention but was difficult to measure because the objectives were often difficult to isolate or identify. She believed there was a need for good research but this might not occur because of the National Institute's reluctance to change.

Parenting was believed to be the most important variable in the prediction of substance abuse by this expert. She also talked about self-medication through substances, and asked if depressed youth were seeking some relief by selfmedicating with drugs or alcohol? The question was also asked if there were organic causes, and how would those be measured to intervene or prevent them? She talked about 
denial in substance abuse and how would a credible study determine if this existed and abuse deterred?

The second expert also questioned Dr. Hawkins' risk factors and felt that all research in substance abuse was faulty. She believed that family research was appropriate and necessary but that Dr. Hawkins' many research studies were not altogether valid. There was a belief that perfect research did not exist and she did not often utilize the results of such studies in treatment. She also noted the serious lack of longitudinal studies and good research in youth substance abuse prevention.

The third expert referred to a practical research study reported in the June 1989 issue of the Journal of the American Medical Association. The article documented a three year longitudinal study of a model for youth substance abuse prevention carried out in Kansas. This model included: mass media programming, school-based educational programs, parents and community involvement, and health policies. The study documented positive outcomes in several communities and later found its way into the Federal policy of 1989 (President Bush's Drug Initiative).

This treatment expert felt he had less understanding of youth issues than adult issues, but had a wide range of policy understanding which were particularly enlightening for this case study. He referred to the serious split in the substance abuse community about the disease model, and believed that predisposition to substance abuse was entirely valid. This expert said that professionals in this community questioned the amount of money directed toward treatment in opposition to prevention. He referred again to the split in the community of treatment experts as a reflector of a general lack of research in this area. He believed that a discussion of research was more difficult because there was a reluctance to name key researchers or any set of beliefs, possibly due to the limited number of studies in youth substance abuse.

In an analysis of the three experts, there appeared to be areas of serious disagreements about youth substance abuse which included the following:

1) The question of whether substance abuse was a disease or the result of environment or other variables?

2) The question of whether risk factors were helpful or even valid?

3) The question of how important families were to substance abuse? 
4) The question of the importance of longitudinal studies and their duration in order to be valid?

5) The question of how important the Alcoholics Anonymous model was to successful treatment?

6) The question of how effective and inclusive Dr. Hawkins' research was to substance abuse treatment?

There were many questions answered and many more left to answer after these interviews. It appeared that even in 1989, it was impossible to determine a single set of beliefs in youth substance abuse that could have been helpful to policy makers. The general lack of research studies or common belief system among treatment experts certainly pointed to a problem for policy developers. The general lack of structure to provide research, the serious rifts in the community about treatment, the number of variables, and a lack of research or longitudinal studies that existed four years after the policy was passed point to findings that utilizing research in substance abuse policy was a difficult, if not impossible task. 
Case Study Data

Exhibit 11

\section{Oregon's 1985 and 1989 substance Abuse Policy}

Although Oregon's substance abuse policy of 1985 was directed both at adults and youth, this case study focused only on the areas of youth policy. The following points relate to the 1985 policy focus on youth:

1) Agencies shall coordinate resource distribution for better coordination and unnecessary duplication.

2) Standards in drug and alcohol must be met for prevention and early intervention programs.

3) Comprehensive community based programs should include:
a) Parent support groups
b) School curriculum
c) Formal school policies
d) Student intervention strategies
e) Adolescent treatment capacity increase

4) Intervention strategies are priorities.

5) State funds to be expended on prevention strategies encourage no use.

6) Use of alcohol and drugs is unhealthy and illegal. strategies that promote no use will only be utilized.

7) Strategies should be targeted for youth and proven effective in preventing use, delaying onset, and impacting a variety of behaviors correlated to drug and alcohol use.

8) Comprehensive studies should be initiated to determine strategies for use in state institutions and youth care facilities.

The provisions of this policy include:

1) Provision of information about negative effects of substances.

2) Techniques for expanding behavior repertoires for resisting peer pressure.

3) The first priority is no use. 
New legislation passed in 1989 focused on the following areas :

1) School districts and higher education will institute prevention curriculums and public information programs addressing students, parents, teachers, administrators, and school board members.

2) A review of the nature and extent of school district expectations of intervention with students who appear to have substance abuse problems.

a) The extent of the district's alcohol and drug abuse problems.

b) District strategies to gain access to federal funds for drug and alcohol abuse prevention programs.

The broad policy goals were reflected again in 1989s policy. 
Case Study Data

Exhibit 12

\section{Establishment of the Governor's Task Force}

In June of 1983 , a budget note directed the Division of Mental Health to conduct a study of alcohol and drug programs which would include the following:

1) An evaluation of the quality and effectiveness of alcohol and drug programs.

2) An analysis of the service delivery system.

3) An examination of funding sources and formulas.

Dr. Joe Treleaven, Administrator of the Mental Health Division in 1983 was asked by then Governor Atiyeh to appoint a "blue ribbon panel" to study alcohol and drug issues to conclude with a final report to the Emergency Board or to the Joint Committee of Ways and Means during the 1985 legislative session.

Nine members were chosen by Jeff Kushner (rather than Dr. Treleaven) of Alcohol and Drug Programs and included:

Judge William Beckett, Lane County District Court Judge

Hank Crawford, lobbyist for Health Care Providers (Blue Cross, Blue Shield)

Tom Dargan, KATU television broadcaster from Portland

Doug Egan, Professor of Business Education, Lewis \& Clark College

Kristine Gebbie, Director of Oregon Health Division

Robert Hatch, Mount Hood Clinic for Alcohol and Drug Abuse

Vera Katz, Speaker House of oregon Representatives

Spero Manson, Professor of Psychiatry, Oregon Health

Sciences University

Bob Yates, Salem Businessman

Staff: Jeff Kushner, Director of Alcohol and Drug Program office 
Clark Campbell, Assistant Director of Alcohol and Drug Program office

one of the most serious problems facing the oregon legislature was determining how the $\$ 43$ to $\$ 47$ million were being spent for alcohol and drug programs in various agencies. There appeared to be little coordination of efforts or budgets and it was difficult to determine if the money spent was successful in alleviating alcohol and drug abuse among Oregon's citizens.

The public outcry about crime and substance abuse had some effect upon then President of the oregon Senate, Fred Heard, and Speaker of the oregon House, Vera Katz who decided to devote time and energy to the problem.

Each of the members of the Governor's Task Force contributed particular skills to this process. Much has been made of their cohesiveness and professionalism during the proceedings. There were also some unusual circumstances surrounding at least two who served in this capacity. A short presentation of the skills of each committee member may illuminate the potential and advantages of a blend of public and private individuals in such a policy process.

Judge William Beckett of Lane county circuit court had served in the judicial system for at least 30 years. He had observed the problems of alcohol and drug abuse in his long tenure. Judge Beckett believed there were conflicts of interest when a member of the judicial system served on a policy review committee.

Hank crawford was a well-respected lobbyist for the health care providers in oregon. He understood the importance of political maneuvering in the oregon legislature and appeared to have a good balance between the legislation and his own lobbying interests.

Tom Dargan was a well-known television personality from portland who agreed to serve on this committee. It was unusual for a member of the press to serve on such a committee in state government, and this was prized by some, including then Governor Atiyeh. Tom Dargan had a personal interest in alcohol and drug abuse because he was a recovering alcoholic. He persevered in the process because of his interest and possibly because of some personal qualities that were important to the work of the task force.

Doug Egan of Lewis \& Clark College offered academic advice because of his interest in public administration and policy process. He understood accountability and research well and offered important expertise to the committee and staff. 
Kristine Gebbie of the Oregon Health Division was an administrator who understood the health implications of substance abuse. She offered a particular point of view by an agency administrator and also as one who cared about the new role of health in such a policy issue. Kristine Gebbie appeared to handle appropriately the role of administrator and that of policy developer who was likely to be affected by the legislation.

Robert Hatch represented the alcohol and drug treatment providers who had a stake in this legislation, and lent important knowledge to the committee.

The Honorable Vera Katz offered expertise about the Oregon legislature as well as the politics of such a process. Her alignment with the committee and with the legislative process were necessary and decidedly important to all those involved.

Spero Manson, Professor of Psychiatry at oregon Health Sciences University represented the academic community. He understood the role of research and academic potential in policy development, and the importance of prevention and intervention in such a process.

Robert Yates owned a painting supply business in Salem. He represented the small business owner and probably the average citizen on the Governor's Task Force.

The Governor's Task Force was a good blend of interests and appeared to provide good analysis and reporting for the oregon legislature. Most of their recommendations were utilized in the policy and they appeared to provide broad goals that pointed to many of the problems in substance abuse from 1983 to 1985. 
Case Study Data

Exhibit 13

\section{Demographics of substance Abuse in the united states and oregon}

Previous to the legislation of 1985, alcohol and drug problems in Oregon and the United States affected many people. This overview will review the United States demographics first since they correlated well with oregon's problems during the early 1980s. Oregon's demographics will follow in order to further understanding about the perceived need for legislation during the 1980s.

United states statistics revealed that alcohol and drug abuse increased 60 fold from 1960 to 1985 (Van Dougherty, 1987). Alcohol and drug problems increased the risk of injury, violence, suicide and long-term health problems. An example of the problems associated with substance abuse included a $100 \%$ increase in teenage arrests from 1960 to 1980, and unemployment increased $35 \%$ for males and $60 \%$ for non-whites in that same period (National Drug Control Strategy, 1989). Other statistics revealed that alcohol was a factor in:

1) Sixty percent of all homicides.

2) Fifty percent of all rapes.

3) Seventy percent of all assaults.

4) Eighty percent of all suicides.

5) Fifty percent of all traffic deaths.

In 1985, there were 14 million people using illegal drugs on a regular basis of once a month. Three fourths of all robberies and half of all felony assaults were committed by youth involved in drug use (National Drug Control strategy, 1989). One out of every eight Americans or 28 million children had parents who abused substances (Children of Alcoholics Foundation, 1985). At least 50\% of the fathers and 418 of the mothers under court protection were substance abusers.

Parents who abused substances created serious problems for their children. In a study of 300 abused children (Children of Alcoholics Foundation, 1985), alcohol was a serious problem in $60 \%$ of the families, which correlated with Oregon's Children's Services Division reports in 1989. Thirty-nine studies by this foundation revealed that in 
families of alcoholics, members were six times more likely than the general population to have one or more alcoholic parents. Alcohol and drug abuse affected youth in a variety of ways, including:

1) Learning problens in school, hyperactivity, social aggression, low self-esteem, increased anxiety, and psychosomatic complaints.

2) Emotional neglect, sexual and physical child abuse, and parent battering.

3) Possibility of becoming substance abuser was very high.

4) Teen suicide highly correlated to substance abuse.

5) Eating disorders, truancy, delinquency, and substance abuse related to parental modeling of substance abuse.

Tom Dishion of the oregon Social Learning Center in Eugene, oregon reported that parents who modelled substance abuse risked raising children who were far more likely to develop the same patterns. Peers were important for first use and abuse of substances (Dishion, 1985).

\section{Oregon's Demographics}

Oregon's statistics for substance abuse did not differ significantly from the United States' numbers. In a report to the legislature in 1985, the office of Alcohol and Drug Programs reported that $12 \%$ of all citizens had substance abuse problems. They reported that 175,000 people were problem drinkers or alcoholics, and 140,000 people in oregon were chemical substance abusers. Statistics in 1982 revealed that alcohol was related at the following rates to the crimes listed (Strategy Paper on Alcohol and Drug Abuse, June 1985):

1) Sixty-five percent of all murders.

2) Thirty-five percent of all rapes.

3) Forty percent of all assaults.

4) Thirty percent of all suicides.

5) Eighty percent of all deaths by fire.

6) Sixty-five percent of all drownings.

The statistics for families were particularly poignant since alcoholism was a major factor in divorce and affected $40 \%$ of 
all problems brought to family courts. In Oregon's Task Force on Family Violence (September 1984), alcohol abuse was either a direct cause of violence within the family or a significant contributing factor. Other problems associated with substance abuse included incest, people turning to alcohol because of problems, and Fetal Alcohol syndrome was on the rise at one to two per 1,000 births in 1985 (Oregon Health Division, 1985).

In 1985, there were 8,000 adolescents with significant alcohol problems and more than 12,000 suffering from drug abuse. There were 22,000 youth classified as problem drinkers (once a week at least and consuming 5 to 12 drinks on a single occasion). In Children's Services Division contracted child care centers, $54 \%$ of youth served had serious substance abuse problems. In juvenile training schools, $43 \%$ had a history of substance abuse (strategy Paper on Alcohol and Drug Abuse, 1985).

of all those arrested for crimes in oregon in 1982, 55\% were under the influence of substances. Twenty-five percent of those arrested while driving were under the influence of intoxicants. Alcohol was involved in one half to two thirds of the deaths on highways in 1983. Finally, for the 50 consecutive year in 1982, the oregon Serious crime Commission survey ranked alcohol and drug abuse as two of the five most serious community problems in oregon (strategy Paper on Alcohol and Drug Abuse, 1985).

In conclusion, the economic costs for the United States were calculated by the Research Triangle Institute in 1984. The costs nationally were calculated to be close to 400 billion dollars, while oregon's costs for substance abuse amounted to approximately $\$ 1.6$ million annually, with a per capita cost of $\$ 601$. It was believed in 1985 that $85 \%$ of those with serious substance abuse problems were receiving no treatment for their condition (strategy Paper on Alcohol and Drug Abuse, 1985). 
Case Study Data

Exhibit 14

\section{Onited states Policy in Alcohol and Drug Abuso Prevention}

Concern in the United States about alcohol and drugs began well before the now notorious 1960s. Illegal drugs were introduced into the mainstream of society, but the opium dens of the 1900s were concerning then, too. Hand-wringing about what to do about substance abuse is not a new problem.

President Nixon in 1970 politicized drug and alcohol policy in our country, and he was elected on an anti-crime platform. Then President Nixon believed that the drug lords of South America needed to be stopped or turned over to the criminal justice system. Billions of dollars were spent to stop those drug lords and they still infiltrate our borders.

President Ronald Reagan also ran on the anti-crime and drug commitment. He saw to it that the policy was the same as before, little prevention and much attention to stopping the supply of drugs.

President George Bush was elected in 1989, and hired william Bennett to be his "Drug Czar." A new drug policy was outlined in January of 1989 , and was aimed at those who purchase drugs rather than the suppliers. The policy was fairly innovative and focused on community action, prevention, and treatment of those who sought drugs. Health issues found their importance in this policy. Prevention programs were recognized for their efforts at stopping the problems before they started.

The key points of the President's National Drug Control Strategy in 1989 were:

1) Schools are important places to teach about drug prevention. Curriculum should include (David Hawkins) resistance skills and teaching about self-worth.

2) Schools shall adopt policy to keep drugs away from students by keeping campuses safe.

3) Research shall be sought that looks at preventing student drug use.

4) Media campaigns shall be used to combat drugs in communities. 
5) Evaluation and dissemination of successful programs shall be sought to prevent drug us.

6) Promotion of model alternative schools for youth with drug problems.

7) Recommendation of legislation for school yard laws to prevent selling there.

The Director of Oregon's Alcohol and Drug Program office, Jeff Kushner, served on the commission that drew up this policy. The policy utilizes much of the risk factor and prevention research which was available to oregon's policy makers in 1985. 
Case Study Data

Exhibit 15

\section{Youth substance Abuse Risk Factors}

Risk factors for youth substance abuse have been the focus of various researchers since 1970. David Hawkins of the University of Washington School of Social Work has reviewed the studies and determined that certain factors have greater bearing for youth who abuse substances. Risk factors are identified with family, school, behavioral and constitutional issues.

Addiction refers to the patterns of social life when patterns are embedded, is multiply-determined, and has complex behavior problems with physical and physiological components (Hawkins, 1983). Substance addiction may be the result of conflict in norms and expectations in social life. Social life refers to peers and family which are both high contributors to dysfunction and abuse.

There are various theories that form the foundation for substance abuse risk factors and provide important information to understand, especially for prevention interventions. Social theories of deviance refer to the proposition that human beings are universally socialized to aspire to legitimate, culturally approved goals in both financial and social success. The incongruence between goals and means often creates the motivation for successful attainment or other routes which are less successful. Cultural deviance theory refers to people who conform under normal circumstances, and deviance occurs when cultural differences conflict with societal expectations. Control theories propose that people want to conform to society's norms.

Strain theories relate to people and their socialization to aspire, and their commitment and involvement with conventional activities. Often, people also attach to others who support their values and, as a result, there is a link between social class and delinquency. Research does not support the belief that non-conformists have their goals blocked. Ambition, for example, does reduce the chances that a person will resort to crime, but there are many other issues involved when this occurs (Hawkins, 1985).

Tom Dishion of the oregon Learning center in Eugene, Oregon believes that we knew a great deal about predictors of drug and alcohol abuse (interview, 1989). He notes that "we simply don't know what to do about it." Tom Dishion believes that there was a lack of longitudinal research 
related to youth because of the urgency and currency of the problem, and that developmental stages were difficult to assess. Gerry Patterson, Director of the oregon Social Learning Center, reports there is little or no research on children who abuse drugs and alcohol before the age of 10 (Patterson, 1985).

The oregon Social Learning Center was involved in a project to work with middle school children to screen at-risk predictors by a multiple-gating device. Teachers and peers were highly important in this process, and this institute was working on a treatment plan for those identified to involve parents, peers, family, and to utilize problemsolving techniques. Oregon appeared to be carrying out "cutting-edge" substance abuse research.

Dr. David Hawkins and others (Majchrzac, 1984) selectively pulled together and synthesized theoretical literature and data that supported a particular argument or thesis which supported risk factors as causative in youth substance abuse. This research approach had a moral or philosophical foundation with supporting data found in many studies. Following are some of the risk factors that Hawkins and his associates found.

\section{Family and Peer Factors}

1) Family modelling of drug and alcohol abuse is the major initiator for children and youth into drugs and alcohol (Bushing \& Bronley, 1975).

2) Male alcoholism is higher than that of females. Boys have a 50\% higher chance of alcoholism because of genetics alone (Goodwin, 1985).

3) Family dysfunction, including overly permissive or authoritative parents, lack of monitoring or positive reinforcement all figure highly as predictors of drug and alcohol abuse. Lack of consistent discipline, rewards, and structure can all lead to conflict and highly predictable of later abuse (Patterson, 1982).

4) Communication is the highest positive variable in family functioning. Bonding to parents at an early age is extremely important to prevent risk (Hindelang, 1973).

5) Family social and economic deprivation are characterized by isolation, multiple entrapment of parents in extreme poverty, poor living conditions, and low status occupations, or unemployment are high predictors of risk (Hawkins, 1986). 
6) Drug initiation and use with peers as models and cohorts is the most powerful risk predictor for youth and children (Dishion, 1985).

The highest predictors of drug and alcohol abuse are family dysfunction, modelling by family and peers, and lack of bonding. Risk factors for families and peers were probably important to understand before policy development.

\section{8chool Factors}

There appeared to be a great deal that schools could do to prevent drug and alcohol abuse, and teachers were found to be critical in identification and appropriate intervention. Alternative school teachers had a high success rate with students at-risk because of their bonding and connection to their students. Following are some important understandings about schools and risk factors:

1) At-risk youth differ in their rate of academic learning time, their rates of discipline contacts, and physical and verbal behavior on the playground (Walker, 1987).

2) School failure for at-risk youth is characterized by truancy, special class placement (as in learning disabilities or mentally retarded), and their early dropping out of school (Hawkins 1985).

3) Students at risk of substance abuse had low peer and teacher sociometric ratings (Walker, 1987).

4) Poor school performance is an antecedent to drug and alcohol abuse, and tends to occur after the 3 rd grade rather than in the 1st or 2nd grades (Jessor \& Jessor, 1977).

5) Children who score average or better on intelligence or readiness tests who are underachievers seek drugs and alcohol at a rate $50 \%$ higher than other children

(Fleming, Kellman, \& Brown, 1982).

6) Low degree of commitment to educational pursuits and activities. This is especially true for those who do not plan to go to college (Hirsch, 1969).

7) Low school performance does not lead to drug and alcohol use, rather the factors that lead to poor school performance are highly predictive (Hirsch, 1969).

8) Poor vocabulary and verbal reasoning are linked to later drug and alcohol abuse (Fleming, Kellman \& Brown, 1982). 
The above risk factors point to the need for early intervention, especially by 1 st and 2 nd grade teachers, and parent involvement is necessary for youth and children. The importance of activities and teachers that will permit students to bond to schools is supported by this research. children who are identified as high achieving but low producers need to be assisted and monitored. Family dysfunction may become a part of the school curriculum and focus. The cost is very high to schools as well as unhealthy to all involved.

Trained staff to identify students and get them into appropriate skills' training classes and counseling are called for by this research, and parents need to be trained and involved. Peers need to be acknowledged and treated cooperatively when dealing with a youth or child. Bonding to school needs to be a focus of all curriculums. Acting out is acknowledged as a symptom of a problem, rather than necessitating disciplinary action first, and counseling or help later. Schools are very important in the prevention loop, but need specific curriculums such as the preceding for success.

\section{Bocial and Behavioral patterns}

The overt behaviors of youth indicate inner and outer controls, and the social context of behavior patterns is a major focus of risk factors in substance abuse. Following are several behavioral situations which concern social scientists who deal with predictive factors:

1) Attachment to parents, school, education, and church demonstrated by the belief in general norms, expectations, and values when low are predictive (Hindelang, 1973).

2) Rebelliousness, nonconformity, and high tolerance of authority as revealed by resistance to traditional authority. Children and youth who are not bonded socially to society and have a high need for independence are considered at-risk (Smith \& Fogg, 1978).

3) A low response to measurable variables of obedience, diligence, achievement, and orientation (Smith \& Fogg, 1978).

4) Youth and children who demonstrate sensation-seeking or lack of fear in terms of risk and danger are at risk (Penning \& Barnes, 1984). 
5) Attention-deficit or conduct disordered, hyperactive youth and children are highly at risk for drug and alcohol abuse (Hawkins, 1986).

6) Behavioral or interpersonal factors, especially prior to 15 years old. Crime and selling of illegal substances occurs often later in life (Robbins \& Prysbeck, 1985).

7) The earlier the initiation, the more persistent the use of dangerous drugs (Robbins \& Prysbeck, 1985).

8) Problem-behavior proneness or manifestation of deviance syndrome are higher predictors of use later one (Robbins, 1980).

9) Personality-perceiving environment and behavioral systems have a greater degree of problem behavior and result in greater likelihood of later use (Kaplan, Martin, \& Robbins, 1982).

10) Deviant responses are motivated by development of selfrejecting attitude in course of normative interactions operate as predictors (Kaplan, Martin, \& Robbins, 1982).

11) Deviant patterns are means to gain self-esteem and avoidance of self-devaluing experiences and both may point to deviance. The adoption of deviant patterns are functions of experience, exposures, and available opportunities (Kaplan, Morris, \& Robbins, 1982).

12) Childhood anti-social behavior can be predictors (Consi, 1987).

13) Negative moods, withdrawal, impatience, impulsivity, deviance for youth and children are all predictors (Lerner \& Vicray, 1983).

14) Cognitive deficits in verbal activities (Hawkins, 1986).

15) Social networks are major factors in initiation and later use, and provide the rewards for youth and children to survive, no matter how deviant they may appear (Hawkins, 1986).

16) Neighborhood attachment and community disorganization can be risk factors (Hawkins, 1986).

Dr. David Hawkins and Associates developed a social development model based on the work of Nye's Social control and Alfred Bandura's Social Learning Theory. The model included parent training, increasing communication and bonding to society, school, and family which includes 
involvement in prosocial activities, social interactions, and problem-solving. The important goal of bonding to society is key to this approach.

Building public policy in light of risk factors is multifaceted and difficult since there were many of them. Policy, in order to be effective and reasonable, has to choose those most critical and manageable in society. 
Case Study Data

Exhibit 16

\section{Prevention of Youth substance Abuse}

Prevention of youth substance abuse was an assumed focus of this legislation, but the task to define what the term signified for policy makers, or even what the programs were designed to do was difficult to ascertain. The perspectives of some members of the Governor's Task Force may lend understanding to the problems inherent for prevention in any policy. The higher concern for the day to day issues in government over those of future or preventative actions was relevant to this study.

Vera Katz (interview, 1989) felt that prevention was little understood. Spero Manson (survey, 1993) referred to the tension apparent between treatment advocates and prevention, and he believed that treatment captured most of the resources. The Alcohol and Drug Program staff appeared to understand the importance of prevention. Clark campbell (interview, 1989) believed that prevention was important to the efforts of policy development from the beginning.

The appointment of Dr. David Hawkins of the University of washington School of Social Work as consultant for this policy development was a good indication of Oregon's commitment to prevention for youth substance abuse. Dr. Hawkins' risk factors, survival skills, assertiveness training, and other methods for working with youth were all aimed at prevention. The methods for prevention were presented in broad program goals, if at all in the final policy.

One example of a structure already in place in oregon's government that could have easily implemented prevention or early intervention efforts was the child Development specialist program. The educators were available in most school districts around the state and had a good track record in the identification and training of at-risk five, six and seven year olds. Parent training which research identified as successful for treatment or prevention of youth abuse, was something they did particularly well. The cost of such a program would have been high, but the structure was already in place to carry it out. Administrators from the Department of Education were not included in deliberations about the policy which may have given important knowledge to planners and established that these professional were ready to implement a program such as this with a good research base. 
Doug Egan (interview, 1989) of the Governor's Task Force did not understand or know about early intervention models for schools but understood the importance of education in this process. Dr. Joe Treleaven (interview, 1990) believed that prevention and intervention were the same. Finally, then Governor Atiyeh (interview, 1989) referred to the prevention efforts of the Juvenile Services Commission (now the Youth Services Commission) and felt there was a "lack of innovation there."

The area of prevention, though alluded to in this policy, was difficult to define, to locate, or even to gain an understanding from members of the Governor's Task Force about its importance. Programs were available which demonstrated prevention efforts, but never found their way into policy except in the definition of school curriculums to tell students about the dangers of drugs, far from the research about early intervention, teaching survival skills, or parent training. 
Case Study Data

Exhibit 17

\section{Policy Intentions and Report by Governor's Task Force to Legislature}

In 1983, the Oregon legislature sub-Committee of Ways and Means, directed the Mental Health Division to study alcohol and drug programs in the state. This concern originated from Vera Katz, then Speaker of the House, and Fred Heard, then President of the senate. Their concern emanated from the large sums of money that were being spent in substance abuse within various agencies without apparent purpose or coordination. The following areas were the original purposes of this policy development:

1) Evaluation of drug and alcohol abuse program quality and effectiveness

2) Analysis of service delivery system for these programs.

3) Examination of related funding sources and formulas.

Nine members were appointed to the Governor's Task Force, sometimes called the Special Committee or the Blue Ribbon Task Force. The nine members travelled around oregon to gather testimony from a variety of groups and individuals. After approximately four months of exhaustive work, the task force concluded the following:

\section{Program Quality and Effectiveness:}

1) There are many programs serving the 14 state agencies which range in diversity and purpose. The overall effectiveness of these programs is difficult to assess because of their numbers and accessibility.

2) There are no standards for training and treatment services, and program success is based on completion of the program.

3) There are no fiscal and philosophical approaches to statewide alcohol and drug abuse problems across agencies.

4) Client concerns are being unmet in most agencies. Training for staff is non-existent.

Service Delivery system: 
1) Services across the state are uneven and often unavailable.

2) State agencies offer a wide variety of services. Some systems are centralized while others are not.

3) Citizens may be taxed uniformly, but services vary significantly among locations.

4) Service objectives in agencies do not define drug and alcohol abuse as major ones.

5) The technical expertise in the office of Drug and Alcohol Abuse Prevention Programs has not been utilized because of the lack of coordination.

Funding sources and Formulas:

1) There is no coordination for the $\$ 43$ million to $\$ 78$ million expended on drug and alcohol abuse programs.

2) There is no way to coordinate the numerous programs through the legislative and budgetary process.

3) Funding formulas and lack of regular auditing can be major problems.

The Governor's Task Force concluded that the state had not developed a focus or policy which permitted coordination and comprehensive approaches to alcohol and drug abuse. The committee believed that a comprehensive and focused policy was necessary for development of consistent and effective programs to address the problems. The task force offered the following primary goals:

1) Public awareness and concern for the responsible use of alcohol and drugs for the adult population.

2) Public awareness of and concern for positive alternatives to alcohol and drug use by under-age populations.

3) Prevention of socio economic problems caused by drug and alcohol abuse.

4) Reduction of socio economic problems through intervention in the misuse of drugs and alcohol.

5) Reduction of socio economic problems created by alcohol and drug abuse through effective treatment of the illness of alcoholism and drug addiction. 
Major recommendations for the legislature contained the following:

1) The legislature should establish major goals in awareness, prevention, intervention, and treatment of abuse.

2) Local programs should receive state funds only as they address legislative established goals and state priorities for drug and alcohol abuse programs.

3) The Office of Programs for Drug and Alcohol Problems shall be moved from Mental Health to the Department of Human Resources as a separate division.

4) Standards should be established for licensure and program certification with periodic review.

5) Continuing evaluation of clients should occur after completion of treatment.

6) An advisory board should be established in the Alcohol and Drug office and given the responsibility for advising (not approving), reviewing plans and proposals for division actions, and serving as an appeal mechanism for review and recommendations on agency decisions.

7) Creation of an Interagency Committee with membership and representation of all state agencies with drug and alcohol involvement.

8) Emphasis on training of state employees who deal with clients with drug and alcohol abuse problems.

9) Establishment and support of local councils on alcoholism and drug abuse in relevant communities for information and referral.

10) The Alcohol and Drug Program office can be given funds and authority to audit county expenditures of local treatment and contributions for alcoholism treatment programs. 
APPENDIX B

BUDGET NOTES 
209

BUDGET NOTE REQUIREMENT

FOR

STUDY OF STATE FUNDED ALCOHOL AND DRUG SERVICES 
BUDGET NOTES

Adult and Family Services Division

Page No.

- Controls on Medical Utilization.

Children's Services Division

- Governor's Task Force on Juvenile Corrections Alternatives . . . 3

- No Reorganization in Juvenile Corrections.......... 5

Corrections Division

- Emergency Fund Reservation for OSP Telephone System. . . . . . 6

- Emergency Fund Reservation for Multnomah County

Psychological Evaluation Costs .............. 7

- Emergency Fund Reservation for 2 Months EOCI Operation . . . . . 8

Health Division

- Epidemiology Program Directions. . . . . . . . . . . 9

- 10\% of Metabolic Testing Funds for Education ........... 10

Mental Health Division

- Report to April 1984 Emergency Board on Continued Need for Ward. . 11

- Institutional Staffing Standards Related to Population Changes . : 12

- Conversion of 3 ICF/MRs to Intensive Training Homes....... 13

- Alcohol and Drug Program Study.......................... 14

- Legislative Intent for Parity Between State

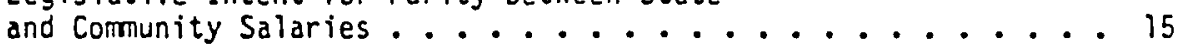

Senior Services Division

- Long Term Care Ombudsman Program Study ............ 16

Vocational Rehabilitation Division

- General Assistance Maintenance7Medical Transfer. . . . . . . 17

- Sheltered Service Slots Targeted to Activity Center ci ients. : - 18

- Disability Determinations Program Priorities ......... 19

Director's Office

- Comprehensive plan for Multi-handicapped.......... 20

New Budget Notes

- Drug Cost Containment Study: AFS .............. 21

- Medical cost Containment: Afs. . . . . . . . 22

- Downsize Kiamath Pilot Co-op Day Care Funding. . . . . . . 23

$0773 k$

6/1/83 MLLLIVLL

$\therefore$ l $11, i$

Fisca! Senigrs 
BUDGET NOTE: Draft A

Study of Alcohol and Orug Programs

The Subcommittee directed the Division to conduct a study of alcohol and drug programs to include an evaluation of their quality and

effectiveness, an analysis of the service delivery system, and an examination of funding sources and formulas. The study should include all state agencies which receive funds or provide services in the alcohol and drug abuse area. The study should be completed in consultation with the Executive Department, the Juvenile Services Commission, the Traffic Safety Commission, the Department of Education, and other relevant state agencies. The final report should be presented to either the Emergency Board or to the Joint Committee on Ways and Means during the 1985 Legislative Session.

pat0765k

$6 / 1 / 83$

$-14-$ 